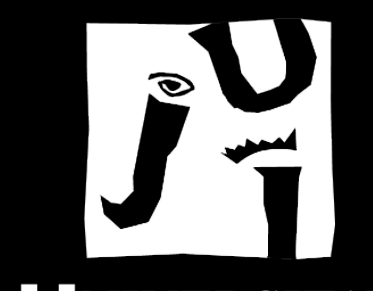

UNIVERSITAT

JAUME•I

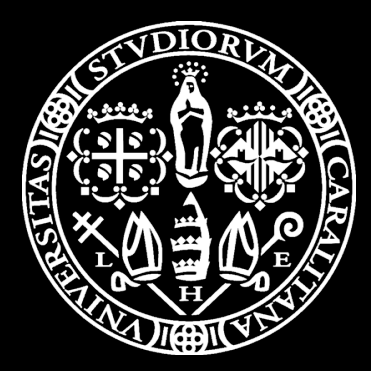

Behavioral and neurochemical assessment of the role of ERK pathway in the psychopharmacological effects of ethanol, caffeine and of their interaction

Author:

Simona Porru

\author{
Directed by: \\ Dr. Elio Acquas \\ Dra. Mercè Correa Sanz
}



Behavioral and neurochemical assessment of the role of ERK pathway in the psychopharmacological effects of ethanol, caffeine and of their interaction

Memòria presentada per Simona Porru per a optar al grau de doctora en règim de cotutela per la Universitat Jaume I i per la Università degli Studi di Cagliari
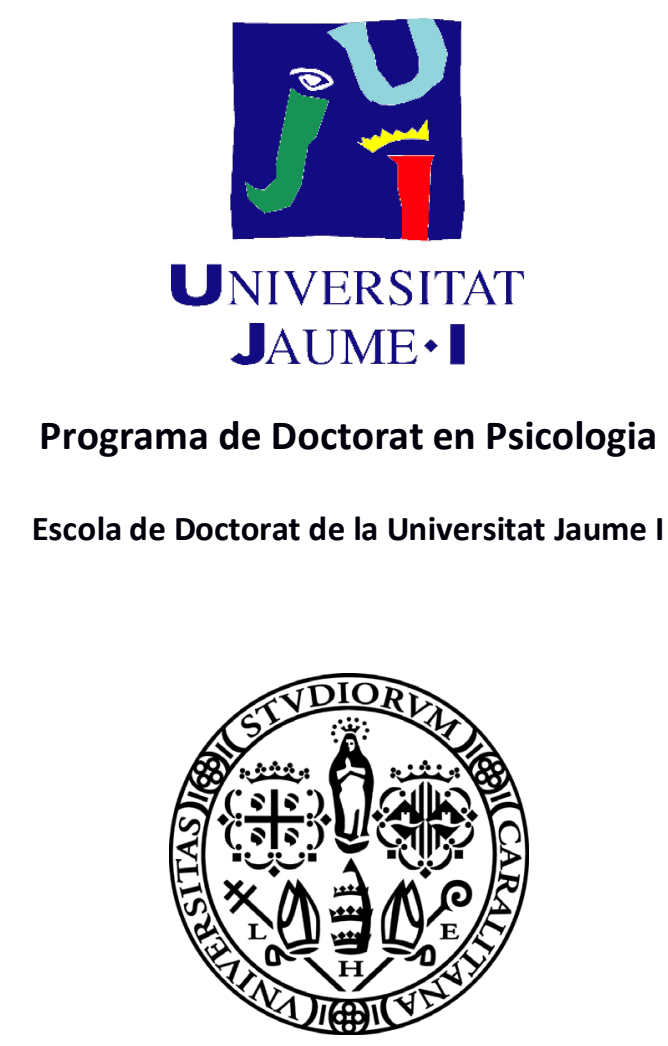

Corso di Dottorato in Scienze della Vita, dell'Ambiente e del Farmaco

Dipartimento di Scienze della Vita e dell'Ambiente della Università degli Studi di Cagliari

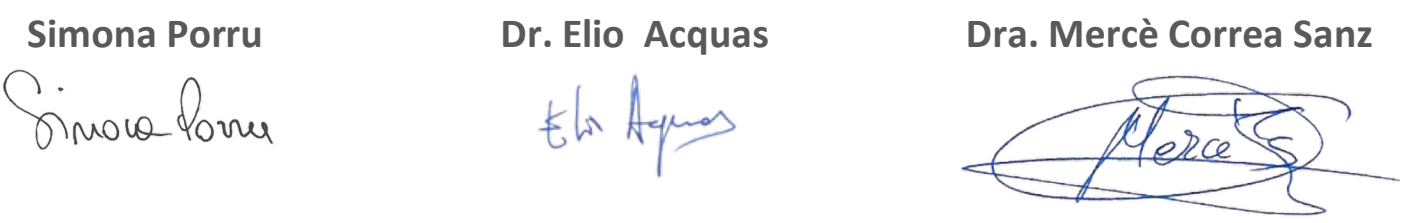





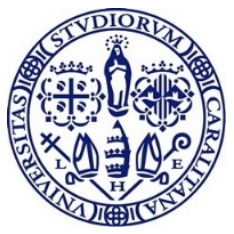

Università degli Studi di Cagliari

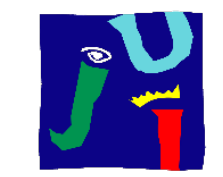

$\mathbf{U}_{\text {NIVERSITAT }}$

JAUME•I

\title{
PHD DEGREE IN LIFE
}

\section{ENVIRONMENTAL AND DRUG SCIENCES}

\author{
Cycle XXXII
}

Behavioral and neurochemical assessment of the role of

ERK pathway in the psychopharmacological effects of ethanol, caffeine and of their interaction

Scientific Disciplinary Sector: BIO/14 - Pharmacology

PhD Student:

Coordinator of the PhD Programme

Supervisor

Co-supervisor
Simona Porru

Prof. Enzo Tramontano

Prof. Elio Acquas

Prof. Mercè Correa Sanz

Thesis under joint supervision between University of Cagliari (Italy) and University Jaume I (Spain)

Final exam: Academic Year 2018- 2019

Thesis defence: February 2020 session 



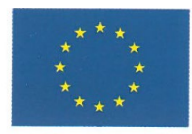

UNIONE EUROPEA Fondo sociale europeo

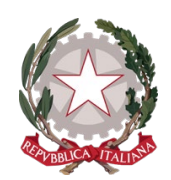

REGIONE AUTONOMA DE SARDIGNA REGIONE AUTOONOMA DE SARDIGNA
REGIONE AUTONOMA DELLA SARDEGNA
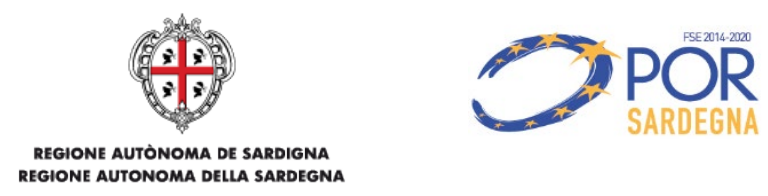

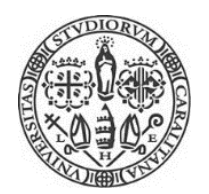

\section{FUNDING}

Simona Porru gratefully acknowledges Sardinian Regional Government for the financial support of her PhD scholarship (P.O.R. Sardegna F.S.E. - Operational Programme of the Autonomous Region of Sardinia, European Social Fund 2014-2020 - Axis III Education and training, Thematic goal 10, Investment Priority 10ii), specific goal 10.5.

This doctoral thesis was also supported by:

- Regione Autonoma della Sardegna (RAS, CRP2_537-CUP F71J090006200002) and Fondazione di Sardegna (Sassari, Italy) to Elio Acquas.

- Ministerio de Ciencia, Investigación y Universidades (RTI2018-101424-B-I00) to Mercè Correa Sanz. 



\section{INDEX}

SUMMARY

GENERAL INTRODUCTION

$\begin{array}{ll}\text { Motivated behavior } & 9\end{array}$

$\begin{array}{ll}\text { A model of associative learning: pavlovian conditioning } & 10\end{array}$

$\begin{array}{ll}\text { Conditioned Place Preference and Conditioned Place Aversion } & 10\end{array}$

$\begin{array}{ll}\text { From motivation to addiction } & 12\end{array}$

$\begin{array}{ll}\text { The mesolimbic system: neurophysiology } & 12\end{array}$

$\begin{array}{ll}\text { The nucleus accumbens: neuroanatomy } & 13\end{array}$

$\begin{array}{ll}\text { Biochemical basis of addiction } & 14\end{array}$

$\begin{array}{ll}\text { ERK signaling } & 14\end{array}$

$\begin{array}{ll}\text { ERK and drugs of abuse } & 15\end{array}$

$\begin{array}{ll}\text { DARPP-32 signaling } & 17\end{array}$

$\begin{array}{ll}\text { DARPP-32 and drugs of abuse } & 19\end{array}$

$\begin{array}{lr}\text { Ethanol motivational properties } & 20\end{array}$

Caffeine and ethanol interaction: effects on adenosinergic system 23

Is caffeine an addictive drug? $\quad 26$

$\begin{array}{ll}\text { AIMS } & 29\end{array}$

EXPERIMENTAL STUDIES

CHAPTER 1: Differential effects of the MEK inhibitor SL327 on the acquisition and expression of ethanol-elicited conditioned place preference and aversion in mice

CHAPTER 2: Caffeine prevents ethanol-elicited place preference and aversion and ERK phosphorylation in the nucleus accumbens and other areas of the extended amygdala $\quad 57$

CHAPTER 3: Impact of caffeine on ethanol induced sensitization: relation to dopamine metabotropic changes in ERK and DARPP-32 89

$\begin{array}{ll}\text { GENERAL DISCUSSION } & 115\end{array}$

$\begin{array}{ll}\text { REFERENCES } & 123\end{array}$ 

Summary 



\section{SUMMARY}

The intracellular signaling cascades constitute the means by which addictive substances induce the remodeling of the circuits involved in motivated behaviors which underlie the learning processes and the development of memories at the basis of the progression of addiction. A protagonist in such signaling cascades is the Extracellular signal-Regulated Kinase (ERK), a member of the mitogen-activated protein kinase, that constitutes an important biochemical factor common to many cellular functions. The abundant expression of ERK in brain areas of addiction circuits emphasizes the relevance of this kinase in modulating behavioral functions mediated by these circuits. These findings led to the development of new research lines aimed at understanding the involvement of ERK in the processes related to the onset of addiction and at characterizing their role in various aspects of this pathology, including substances' consumption, sensitization as well as substances' involvement in its cognitive and motivational aspects. Another biochemical factor involved in this process is the Dopamine and CAMP-regulated phosphoprotein Mr 32,000 kDa (DARPP-32), which acts upstream of the MEK/ERK cascade, and regulates the activity and the phosphorylation state of this pathway. Thus, the general aim of the present doctoral thesis was to study the role of ERK in terms of protein kinase expression induced by ethanol, caffeine and their association, and its relationship with some behavioral responses in validated animal models of drug addiction such as the response to stimuli associated to their intrinsic properties and conditioned to the environment (place conditioning), or the psychomotor activation mediated by these substances.

The first and second chapters of this dissertation examined the involvement of protein kinases ERK in different aspects of ethanol-induced place conditioning. Specifically, in the first chapter we used SL327, a compound that inhibits MEK, to study how the blockade of this cascade could affect the acquisition and expression of Conditioned Place Preference (CPP) and Conditioned Place Aversion (CPA) induced by ethanol. Furthermore, we also studied the expression of ERK phosphorylation (pERK) in different areas of the motivation circuit in response to acute SL327 and ethanol administration. In the second chapter we explored the results of the pharmacological 
relationship between caffeine, ethanol and their association in the experimental paradigm of ethanol-elicited CPP and CPA previously utilized for experiments described in chapter 1 . We also investigated the expression of pERK in various brain areas as a result of either the acute administration of both substances and of the presentation of the positively (CPP) or negatively (CPA) stimuli conditioned to ethanol. The last chapter examines the effects of caffeine, ethanol and their interaction through the analysis of horizontal and vertical locomotion. Moreover, using the open field, we studied the effects of these substances and their interaction in novelty-induced exploration in order to observe whether a cross-sensitization effect could develop. Finally, we studied the phosphorylation in the nucleus accumbens of ERK and DARPP32(Thr75), related to $D_{1}$ and $D_{2}$ receptor activation, respectively. The findings of these studies revealed that:

- The MEK/ERK pathway is differentially involved in distinct phases of associative learning behavior expressed in the CPP and CPA elicited by ethanol; specifically, the acquisition phase, as well as the appetitive motivation (CPP), seems to be more sensitive to the blockade of the intracellular signaling cascade. However, the ability of the kinase inhibitor, SL327, to prevent ethanol-induced ERK phosphorylation is not reflected in the differential results of behavioral experiments.

- Caffeine was devoid of conditioning effects but significantly impaired ethanolelicited place conditioning (both CPP and CPA), which could be referred to a functional antagonistic action exerted by these two drugs on the adenosinergic system. Furthermore, the results of acute administration experiments support this hypothesis of a functional antagonistic interaction since caffeine is able to prevent ethanol-induced pERK expression in several brain areas. Nevertheless, the evaluation of PERK expression following the presentation of the conditioned stimuli reflects a differential activation patterns depending on the brain area examined.

- Caffeine and ethanol, administered acutely, affected horizontal and vertical locomotion in the open field in a biphasic manner and caffeine potentiated acute ethanol-induced locomotion. However, the acute administration of 
caffeine to mice that were previously sensitized to the effects of ethanol had reduced stimulating effects compared to ethanol naïve mice. Finally, caffeine prevented the ethanol-elicited pERK expression in the nucleus accumbens whereas there were no effects on pDARPP-32(Thr75), suggesting an effect mediated by $D_{1}-A_{1}$ receptors on this area.

Taken together the results of the present thesis offer new insights into the complexity of the involvement of ERK cascade in the acquisition of associative learning and in the expression of acquired responses related to models of drug addiction. These data provide new information about the antagonistic interaction between caffeine and ethanol in the motivational properties expressed in the place conditioning paradigm and in the ability of ethanol sensitization to blunt the stimulatory effects of caffeine. 


\section{RESUMEN}

Las cascadas de señalización intracelular constituyen el medio por el cual las sustancias adictivas inducen la remodelación de los circuitos involucrados en comportamientos motivados que subyacen en los procesos de aprendizaje y desarrollo de memorias en base a la progresión de la adicción. Una molécula protagonista en tales cascadas de señalización es "Extracellular signal-Regulated Kinase" (ERK), un miembro de la proteína quinasa activada por mitógenos, que constituye un importante factor bioquímico común a muchas funciones celulares. La abundante expresión de ERK en áreas cerebrales implicadas en el circuito de la adicción, enfatiza la relevancia de estas quinasas en la modulación de las funciones del comportamiento mediadas por estos circuitos. Estos hallazgos condujeron al desarrollo de nuevas líneas de investigación destinadas a caracterizar el papel de la ERK en varios aspectos de la adicción a las drogas, incluido el consumo, la sensibilización y la participación de las sustancias en aspectos cognitivos y motivacionales de esta patología, para comprender la participación de la ERK en los procesos relacionados con su inicio. Otro factor bioquímico involucrado en este proceso es "Dopamine and cAMP-regulated phosphoprotein Mr 32,000 kDa (DARPP-32)", que actúa como parte de la cascada MEK/ERK, regulando la actividad y el estado de fosforilación de la ERK. De este modo, el objetivo general de la presente tesis doctoral fue estudiar el papel de ERK, en términos de expresión de proteína quinasa inducida por drogas (etanol, cafeína y su asociación), así como su relación con respuestas conductuales relacionadas con el desarrollo de la adicción tales como la respuesta a estímulos asociados a las propiedades intrínsecas y condicionadas al entorno (condicionamiento de lugar). Finalmente, también investigamos la actividad psicomotora mediada por estas sustancias.

Los capítulos primero y segundo de esta tesis doctoral examinan la participación de la proteína quinasa ERK en diferentes aspectos del condicionamiento de lugar inducido por etanol. Específicamente, en el primer capítulo usamos SL327, un compuesto que inhibe la MEK, para estudiar cómo el bloqueo de esta cascada podría afectar la adquisición y la expresión de la preferencia de lugar condicionada (CPP) y la aversión de lugar condicionada (CPA) inducidas por etanol. Además, también estudiamos la 
expresión de la fosforilación de ERK (pERK) en diferentes áreas de circuitos motivacionales tras la administración aguda de SL327 y etanol. El segundo capítulo explora los resultados de la relación farmacológica entre cafeína, etanol y su asociación en el mismo paradigma experimental de CPP y CPA inducidos por etanol. También investigamos la expresión de pERK en diversas áreas del cerebro como resultado de la administración aguda de ambas sustancias y su impacto en la expresión del condicionamiento positivo (CPP) o negativo (CPA) al etanol. El último capítulo examina los efectos de la cafeína, el etanol y su interacción a través del análisis de la locomoción horizontal y vertical. Además, utilizando el campo abierto, estudiamos los efectos de estas sustancias y su interacción en la exploración inducida por novedad para observar si se desarrolla un efecto de sensibilización cruzada. Finalmente, estudiamos la fosforilación en el núcleo accumbens de pERK y pDARPP-32(Thr75), relacionado con la activación de los receptores $D_{1}$ y $D_{2}$, respectivamente. Los resultados de estos estudios revelaron que:

- La vía MEK/ERK participa de manera diferencial en distintas fases del comportamiento de aprendizaje asociativo expresado en el CPP y el CPA inducido por el etanol; específicamente, la fase de adquisición, así como la motivación apetitiva (CPP), parece ser más sensible al bloqueo de la cascada de señalización intracelular. Sin embargo, la capacidad del inhibidor de la quinasa SL327, para prevenir la fosforilación de ERK inducida por etanol, no se refleja en los diferentes resultados de los experimentos conductuales.

- La cafeína no produce efectos por sí misma en condicionamiento, pero afecta significativamente el condicionamiento de lugar inducido por el etanol (tanto CPP como (PA), lo que podría reflejar una acción antagonista funcional ejercida por estos dos fármacos sobre el sistema adenosinérgico. Además, los resultados de los experimentos de administración aguda respaldan esta hipótesis de una interacción antagónica ya que la cafeína puede prevenir la expresión de pERK inducida por etanol en varias áreas del cerebro. Sin embargo, la evaluación de la expresión de pERK después de la expresión de los estímulos condicionados refleja diferentes patrones de activación dependiendo del área del cerebro examinada. 
- La cafeína y el etanol, administrados de manera aguda, afectan la locomoción horizontal y vertical en campo abierto de manera bifásica y la locomoción inducida por etanol potenciada por cafeína. Sin embargo, la administración aguda de cafeína a ratones que previamente habían estado sensibilizados a los efectos del etanol reduce los efectos estimulantes en comparación con los ratones sin tratamiento previo con etanol. Finalmente, la cafeína evita la expresión de pERK provocada por etanol en el núcleo accumbens, mientras que no hay efectos sobre pDARPP-32(Thr75), lo que sugiere un efecto mediado por los receptores $D_{1}-A_{1}$ en esta área cerebral.

Tomados en conjunto, los resultados de la presente tesis ofrecen nuevos conocimientos sobre la complejidad de la participación de la cascada ERK en la adquisición del aprendizaje asociativo y en la expresión de las respuestas adquiridas. Estos datos proporcionan nueva información sobre la interacción antagónica entre la cafeína y el etanol en las propiedades motivacionales expresadas en el paradigma del condicionamiento de lugar y en la capacidad de sensibilización del etanol para mitigar los efectos estimulantes de la cafeína. 
General Introduction 



\section{GENERAL INTRODUCTION}

\section{MOTIVATED BEHAVIOR}

Since the dawn of psychology, the study of the mechanisms underlying the concept of motivation has been considered essential for understanding human behavior. In general, the term motivation refers to the set of conditions that convey our behavior, determining the orientation towards a specific goal. Motivation is a necessary ingredient of interaction for all the species. In fact, all animals are guided by motivation to satisfy natural needs essential for survival and these behaviors are the result of biological and psychological processes that have been subjected to evolution at various levels (Simpson \& Balsam 2016). Motivated behavior can be described by activational and directional aspects. The activational aspects concern the fact that the beginning and the maintenance of motivated behaviors can be represented by high levels of activity and vigor and persistence in the working results (Salamone et al. 2018). Moreover, the directional aspects are related to the fact that the behavior can be directed towards or away from a specific stimulus, in order to search for some (i.e., water, food, social and sex interaction) and avoid others (i.e., pain, discomfort) (Salamone 2010; Salamone \& Correa 2012). This difference in the emotional response reflects the motivational valence of the stimulus and can be positive or negative, depending on the purely instinctive perception of reacting to stimuli. Natural stimuli are characterized by a positive motivational value and can be considered appetitive stimuli and, due to their intrinsic nature, the descending behavior will be indeed "motivated" to their research. On the contrary, in case of unpleasant stimuli, the reaction will be avoidance (aversive behavior). Operationally, a motivated behavior can be defined as the result of two consecutive phases: the initial phase consisting mainly of approaching or seeking the reinforcing goal stimulus (e.g., seeking behavior), while in the subsequent phase the organism gains access to the stimulus and directly interacts with it (consummatory behavior) (Salamone \& Correa 2012). However, motivated behaviors are widely adaptable, even though they can become habitual. Both the first motivation to emit the behavior and the subsequent behaviors are influenced by past and present experience with the reinforcing stimulus (Volkow et al. 
2017). Therefore, the perception of a stimulus can be manipulated through learning processes, such as in the associative learning.

\section{A MODEL OF ASSOCIATIVE LEARNING: PAVLOVIAN CONDITIONING}

The associative learning can be described as a process in which the subject learns the relationships between two stimuli, or between a stimulus, and a behavior. In the classification of the experimental procedures, the associative learning can be distinguished in classic conditioning, that involves learning the relationships between two stimuli, and operant conditioning, that includes learning the relationship existing between one or more stimuli and the reaction derived from interacting with it. The modern neuroscientific study of classical conditioning, also called "Pavlovian conditioning", was originally described by Russian physiologist Ivan Pavlov (1927). In Pavlov's seminal experiment two stimuli were presented paired to a dog: a bell tone simultaneously with some food. The repeated association (conditioning procedure) between these two stimuli changed the dog's behavior in response to the presentation of the first stimulus. In fact, the tone never would have caused a reaction (salivation) until it would have been paired with the food. In this study, the tone is called conditioned stimulus (CS), whereas the food is the unconditioned stimulus (US) and the learned response, as a consequence of a repeated exposure to the appetitive stimulus, is named the conditioned response (CR) to differentiate it from the innate unconditioned response (UR), because dog salivated less or more depending on its hunger status. In fact, the CS upon the learning experience acquires the property of eliciting a new response, the $C R$, strictly related to and dependent from the conditioning process (Fanselow \& Wassum 2016).

\section{Conditioned Place Preference and Conditioned Place Aversion}

A model of Pavlovian conditioning is the experimental procedure of place conditioning in its two variants, Conditioned Place Preference (CPP) and Conditioned Place Aversion (CPA). The CPP paradigm is characterized by the pairing of two distinct sets of environmental cues (e.g., apparatus with different wall color or pattern, size or shape) with the US (e.g., drug, food). The conditioning itself is represented by the repeated exposure to the US in one compartment of the CS (conditioned stimulus paired with 
drug; $\mathrm{CS}+$ ), while the exposure to the other compartment occurs without the US (conditioned stimulus paired without the drug; CS-). At the end of the conditioning, the animal, in US absence, is exposed to both contexts (CS+ and CS-) and a choice test is performed. This condition is one of the greatest advantages of place conditioning as, being the animal tested in a drug-free state, there cannot be interference with the emitted choice as a consequence of the pharmacological effects of the drug. A significant increase in time spent in the paired compartment relative to a control value is an indication that the US was provided of positive motivational properties (Bardo \& Bevins 2000; Tzschentke 2007). A significant reduction in time spent in the paired compartment relative to a control value is an indication that the US was provided of negative motivational properties (Bardo \& Bevins 2000; Tzschentke 2007). The CPP, under appropriate conditions, is a method for measuring drug reinforcement. Drugs of abuse have been widely used for CPP experiments, such as cocaine (Sellings 2006), ecstasy (Robledo et al. 2004), morphine (Ruiu et al. 2013; Zhu et al. 2015), nicotine (Ahsan et al. 2014), THC (Vann et al. 2008) and ethanol (Cunningham et al. 2003, 2006; Spina et al. 2015), although this latter, similarly to others such as nicotine, is endowed with the property, under appropriate conditions, to elicit both CPP and CPA (Cunningham et al. 2006; Spina et al. 2015). Moreover, if the learning process resulting in CPP is grounded on the ability of animals to transfer the positive biological significance (wellness and euphoria), that related to CPA is founded on the opposite principle, i.e. to the transposition of negative (sickness and dysphoria) feelings to motivationally neutral components of the environment (Bardo and Bevins 2000; Tzschentke 2007). In addition, upon an appropriate manipulation of the experimental conditions it is possible to shift the ability of a given US from that of resulting in a preference state, in which the animals choose to spend more time in the context associated with the drug, to that of resulting in an aversion state, such as in case of high doses of the same drug, e.g. nicotine that has dose-dependent rewarding and aversive effects (Risinger \& Oakes 1995). With due caution, also the condition of withdrawal (from a drug) states have been shown to elicit CPA (Stinus et al. 2005). 


\section{FROM MOTIVATION TO ADDICTION}

\section{The mesolimbic system: neurophysiology}

The mesolimbic system plays a pivotal role in the coordination of behaviors, emotions and memories, and interconnects cortical and subcortical structures devoted to linking primordial states and emotion to learning and behavior. The stimulation of the circuit is involved in the acquisition of motivational properties to neutral stimuli (Catani et al. 2013). This system has been described for the first time in 1954 by Olds and Milner. In their experiment these Authors discovered that rats responded to reinforcing stimuli, brain electrical stimulation, only when applied in specifically brain areas (Olds \& Milner 1954). Subsequently, it was established that the area of mesolimbic system most involved in reinforcement processes and related behavior is the nucleus accumbens (Acb). Natural stimuli, such as food, water and sex, but also drugs of abuse, have the common property to enhance the release of dopamine in the Acb (Di Chiara \& Imperato 1988). However, the continuous stimulation of dopaminergic neurons and the consequent increases of extracellular dopamine in the Acb elicited by addictive drugs, unlike the natural stimuli, does not develop the adaptive mechanisms of habituation but, on the contrary, strongly encourages the acquisition of motivational properties by drug conditioned stimuli (Di Chiara \& Bassareo 2007). Furthermore, drugs of abuse promote an adaptive function, the incentive learning, defined as the acquisition by previously neutral stimuli of the capacity to elicit effects and other responses and occurs in association with the presentation of reinforcing stimuli (Berridge \& Robinson 1998). Thus, abnormal changes in the motivation are a key element to develop disorders of motivated behaviors that can be divided into two groups. The first group is characterized by pathological deficits in motivation frequently in patients with schizophrenia and affective disorders. The second group consists in problematic excesses in behavior as well as addiction disorder elicited by addictive drugs (Simpson \& Balsam 2016). Indeed, in susceptible subjects, repeated use of drugs of abuse carries the risk of developing dependence and addiction, defined as a chronic disease characterized by compulsive drug use despite adverse consequences, loss of control over drug-seeking behavior and high risk of relapse (Koob \& Volkow 2009). Since ancient times humans began to use psychoactive 
substances, initially in a ritual and/or religious context and then inspired by personal "recreational" desires. These substances have the common characteristic to induce a set of emotional and physical feelings that, by mimicking the reinforcing properties of natural stimuli, are recognized as pleasurable (pleasure). The perception of pleasure, due to the stimulation of the mesolimbic system, leads a motivated behavior aimed to seek and re-experience the same gratifying feeling perceived during the consumption of the drug. Consequently, the substance acquires a positive value (primary reinforcement) in the individual who carries out a series of behaviors with the sole purpose of obtaining the drug of abuse (Spanagel \& Weiss 1999; Koob \& Volkow 2009). Addictive drugs can reinforce previous intake behavior by inducing pleasant effects (positive reinforcement) or by ending an unpleasant feeling (negative reinforcement). In this regard, the development of physical addiction/dependence could be explained by the possibility of another form of reinforcement: whenever the use of a drug relieves the unpleasant effect of the withdrawal syndrome, the previous behavior is further supported. Even when the development of tolerance attenuates the initial reinforcing effects, drugs of abuse can elicit a recurrent and regular sense of dysphoria or suffering, which is immediately eliminated, and sustained, by another administration (Di Chiara 2002; Koob \& Volkow 2009).

\section{The nucleus accumbens: neuroanatomy}

The Acb is the central area of the limbic system and it is supposed to play a critical role in the motivated behavior, and, specifically, in the translation of limbic information into goal-directed behavior. It receives glutamatergic projections from the hippocampus, basolateral amygdala, prefrontal cortex and dopaminergic inputs from the ventral tegmental area (VTA) (Charara \& Grace 2003). The Acb and VTA receive glutamatergic output from the prefrontal cortex and, moreover, a reciprocal glutamatergic connection has been described between the amygdala and prefrontal cortex. All these regions, that make up a circuit whose key role is played by dopamine, appear to perform an important role in learning processes, motivation, memory and adaptive behavior (Kelley 2004). The Acb is characterized by two functionally distinct subregions termed core and shell. The core is the dorsolateral part, associated with the anterior and orbitofrontal cortex, and regulates the motor expression of motivated 
behavior. The medioventral compartment, the shell, is interconnected with the hypothalamus and VTA and is mostly involved in the perception of gratification. Additionally, the shell is implicated in the relationship between motivational events and simultaneous environmental perceptions that contribute to learning establishment (Kalivas \& Volkow 2005). In the Acb the main cell types are GABAergic and the majority of these are medium spiny neurons (MSNs), on which dendrites converge dopaminergic and glutamatergic inputs (Cahill et al. 2014). Based on the peptide that contain, the MSNs can be divided into two groups, one subpopulation of neurons that express substance $P$ and dynorphin, and another group containing enkephalin. Furthermore, MSNs express different types of receptors, predominantly glutamatergic and dopaminergic. Studies of receptor localization have shown that $D_{1}$ dopaminergic receptors in the striatum are located predominantly at the postsynaptic level (Altar \& Marien 1987), are coupled with a G-protein that stimulates adenylate cyclase activity $\left(G_{s}\right)$ and co-express substance $P$ (Lu et al. 1997), while dopaminergic $D_{2}$ receptors are located both in the presynaptic and postsynaptic terminals (De Mei et al. 2009), are coupled to G-proteins that inhibit adenylate cyclase $\left(\mathrm{G}_{\mathrm{i} / \mathrm{olf}}\right)$ and co-express mainly enkephalin (Lu et al. 1997). When $D_{2}$ receptors are in homologous terminations are inhibitory auto-receptors, but also can be localized in glutamatergic, cholinergic and GABAergic neurons. However, there are biochemical and physiological findings that support the hypothesis that a subpopulation of MSNs that express both $D_{1}$ and $D_{2}$ receptors is also present (Lu et al. 1997; Svenningsson et al. 1999).

\section{BIOCHEMICAL BASIS OF ADDICTION}

\section{ERK signaling}

The Extracellular signal-Regulated Kinases (ERK) are part of the Mitogen-Activated Protein Kinase (MAPK)-signaling cascade, which is a family of serine-threonine kinases expressed in all eukaryotic cells, where they play an essential role in several cellular processes, such as cell proliferation, differentiation and apoptosis (Sweatt 2004). There are several ERK isoforms, but the most characterized and more involved in neurophysiological processes as well as in drug addiction are $E R K_{1}$ and $E R K_{2}$, with molecular weight of 44 and $42 \mathrm{kDa}$, respectively (Girault et al. 2007). Their activation 
requires the dimerization and phosphorylation on two regulatory residues, Thr202/Tyr204 for ERK 1 and Thr183/Tyr185 for ERK 2 (Khokhlatchev et al. 1998). This double phosphorylation is commonly detected by antibodies, and is thereby considered as a reliable index of ERK activation. In neurons ERK are activated through phosphorylation by various extracellular signals and, consequently, by the stimulation of different cellular receptors, including metabotropic $G$ protein-coupled receptors (GPCRs) and tyrosine kinase receptors. The two pathways converge on the phosphorylation of one common kinase, the mitogen-activated protein kinase/ERK kinase (MEK) which is responsible of ERK phosphorylation. Once activated, ERK can phosphorylate other cytosolic proteins or move into the nucleus where they play a key role in gene regulation, thereby they can phosphorylate a number of transcription factors and control the transcription of immediate early genes (e.g. c-Fos) (Valjent et al. 2001; Davis \& Laroche 2006; Girault et al. 2007; Sun et al. 2016).

\section{ERK and drugs of abuse}

ERK phosphorylation is elicited also by drugs of abuse in a subset of neurons in brain areas related to addiction. The first study which showed an increase of ERK expression in response to morphine or cocaine reported an increase in the VTA of rats after a chronic treatment (Berhow et al. 1996). In particular, in the MSNs of the striatum, the most expressed GPCRs are the dopaminergic $D_{1}$ and $D_{2}$, receptors positively and negatively coupled to cyclic adenosine monophosphate (cAMP)/protein kinase A (PKA) pathway, respectively. Nevertheless, ERK activation requires the activation of both dopamine $D_{1}$ and $\mathrm{N}$-methyl-D-aspartate (NMDA) glutamate receptors, that converge onto the dendrites of the MSNs, in fact, the stimulation of $D_{1}$ receptors cannot elicit ERK phosphorylation per se, but requires an increase of calcium influx through NMDA receptors as a consequence of endogenous glutamate (Pascoli et al. 2011). $D_{1}$ receptors are represented in the cerebral cortex, limbic system, thalamus and dorsal and ventral regions of the striatum (Girault et al. 2007; Cahill et al. 2014). It has been demonstrated that pretreatment with a $\mathrm{D}_{1}$ receptor antagonist $(\mathrm{SCH} 23390)$ is able to prevent cocaine-elicited ERK phosphorylation (Fontana et al. 1993) and raclopride, a $D_{2}$ receptor antagonist, fails to prevent this increase (Valjent et al. 2000). Moreover, studies using $D_{1}$ receptors knock-out mice demonstrated that both the locomotor 
activation (Xu et al. 2000) and the self-administration (Caine et al. 2007) elicited by cocaine have been prevented. Furthermore, also glutamatergic inputs, which attain in the striatum from cortical and subcortical regions, are required for ERK activation. Glutamate receptors, both metabotropic and ionotropic, are co-expressed closely to the dopaminergic receptors. In particular, studies with NMDA receptors antagonist (MK801), as well as with GluN1-knockdown mice, demonstrated a complete prevention of cocaine-induced sensitization (Ramsey et al. 2008; Valjent et al. 2010). Thus, the convergence of dopaminergic and glutamatergic signals on the ERK pathway in response to binding of DA to $D_{1}$ receptor involves the activation of PKA, that quickly phosphorylates the NMDA receptor at Ser897 of the GluN1 subunit. Notably, however, the trigger event for the ERK activation depends on a non-canonical signaling pathway that involves the phosphorylation of GluN2B by the protein-tyrosine kinase Fyn with a consequent increase of $\mathrm{Ca}^{2+}$ influx into the neuron (Pascoli et al. 2011). This last event causes the activation of the calcium-sensitive Ras-guanine releasing factor (Ras-GRF1) that turns on the MEK/ERK pathway, whereas the maintenance of ERK phosphorylation depends on CAMP/PKA pathway. Specifically, the maintenance of activation is due to the deactivation of MEK/ERK-related phosphatases via dopamine and cAMP-regulated phosphoprotein $M_{r}$ 32,000 kDa (DARPP-32) and striatal-enriched tyrosine phosphatase (STEP). In fact, the activation of PKA via $D_{1}$ receptors can phosphorylate DARPP-32 at Thr-34 site, which converts it in a strong inhibitor of the protein phosphatase PP-1, which dephosphorylates the other substrate, STEP (Valjent et al. 2005; Baik 2013; Cahill et al. 2014) (see figure 1).

Moreover, ERK pathway is activated in response to acute (Valjent et al. 2000, 2004; Salzmann et al. 2003; Zhang et al. 2004; Brami-Cherrier et al. 2005; Acquas et al. 2007; Ibba et al. 2009) and chronic (Berhow et al. 1996; Muller \& Unterwald 2004) exposure to addictive drugs in mesolimbic circuit, that play a critical role on neuroplasticity, gene expression and behavioral changes underlying the reinforcing processes induced by these substances. Moreover, the role of these kinases has also been correlated to the motivational properties of drugs evaluated through CPP procedures (Valjent et al. 2000, 2001; Salzmann et al. 2003; Gerdjikov et al. 2004; Lu et al. 2006; Spina et al. 2010) but also to the ability of contextual stimuli to evoke the expression of acquired 
CPP (Miller \& Marshall 2005) and of conditioned stimuli on reinstatement of ethanolseeking behavior in self-administration experiments (Radwanska et al. 2008; Schroeder et al. 2008; Peana et al. 2013).

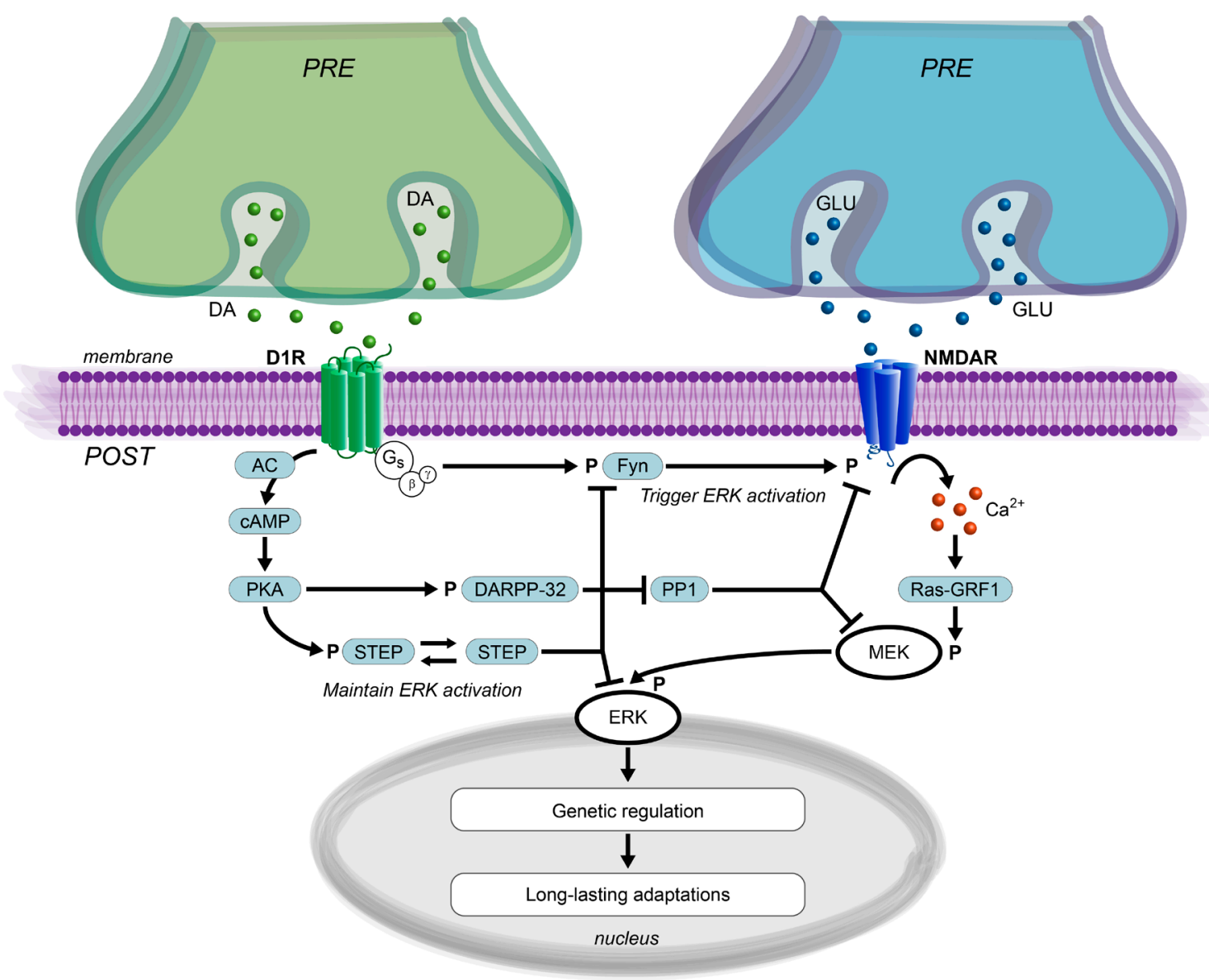

Figure 1. Schematic representation of ERK activation signaling pathway. The simultaneous stimulation of dopaminergic $D_{1}(D 1 R)$ and glutamatergic NMDA receptors (NMDAR) in the striatum mediates ERK phosphorylation. AC: adenylate cyclase; CAMP: cyclic adenosine monophosphate; PKA: protein kinase A; DARPP-32: dopamine and CAMP-regulated phospho-protein $M_{r}$ 32,000 kDa; STEP: striatal-enriched tyrosine phosphatase; PP1: protein phosphatase 1; Ras-GRF1: Ras-guanine releasing factor; MEK: mitogen-activated protein kinase/ERK kinase; ERK: Extracellular signal-Regulated Kinase.

\section{DARPP-32 signaling}

DARPP-32 is a protein kinase/phosphatase inhibitor highly expressed in dopaminergic brain areas, the major levels of DARPP-32 being found in the striatum (caudateputamen and Acb), olfactory tubercle and nuclei of amygdala (Ouimet et al. 1998). Moreover, DARPP-32 is abundantly expressed in all parts of MSNs including dendrites, axons and terminals. Given its ability to be phosphorylated on different sites, and their different resulting effects, DARPP-32 appears of fundamental importance for the integration of biochemical and behavioral responses regulated by dopamine and other neurotransmitters (Svenningsson et al. 2005). Interestingly, the phosphorylation of 
DARPP-32 (pDARPP-32) at various sites and their effects on several substrates, as well as on DARPP-32 itself, produces a multifaceted system of positive and negative feedbacks (Yger \& Girault 2011). Indeed, it has been hypothesized that DARPP-32 is a sensor of glutamatergic and dopaminergic inputs, allowing to assume a role in the processing of responses in the MSNs (Barbano et al. 2007). Dopaminergic signaling is controlled by the phosphorylation of DARPP-32 at various residues in $D_{1}$ and $D_{2}$ receptors of MSNs (Nishi \& Shuto 2017). One of the most widely studied sites is the phosphorylation at Threonine-34 (Thr-34) by PKA that converts DARPP-32 in a potent inhibitor of the serine/threonine protein phosphatase-1 (PP1). This event has important consequences in the amplification of $D_{1}$ dopaminergic signaling because allows to increase the phosphorylation state of all the substrates PKA/PP1 downstream regulated and, moreover, is crucial to maintain the ERK activation elicited by addictive drugs through the regulation of STEP, a potent inhibitor of ERK (Yger \& Girault 2011). Furthermore, DARPP-32 is a physiological target of the cyclin-dependent kinase 5 (Cdk5) which phosphorylates it at Threonine-75 (Thr-75) residue with the resulting effect of PKA inhibition and consequent reduction of $D_{1}$ signaling cascade. Specifically, the phosphorylation at Thr-75 is more potent than that at Thr-34 in terms of PKA inhibition and related substrates. On the contrary, the inactivation of pDARPP-32 at Thr-75 is caused by dopamine through the phosphatase PP2A/B56 $\delta$ via $D_{1}$ receptor/PKA, which results in the disinhibition of PKA, i.e. in the removal of their tonic inhibition (Bibb et al. 1999) (see figure 2).

However, also glutamate can regulate the DARPP-32 signal. In fact, via NMDA and AMPA receptors glutamate reduces pDARPP-32(Thr-34) with the resulting effects to activate PP1. Nevertheless, when pDARPP-32(Thr-34) is low, the dephosphorylation of pDARPP-32(Thr-75) and the consequent disinhibition of PKA could act to potentiate dopamine $D_{1}$ receptor/PKA/pDARPP-32(Thr34) cascade. Furthermore, as mentioned above, pDARPP-32(Thr-34) plays a critical role in the regulation of the ERK pathway, not only with the inhibition of PP1, but also preventing ERK deactivation through the maintaining of the tyrosine phosphatase STEP in an inactive, phosphorylated, state (Svenningsson et al. 2005). Thus, as a consequence of $D_{1}$ receptors activation, pDARPP- 
32(Thr-34) moves to the nucleus and enables the phosphorylation of histone H3 on Ser- 10 which promotes gene expression (Stipanovich et al. 2009).

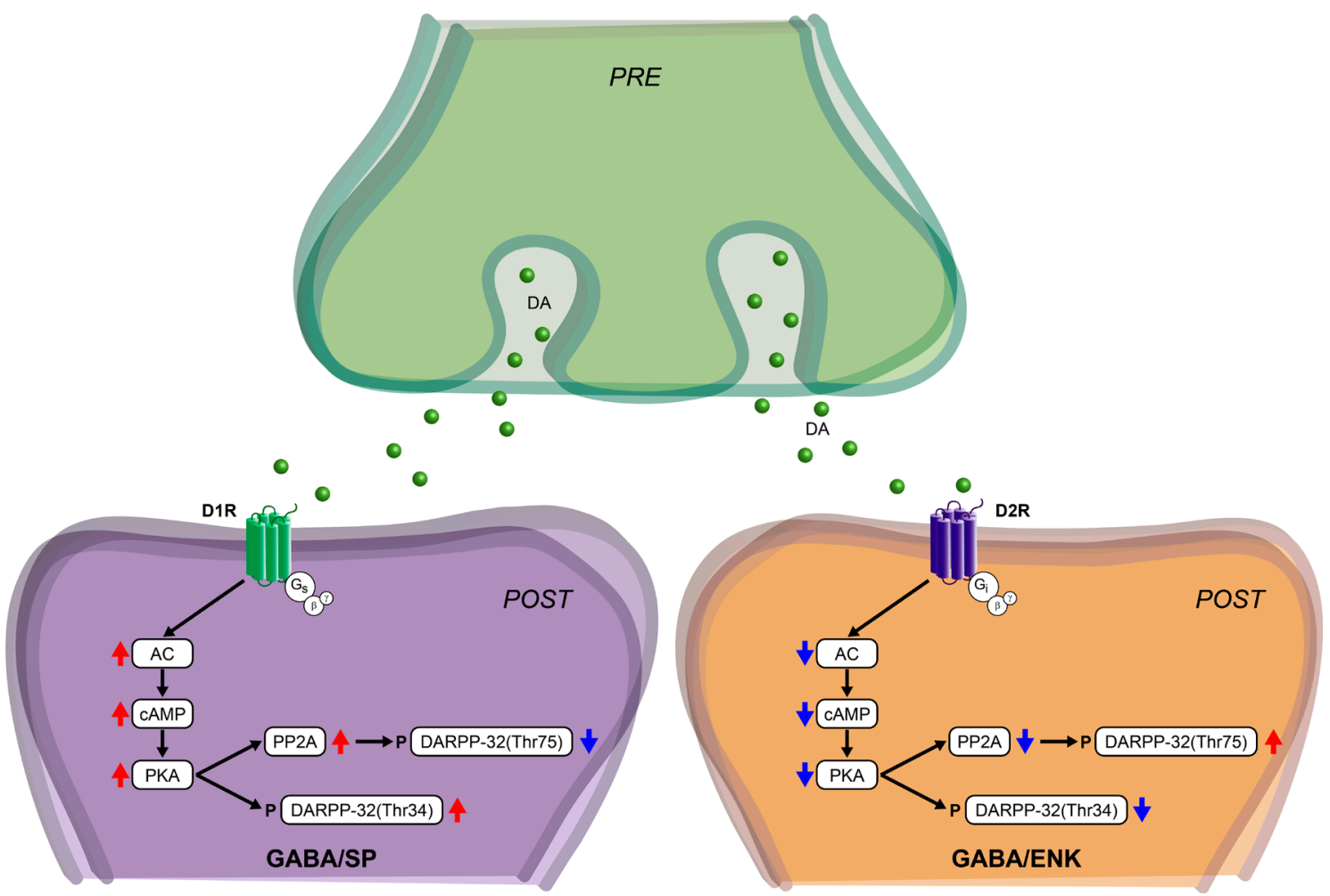

Figure 2. Schematic representation of the intracellular cascade and effect of dopamine on the phosphorylation of DARPP-32 at -Thr34 and -Thr75 residues. The different stimulation of $D_{1}$ and $D_{2}$ dopamine receptor is critical to exert opposing effects on the two different types of MSNs. D1R: $D_{1}$ receptor; D2R: $D_{2}$ receptor; $A C$ : adenylate cyclase; PKA: protein kinase A; DARPP-32: dopamine and CAMP-regulated phospho-protein $M_{r}$ 32,000 kDa; PP2A: protein phosphatase 2A; GABA/SP: GABAergic medium spiny neurons co-express substance P; GABA/ENK: GABAergic medium spiny neurons co-express enkephaline.

\section{DARPP-32 and drugs of abuse}

DARPP-32 plays an essential role in addictive disorders mediating or modulating shortand long-term effects of drugs of abuse. This implication has been shown in several studies using DARPP-32 knockout and transgenic mice (Svenningsson et al. 2005; Borgkvist \& Fisone 2007). DARPP-32 is ubiquitously expressed in two types of MSNs but seems to be subjected to different regulatory mechanisms in $D_{1}$ and $D_{2}$ receptors. It has been demonstrated that acute cocaine administration increases pDARPP32(Thr34) and reduces pDARPP-32(Thr75) expression in MSNs containing $\mathrm{D}_{1}$ receptors, while opposite results were found upon the activation of MSNs that express $D_{2}$ receptors (Bateup et al. 2008). Furthermore, in mutant mice selective deletion of $D_{1}$ receptors in MSNs elicited a reduction of cocaine-induced locomotor stimulation, 
while the deletion of $D_{2}$ receptors caused an increase of locomotor activity (Bateup et al. 2010). Moreover, in a CPP paradigm DARPP-32 knockout and DARPP-32(Thr34) mutant mice show a reduction in cocaine-elicited place preference compared to the DARPP-32(Thr75) mutant mice (Zachariou et al. 2006). In addition, also acute morphine treatment shows an increase of pDARPP-32(Thr34) via $D_{1}$ receptors in the Acb but not of pDARPP-32(Thr75) (Borgkvist \& Fisone 2007). This different activation of DARPP-32 seems to be correlated to the duration of the pharmacological treatment: indeed it has been observed that in acute psychostimulant treatment, the expression of pDARPP-32(Thr34) sustains the reinforcing effects through $D_{1} /$ PKA signaling, whereas in a schedule of repeated administration the inhibition of PKA, as a consequence of pDARPP-32(Thr75) expression, appears as a homeostatic event against the development of addiction (Nishi \& Shuto 2017).

\section{ETHANOL MOTIVATIONAL PROPERTIES}

Ethanol is the psychopharmacological active component of alcoholic drinks and it is responsible for several disorders and alcohol-related chronic diseases that strongly interest individuals and society. Ethanol is a small molecule with lipophilic and hydrophilic characteristics, that render it able to distribute rapidly in all the body districts. Curiously, the precise target(s) of ethanol have not yet been established, but it is well known that its effects in neurons and synapses of the brain are due on one hand to an increase of inhibitory transmission via $\gamma$-aminobutyric acid-A $\left(G A B A_{A}\right)$ receptors, and on the other hand to an inhibition of excitatory transmission via NMDA glutamate receptors (Ron \& Wang 2009; Trudell et al. 2014). The characteristic acute behavioral effects of ethanol range from disinhibition to sedation, and acute intoxication with hypnosis at high doses. The reinforcing properties of ethanol can be attributed to the activation of mesolimbic dopaminergic system, indeed, ethanol preferentially increases firing of dopaminergic neurons in the VTA and dopamine transmission in the Acb and other brain regions of extended amygdala (Gessa et al. 1985; Di Chiara \& Imperato 1988; Carboni et al. 2000; Gonzales et al. 2004) through a mechanism of disinhibition of GABAergic control on dopaminergic neurons of the VTA (Brodie \& Appel 1998). This mechanism is supported with intra-VTA ethanol selfadministration experiments (Gatto et al. 1994; Rodd et al. 2004). 
Moreover, through place conditioning studies it has been widely confirmed the ability of ethanol to induce a significant CPP and CPA for the drug-paired compartment. The literature describes several studies of ethanol place conditioning in rats and mice, using different routes of administration and different doses of ethanol. The intraperitoneal administration of the drug at the dose of $2 \mathrm{~g} / \mathrm{kg}$ produces a significant CPP in mice (Cunningham et al. 1997; Itzhak et al. 2009; Bhutada et al. 2010; Spina et al. 2015; Rosas et al. 2017) and rats (Cole et al. 2003), as well as the intragastric administration (Peana et al. 2008). However, the final result of the conditioning process is closely dependent on the timing of administration; in fact, in mice an intraperitoneal injection of ethanol $(2 \mathrm{~g} / \mathrm{kg})$, immediately before the exposure for 5 min in a given compartment of the conditioning apparatus, is able to elicit CPP, while the same dose administered immediately after a $5 \mathrm{~min}$ exposure to the paired compartment elicits CPA (Cunningham \& Henderson 2000; Cunningham 2019). Similarly, intragastric administration of ethanol can produce CPP or CPA (Cunningham et al. 2002; Fidler et al. 2004). The ability to give CPA or CPP, independently from the route, intraperitoneal or intragastric administration, is dependent on the dose of ethanol and the temporal relationship between its administration and the exposure to the compartment. In both modalities of administration, the CPA can be due to an initial, but temporary, adverse effect of ethanol, while the CPP has a delayed gratifying effect. Furthermore, the CPA produced by the intraperitoneal administration of ethanol is attributed to the burning sensation and irritation given by the substance, while the CPA induced by the intragastric administration can be correlated with the rapid passage from the condition of sobriety to that of the state of intoxication (Cunningham et al. 2002).

As previously described, the key role of dopamine in the reinforcing effects of ethanol has been widely demonstrated, and, furthermore, the literature contains several studies that relate the role of dopaminergic receptors in the learning of stimuli associated with ethanol. It has been shown that the $\mathrm{D}_{1}$ receptor antagonist $\mathrm{SCH}-23390$ is able to impair the acquisition of conditioned taste aversion elicited by ethanol in mice (Risinger et al. 1999) and the self-administration in rats (Hodge et al. 1997). Moreover, it has also been demonstrated a positive correlation between the capacity 
of ethanol to induce a significant CPP for the drug-paired compartment and dopaminergic $D_{1}$ receptor activation, which has been fully prevented by the pretreatment with the $D_{1}$ antagonist SCH39166 (Spina et al. 2010). The differential role of dopaminergic receptor subtypes in the Acb in the effects of ethanol has been widely confirmed with several studies. It has been demonstrated that the down-regulation of $D_{1}$ receptors using lentiviral vectors in the Acb of mice significantly reduced ethanol consumption, ethanol-elicited-locomotor sensitization and acquisition, but not expression, of ethanol-elicited CPP (Bahi \& Dreyer 2012). Moreover, in other studies with $D_{2}$ knockout mice, ethanol-elicited CPP is reduced (Cunningham \& Henderson 2000) and in a more recent study it has also been observed that the bilateral intra-Acb infusions of the $D_{1}$ receptor antagonist, $S C H 23390$, but not the use of $D_{2}$ antagonist raclopride, is able to prevent the acquisition of ethanol-elicited CPP (Young et al. 2014).

However, the individual response to ethanol depends on the additive actions exercised on the integration of the glutamate-dopamine signal at MSNs level (Tabakoff \& Hoffman 2013). In this sense, the activation of the ERK pathway plays a key role since it depends on both glutamate and dopaminergic receptors activation and is one of the focal points of adaptive behaviors in response to substances of abuse (Girault et al. 2007). Thereby, the study of Ibba et al. (2009) demonstrated for the first time that ethanol, in a dose-dependent manner, is able to activate ERK in the core and shell of $A c b$ and in the nuclei of extended amygdala, through a mechanism mediated by $D_{1}$ receptors. The pre-treatment with the $\mathrm{D}_{1}$ antagonist SCH39166, administered $10 \mathrm{~min}$ before ethanol, totally prevented the expression of ERK (Ibba et al. 2009). Thus, the activation of ERK in these areas and the involvement of $D_{1}$ receptors suggests a contribution of the brain structures implicated in positive reinforcement processes.

Moreover, also the DARPP-32 seems to be implicated in both acute and long-term responses to ethanol. Different ethanol-related behaviors have been evaluated using DARPP-32 knockout mice. These mice showed a reduction of the motivational properties of ethanol measured in CPP and self-administration experiments (Risinger et al. 2018). Nevertheless, in the same study ethanol induced sensitivity to locomotor activation produced by a single dose (Risinger et al. 2018), suggesting that the DARPP- 
32 signaling may be a critical intracellular mechanism regulating ethanol motivated behaviors. A further study with knockout mice showed that DARPP-32 is involved in the reinforcing properties of ethanol through a mechanism mediated by NMDA receptors. Under normal conditions, ethanol reduces NMDA synaptic currents; in DARPP-32 knockout mice the regulation of ethanol sensitivity of NMDA receptors via $D_{1}$ receptors is absent and the $D_{1}$ activation does not impair the ethanol ability to inhibit NMDA receptors (Maldve et al. 2002).

Taken together, all these evidences support the idea that dopaminergic activation of $D_{1}$ receptors in the $A c b$ is involved in developing and mediating the rewarding effects of ethanol or in learning of motivated behaviors related to its effects.

\section{CAFFEINE AND ETHANOL INTERACTION: EFFECTS ON ADENOSINERGIC SYSTEM}

Caffeine (1,3,7-trimethylxanthine) is a natural alkaloid derived from xanthine and is contained in the seeds, nuts, or leaves of a various plant species. The most well-known source of caffeine is the coffee bean and is, actually, the most widely taken psychoactive stimulant in the world (Evans \& Battisti 2019). It is rapidly absorbed in humans and the process is not influenced by the ingestion of food or alcohol. Moreover, rapidly crosses the body membranes and is uniformly distributed in all district and fluids (Ferré \& O’Brien 2011).

The impact of caffeine on ethanol consumption and abuse has become a topic of great interest due to the rise in popularity of "energy drinks", whose main, although not the only, active ingredient is caffeine. These drinks are frequently taken in combination with ethanol (i.e. alcoholic drinks), with the belief that caffeine can offset some of the intoxicating effects of ethanol. However, scientific research has not universally supported the idea that caffeine can antagonize the effects of ethanol in humans or in rodents, and the mechanisms mediating caffeine-ethanol interactions are not well understood.

Caffeine and ethanol act on different neurotransmitters and neuromodulators, but the adenosinergic and the dopaminergic systems are the ones more evidently affected by these two substances. Adenosine is a central neuromodulator and performs its effects 
through four subtypes of GPCRs; $A_{1}, A_{2 A}, A_{2 B}$, and $A_{3}$, with the $A_{1}$ and $A_{2 A}$ receptor subtypes being the most abundant in the central nervous system (Fuxe et al. 2003). It has been demonstrated with binding studies that $A_{1}$ receptors are largely distributed in the brain, with a quite high concentration in the hippocampus, whereas $A_{2 A}$ subtypes are highly expressed, almost exclusively, in the striatum and olfactory bulbs and tubercle (Svenningsson et al. 1999). Caffeine is a non-selective $A_{1} / A_{2 A}$ receptor antagonist and, as such, mediates its stimulant (Ferré 2008), anxiogenic (Correa \& Font 2008) and motivational effects (López-Cruz et al. 2018). If an increase of adenosine concentration induces sleep and fatigue, caffeine has the opposite effect, in fact it is popularly consumed to increase alertness (Johnson et al. 1990).

Adenosine $A_{1}$ and $A_{2 A}$ receptors are co-localized with $D A D_{1}$ and $D_{2}$ receptors in striatal areas, including the $A c b$, but they are differentially segregated in distinct populations of neurons (Nunes et al. 2013). In particular, $D_{2}$ and adenosine $A_{2 A}$ receptors are colocalized on enkephalin-containing MSNs, whereas $D_{1}$ and $A_{1}$ receptors are co-localized on substance P-containing MSNs (Fuxe et al. 2003). These pairs of receptors can form functional heteromers and can converge on common mechanisms, such as intracellular signaling cascades with opposite effects (Fuxe et al. 2003; Ferré 2008). Indeed, the relationship between these pairs of receptors is antagonistic: it has been shown that the adenosine stimulation of presynaptic $A_{1}$ receptors shunts DA release, whereas that of postsynaptic $A_{1}$ antagonistically interacts with $D_{1}$ receptors and the result is a minor binding and coupling ability of $G_{s}$ proteins. Furthermore, the activation of $A_{2 A}$ reduces the binding availability of $D_{2}$ receptors (Ferré 2008).

Moreover, caffeine and adenosine $A_{1}$ or $A_{2 A}$ antagonists elicit opposite effects to DA antagonists on markers such as DARPP-32 (Nunes et al. 2013). In particular, through the blockade of $A_{2 A}$ receptors, caffeine can modulate the neural substrates through which dopamine produces excitation (Lazarus et al. 2011). Caffeine can also increase dopaminergic neurotransmission through additional block-related mechanisms of presynaptic $A_{1}$ striatal receptors that modulate the release of dopamine and glutamate (Ferré 2016). Furthermore, from the analysis of the literature on this specific aspect it emerges that in very few studies $A_{1}$ and $A_{2 A}$ receptors antagonists and agonists were used in order to investigate their role in the effects derived from the co-administration 
of caffeine and ethanol. Specifically, it has been shown that caffeine acts preferentially through $A_{1}$ receptors as regards the reduction of motor incoordination due to ethanol, although this effect of caffeine is evident only when it is administered at low doses (3 $\mathrm{mg} / \mathrm{kg}$ ), because at moderate concentrations $(30 \mathrm{mg} / \mathrm{kg}$ ) it supports the negative effects of ethanol (López-Cruz et al. 2013). Moreover, regarding the effects of ethanol on the adenosinergic system, although ethanol does not act directly on adenosine receptors, it can enhance adenosine extracellular concentrations by increasing the release and the synthesis, or decreasing Equilibrative Nucleoside Transporters type-1 (ENT-1)-dependent adenosine uptake (Nagy et al. 1990; Nagy 1992; Fredholm \& Wallman-Johansson 1996) (see figure 3).
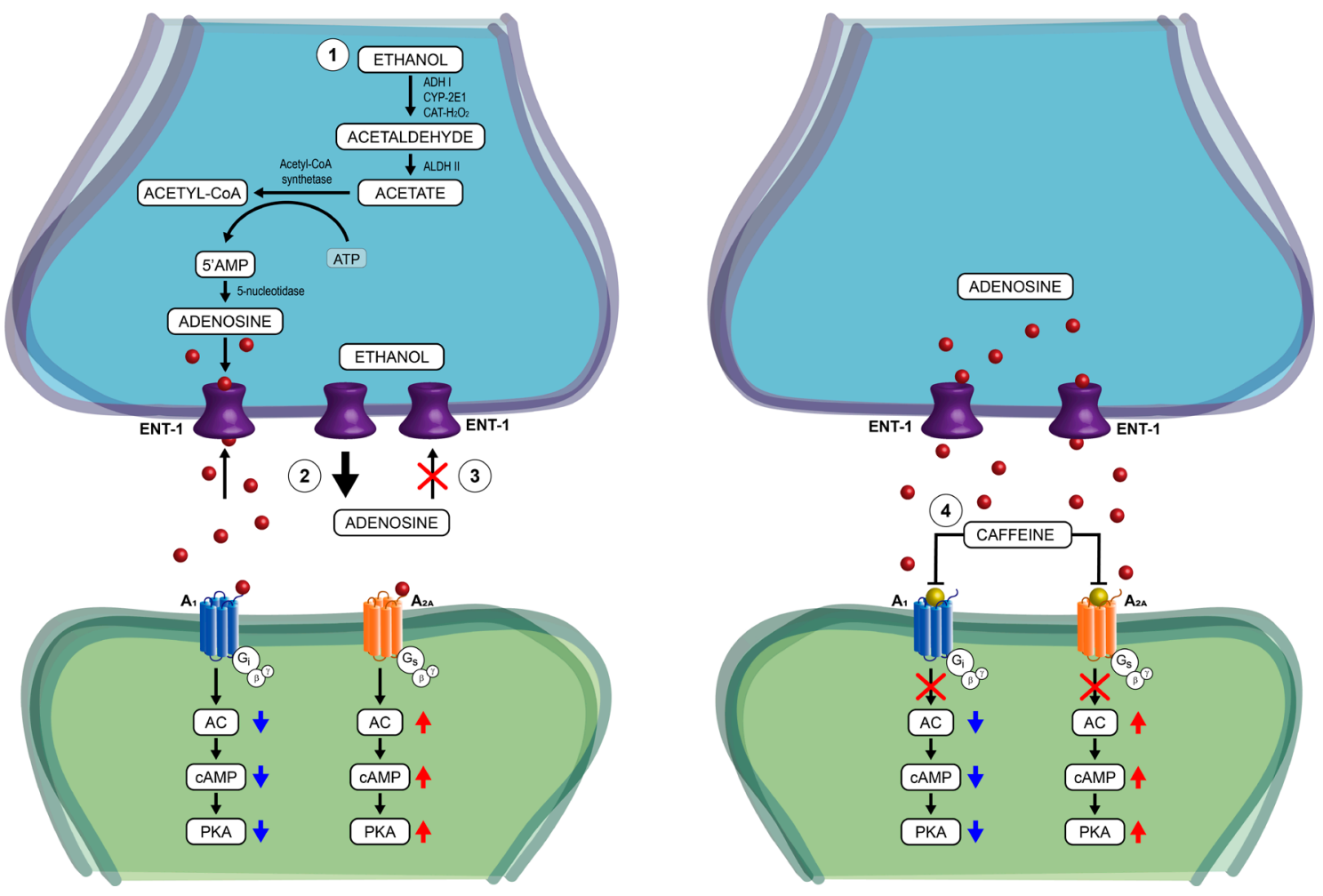

Figure 3. Schematic representation of opposite effects of ethanol and caffeine on brain adenosinergic system. Ethanol regulates adenosine's level by increasing the its production (1), release (3) and preventing the uptake (3), whereas caffeine acts as a non-selective adenosine $A_{1}$ and $A_{2 A}$ receptors antagonist (4). ADH: alcohol dehydrogenase; CYP-2E1: cytochrome P-4502E1; CAT- $\mathrm{H}_{2} \mathrm{O}_{2}$ : catalase; $\mathrm{ALDH}$ II: aldehyde dehydrogenase class 2; ATP: adenosine triphosphate; AMP: adenosine monophosphate; ENT-1: equilibrative nucleoside transporters type 1; $\boldsymbol{A}_{1}$ and $\boldsymbol{A}_{2 \mathrm{~A}}$ : adenosine $A_{1}$ and $A_{2 A}$ receptors; $A C$ : adenylate cyclase; cAMP: cyclic adenosine monophosphate; PKA: protein kinase $A$.

Thus, from the available pre-clinical studies that have investigated the interaction between caffeine and ethanol in rodents, it emerges that it has effects on locomotor activation, learning and memory in different experimental paradigms, as well as in 
ethanol self-administration paradigm (López-Cruz et al. 2013). The literature reveals also a significant lack of data, especially as regards the combined treatment of the two substances in the associative model of ethanol-elicited CPP. Specifically, a work investigated the effect of co-administration of caffeine $(3 \mathrm{mg} / \mathrm{kg})$ and ethanol $(1.75$ $\mathrm{g} / \mathrm{kg}$ ) in C57BL/6J male mice subjected to the CPP paradigm. The results have showed that both ethanol and caffeine administered individually increase the time spent in the compartment paired with the drug, although the effect of caffeine was significantly more modest than that of ethanol. This study also revealed that the combination of the two drugs results in a significant place preference, even if more modest than that determined by ethanol alone (Hilbert et al. 2013). Both the motivational properties of ethanol highlighted through the experimental model of place conditioning and the acute effects, not associated with conditioned stimuli, have also been correlated to the expression of pERK but, also in this case, the combined acute effects of the two drugs have not been extensively investigated.

\section{IS CAFFEINE AN ADDICTIVE DRUG?}

The dopaminergic theory of addiction predicts that all drugs of abuse, although with different molecular mechanisms, are able to directly activate the dopamine transmission in the mesolimbic system (Pontieri et al. 1995; Berridge \& Robinson 1998). It has been demonstrate that caffeine causes an increase of extracellular dopamine (Acquas et al. 2002) and enhances the number of positive pERK neurons in the superficial and deep layers of the prefrontal cortex, but not in the Acb of rats (Valjent et al., 2004; Acquas et al. 2010) as well as in the other regions of extended amygdala of mice (Valjent et al. 2004). Furthermore, the phosphorylation of ERK in prefrontal cortex seems to depend on $D_{1}$ receptors, in fact their blockade prevents the activation of caffeine-induced pERK expression. In this way $D_{1}$ receptors appear to modulate caffeine-mediated activation of pERK and it has been hypothesized that these mechanisms are at the basis of the behavioral consequences of caffeine in the cognitive and memory processes (Acquas et al. 2010). These effects could be linked to the psychostimulant properties of the substance, but it is not yet clear if this is the cause or effect of these properties, raising a still controversial topic about the behavioral and pharmacological properties of caffeine and whether it can be 
considered a substance of abuse, despite its psychostimulant effects (Acquas et al. 2002, 2010). Indeed, caffeine has both positive effects that drive humans to its continuous intake, but also negative ones. However, the withdrawal symptoms it determines are limited and not particularly severe, such as headache and lethargy (Satel 2006).

Furthermore, while the reinforcing properties of ethanol have been widely highlighted in studies of CPP and CPA (Cunningham \& Henderson 2000; Cunningham et al. 2002, 2003; Font et al. 2006) and self-administration (Peana et al. 2014; Faccidomo et al. 2015; Lorrai et al. 2019) in rodents, likewise this does not occur with regard to caffeine. In fact, the studies reporting on caffeine-elicited CPP are inconclusive for different doses and experimental schedules (Steigerwald et al. 1988; Brockwell et al. 1991; Brent Bedingfield et al. 1998; Patkina \& Zvartau 1998). Furthermore, it has been observed that caffeine, in rats, is able to elicit CPP at the dose of $3 \mathrm{mg} / \mathrm{kg}$ (Patkina \& Zvartau 1998) and CPA at the dose of $30 \mathrm{mg} / \mathrm{kg}$ (Brockwell et al. 1991). These results suggest that low doses have probably a weak and inconsistent gratifying effect, while high doses produce aversion to associated environmental stimuli (Patkina \& Zvartau 1998). These data support the biphasic effects expressed by caffeine in both humans and animals. At low doses it determines a stimulation of the central nervous system with positive and desirable effects: increase in concentration, alertness and a state of well-being, while at high doses it determines negative consequences, such as tension, nervousness, anxiety, restlessness, palpitations, sweating and depressive effects (Daly \& Fredholm 1998). Notably, studies investigating the effects of co-administration of the two substances are even less, describing that caffeine, administered either alone $(3.0 \mathrm{mg} / \mathrm{kg}$ ) (Brockwell et al. 1991) or in the same injection with ethanol $(1.75 \mathrm{~g} / \mathrm{kg}$ of ethanol and $3.0 \mathrm{mg} / \mathrm{kg}$ of caffeine) induced a significant CPP, but the effect of caffeine was more modest than that of ethanol itself (Hilbert et al. 2013).

However, as a consequence of the interaction on the adenosinergic and dopaminergic system, caffeine could amplify and act synergistically enhancing the effects of other more powerful drugs, such as psychostimulants as cocaine and amphetamine (Gasior et al. 2000). It has been investigated that administration of caffeine enhanced intravenous cocaine self-administration in rats (Horger et al. 1991; Schenk et al. 1994) 
and reinstatement of cocaine self-administration (Schenk \& Partridge 1999), whereas the self-administration of caffeine alone did not show consistent results (Briscoe et al. 1998). It has been recently demonstrated that caffeine increased the motivation to obtain non-drug rewards, such as saccharin, in a dose-dependent manner. In fact, intravenous caffeine (at moderate doses of $0.5-1 \mathrm{mg} / \mathrm{kg} /$ infusion) when combined with oral saccharin significantly increased the operant responding to it at, whereas oral caffeine increased responding at all doses tested $(2.5,3.5,5,7.5 \mathrm{mg} / \mathrm{ml})$ when it was combined with saccharin. In contrast, oral caffeine administration without saccharin did not increase responding at any dose (Bradley \& Palmatier 2019).

Taken together it appears that the results made available so far from animal studies are not conclusive to define caffeine as a drug of abuse although it produces behavioral and physiological effects similar to other addictive substances. Furthermore, neither the DSM-4 nor the DSM-5, the Diagnostic and Statistical Manual of Mental Disorders, officially recognizes caffeine as a drug that elicits typical addiction symptoms and an addictive-like disorder similar to that elicited by other substances of abuse, although the DSM-5 recognizes the "Caffeine Use Disorder" as a condition that deserves further investigation (Meredith et al. 2013). 
Aims 



\section{AIMS}

The general aim of the present doctoral thesis was to investigate the involvement and significance of the ERK pathway in the psychopharmacological effects of ethanol, caffeine and of their interaction in terms of behavioral and biochemical responses. The motivational properties of ethanol have long been studied in validated experimental models, among which the place conditioning paradigm can be considered a valid investigation tool to model the conditions of acquiring and recalling of drug-associated affective memories. Thus, the same drug is able to elicit and transfer both positive and negative motivational properties to the environment during the conditioning process, which can be highlighted in the behavioral model of CPP and CPA, respectively. Furthermore, while the growing trend of mixing caffeine, often contained in caffeinated beverages, with ethanol is increasingly common, the knowledge of the pharmacological bases of this interaction and the related mechanisms are still unknown. The experimental approach taken to challenge this research question is translated in the structure of the present thesis that sees the experimental part divided into the following three chapters:

Chapter 1: describes the involvement of MEK/ERK protein kinases cascade in the acquisition and expression of CPP and CPA induced by a single dose of ethanol and the effects of the blockade of the kinases downstream ERKs, MEK, by the use of the MEK inhibitor SL327 in both experimental phases of place conditioning. Moreover, following the acute treatment with SL327, chapter 1 describes the results and discusses the experiments aimed at investigating the biochemical results of ethanol-elicited phosphorylated ERK expression in different regions constituting the mesolimbic system.

Chapter 2: explores the interaction of ethanol and caffeine in the acquisition of ethanol-induced place conditioning and, in particular, the effects of caffeine pretreatment on the validated motivational properties of ethanol expressed in CPP and CPA paradigms. Furthermore, it investigates whether caffeine may prevent the ethanol-elicited pERK in different brain regions. Chapter 2 also discusses the results of the experiments aimed at verifying if the stimuli (positive and negative) conditioned to 
ethanol and the drugs combination are related to a differential pERK expression in all brain areas examined.

Chapter 3: evaluates the effects of different doses of ethanol and caffeine administration and their interaction on psychomotor performance measured as horizontal and vertical locomotion in the open field apparatus. Chapter 3 also describes the results of caffeine on mice previously sensitized with ethanol, to investigate if there may be cross sensitization effect. Finally, it discusses the results of the expression of two biochemical markers of neural activation, pERK and PDARPP32(Thr75), in the nucleus accumbens of mice acutely treated with both substances. 


\section{Experimental Studies Chapter 1}





\section{CHAPTER 1: Differential effects of the MEK inhibitor SL327 on the acquisition and expression of ethanol-elicited conditioned place preference and aversion in mice}

\section{ABSTRACT}

The involvement of mitogen-activating extracellular kinase (MEK) in place conditioning may vary depending on the motivational sign (positive or negative) and nature (pharmacological or nociceptive) of the unconditioned stimulus (US) and on the phase (acquisition or expression) of the learning process. This study investigated the role of MEK on the acquisition and expression of ethanol-elicited (given $2 \mathrm{~g} / \mathrm{kg}$ ) backward (preference, CPP) and forward (aversion, CPA) place conditioning. The MEK inhibitor SL327 (50 mg/kg for CPP, and 50 and $100 \mathrm{mg} / \mathrm{kg}$ for CPA) was administered to CD-1 mice $60 \mathrm{~min}$ before an ethanol dose (acquisition) or $60 \mathrm{~min}$ before the postconditioning tests (expression). Ethanol significantly elicited CPP and CPA; SL327 (50 $\mathrm{mg} / \mathrm{kg}$ ) significantly blocked the acquisition of ethanol-elicited CPP, but not that of CPA. Moreover, SL327 (50 and $100 \mathrm{mg} / \mathrm{kg}$ ) significantly reduced the expression of ethanol-elicited CPP, but not that of CPA. Finally, SL327 also prevented ethanol-elicited (given $2 \mathrm{~g} / \mathrm{kg}$ ) increases of phosphorylated extracellular signal regulated kinase (pERK)positive neurons in the nucleus accumbens and other nuclei of the extended amygdala. Overall, these results confirmed the differential involvement of MEK in the acquisition and expression of drug-elicited place conditioning and suggested its differential involvement in distinct behavioral outcomes, depending on the motivational sign of the (same) US and on the significance of the experimental phase of the learning process. 


\section{INTRODUCTION}

The place conditioning is an experimental model widely used to characterize the motivational properties of drugs (both positive and negative) and the role of neural substrates underlying this process. The result of a conditioning paradigm of associative learning leads to the establishment of memories, and more specifically, the CPP aroused by the drug is based on the establishment of positive memories and as such represents a valid experimental model for studying the drug-seeking behavior (Tzschentke 2007). Conversely, the elicited-CPA determines the onset of negative memories and is a model to study negative reinforcement, since the resulting behavior is aimed to prevent adverse experiences previously conditioned to drug-associated stimuli (Tzschentke 2007). In addition, acquiring and recalling of drug-associated memories can be modeled by different phases of place conditioning, the acquisition and the expression, respectively. Interestingly, the ERK pathway represents one of the most investigated molecular mechanisms that have been related to place conditioning. Several previous studies have demonstrated that these kinases cascade is involved in different learning paradigm, such as conditioned taste aversion (Marotta et al. 2014), conditioning fear (Atkins et al. 1998; Villarreal \& Barea-Rodriguez 2006), spatial learning (Blum et al. 1999; Selcher et al. 1999), recognition memory (Kelly et al. 2003), appetitive-reward seeking behavior (Kirschmann et al. 2014) and drug-elicited place conditioning (Valjent et al. 2000; Gerdjikov et al. 2004; Girault et al. 2007; Spina et al. 2010; Longoni et al. 2011; Rosas et al. 2018). Moreover, phosphorylated ERK (pERK) are widely expressed in the mesolimbic circuit areas, such as Acb and nuclei of extended amygdala (bed nucleus of stria terminalis and central and basolateral nuclei of the amygdala) (Valjent et al. 2004; Ibba et al. 2009; Vinci et al. 2010). Furthermore, the involvement of MEK, the kinases that are upstream of ERK, in the acquisition of drug-elicited CPP has been demonstrated with several drugs of abuse, such as $d$ amphetamine (Gerdjikov et al. 2004), ecstasy (Salzmann et al. 2003), morphine (Mazzucchelli et al. 2002; Spina et al. 2010) and cocaine (Valjent et al. 2000) but in the case of ethanol, their involvement is not satisfactorily clear (Groblewski et al. 2011). Additionally, in contrast to the evidence supporting the role of the MEK on the 
acquisition of CPP, their contribution in the expression of drug-elicited CPP and CPA awaits further clarifications.

There are evidences regarding the involvement of MEK in the acquisition of cocaineelicited CPP (Valjent et al. 2000; Miller \& Marshall 2005), but not to its expression (Miller \& Marshall 2005). Similarly, in the CPA paradigm, it has been confirmed that the reversible MEK inhibitor, SL327 (Selcher et al. 1999), is able to prevent the acquisition of lithium-elicited CPA (Longoni et al. 2011) but not the expression of acquired (conditioned) response. However, the literature described that blockade of MEK in the anterior cingulate cortex prevents both phases of CPA procedure induced by intraplantar formalin but not by foot shock nor by the $\mathrm{K}$ opioid agonist, U69,593 (Cao et al. 2009). Taken together these results suggest that the involvement of MEK in aversive memories could depend on the force and nature (nociceptive vs pharmacological) of the unconditioned stimulus (US) as well as on the brain regions involved. Furthermore, these different results are also probably due to different neurobiological mechanisms at the basis of the behaviors modeled by these different phases of place conditioning and may have a common but also distinct and unique mechanisms with respect to MEK involvement (Sanchis-segura \& Spanagel 2006; Shiflett \& Balleine 2011).

To avoid these possible discrepancies, in the present study we decided to characterize the role of MEK/ERK cascade in the place conditioning paradigm using an identical US, the effect of a pharmacologically active, non intoxicating, dose of ethanol, that under appropriate experimental conditions is able to elicit either CPP and CPA (Cunningham et al. 1997). Indeed, in the experiments of Cunningham and Co-workers (1997) it has been established that ethanol, after its intraperitoneal administration, may initially exert an aversive reaction succeeded shortly after by pleasant feelings. As a consequence, depending on the experimental schedule followed during conditioning, the association of the US to the paired compartment (conditioned stimulus, CS) results in CPP if the CS follows the US (backward conditioning) or results in CPA if the CS anticipates the US (forward conditioning) (Cunningham et al. 1997). Therefore, to characterize the role of this kinase cascade in the acquisition and expression of the CS, elicited by the identical US, ethanol, we will establish first whether in our experimental conditions the administration of the MEK inhibitor SL327 can affect the acquisition and 
expression of ethanol-elicited (given $2 \mathrm{~g} / \mathrm{kg}$ ) backward (preference, CPP) and forward (aversion, CPA) place conditioning. The MEK inhibitor SL327 (50 mg/kg for CPP, and 50 and $100 \mathrm{mg} / \mathrm{kg}$ for CPA) will be administered to CD-1 mice 60 min before an ethanol dose (acquisition) or $60 \mathrm{~min}$ before the post-conditioning tests (expression). Finally, we will assess if SL327 pre-treatment also prevented ethanol-elicited pERK-positive neurons in the nucleus accumbens and other nuclei of the extended amygdala. 


\section{MATERIALS AND METHODS}

\section{Animals}

Male CD-1 mice (22-24 g, Envigo, Udine, Italy) were housed in groups of four per cage for at least 6 days before use and maintained on a 12:00/12:00 $\mathrm{h}$ light/dark cycle (lights on at 08:00 h) with food and water freely available. All the experiments were carried out during the light phase, between 09:00 and 16:00 h. The total numbers of mice were $n=42$ and $n=50$ in the CPP and CPA acquisition experiments, respectively, and $n=46$ and $n=40$ in the CPP and CPA expression experiments, respectively. The total numbers of mice used in the immunohistochemical experiments were: $n=9$ for the group vehicle/saline, $n=7$ for the group SL327/saline, $n=8$ for the group vehicle/ethanol and $n=8$ for the group SL327/ethanol. All the experimental procedures were performed in accordance with the Principles of laboratory animal care and with the guidelines and protocols approved by the European Union (2010/63/UE L 276 20/10/2010). Every possible effort was made to minimize animal pain and discomfort and to reduce the number of experimental subjects.

\section{Drugs}

Ethanol (Sigma-Aldrich, Milan, Italy) 20\% (v/v) in isotonic saline, was administered at the dose of $2 \mathrm{~g} / \mathrm{kg}$ (12 mL/kg volume injection). The reversible MEK inhibitor, SL327 (Ascent Scientific Ltd, Bristol, UK), was dissolved at 50 and $100 \mathrm{mg} / \mathrm{kg}$ in a vehicle made as follows: dimethyl sulfoxide (DMSO) (Sigma-Aldrich, Milan, Italy), cremophor (Sigma Aldrich, Milan, Italy) and isotonic saline 30/30/40\% (v/v) (injection volume: $20 \mathrm{~mL} / \mathrm{kg}$ ). The dose of $50 \mathrm{mg} / \mathrm{kg}$ of SL327 was selected in agreement with previous studies (Selcher et al. 1999; Valjent et al. 2000, 2006; Salzmann et al. 2003; Longoni et al. 2011) 2006), whereas the dose of $100 \mathrm{mg} / \mathrm{kg}$ was selected after Longoni et al. (2011). Sodium pentobarbital (Carlo Sessa Spa, Sesto San Giovanni, Milan, Italy) (50 mg/kg) was dissolved in isotonic saline. All drugs and vehicle were administered intraperitoneally (IP).

\section{Apparatus}

The apparatus consisted of two rectangular Plexiglas boxes $(48 \mathrm{~L} \times 20 \mathrm{~W} \times 30 \mathrm{H} \mathrm{cm})$ separated by a guillotine door. The apparatus was placed in a sound-proof room with a 
constant light of 37.5 Lux (ELD 9010 Luxmeter, Eldes Instruments, Italy) provided by a 40W lamp placed above each compartment. Different visual and tactile cues distinguished the two compartments: vertically striped black and white walls and white smooth floor for one compartment (A) and horizontally striped black and gray walls and fine grid floor for the other compartment (B). The spontaneous preference was randomly distributed between compartments (49.2 \% A and 50.8\% B) and average

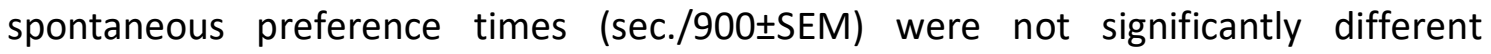
between compartments (Paired t-test: $t=1.68, p=0.093, d f=354$, number of pairs $=178$; with average total session times being $443 \pm 5.89 \mathrm{sec} . / 900$ and $457 \pm 5.89 \mathrm{sec} . / 900$ respectively). However, in spite of such unbiased apparatus, the experimental groups for CPP experiments were made by grouping mice whose spontaneous preferences were, no matter the compartment, A or B, closer to 400 sec. Similarly (but opposite), the experimental groups for CPA experiments were made by grouping mice whose spontaneous preferences were, no matter the compartment, closer to $500 \mathrm{sec}$.

\section{Acquisition of Conditioned Place Preference and Conditioned Place Aversion}

Each experiment consisted of three phases. During the first phase (day 1), the guillotine door was kept raised and each mouse was placed randomly in one or the other compartment and given access to both compartments of the apparatus for 15 min (900 sec.). The time spent in one compartment was recorded and taken as an indication of spontaneous preference. Behavioral schedules for backward and forward conditioning (figure 1) were designed after Cunningham et al. (1997). In particular, during the second phase (days 2-5) of CPP experiments, mice of distinct experimental groups, were administered SL327 (50 mg/kg) or vehicle, $60 \mathrm{~min}$ before ethanol $(2 \mathrm{~g} / \mathrm{kg}$ ) or saline, and were returned to their home cage. Ten minutes after ethanol administration mice were exposed for $5 \mathrm{~min}$ to a given compartment and returned to their home cage. Four hours later, mice were administered vehicle (SL327, $0 \mathrm{mg} / \mathrm{kg}$ ) or SL327 $(50 \mathrm{mg} / \mathrm{kg})$, then returned to their home cage $60 \mathrm{~min}$ before the second administration (ethanol, 0 or $2 \mathrm{~g} / \mathrm{kg}$ ). Ten min after this second administration mice were placed in the compartment opposite to that of the morning exposure. During the second phase (conditioning days 2-5) of CPA experiments, mice of distinct experimental groups, were administered SL327 (50 and $100 \mathrm{mg} / \mathrm{kg}$ ) or vehicle, and 
returned to their home cage for $60 \mathrm{~min}$. At the end of this period mice were exposed for $5 \mathrm{~min}$ to the given compartment. Upon removal from the compartment (i.e. before being returned to their home cage) mice were administered the second injection (ethanol, $2 \mathrm{~g} / \mathrm{kg}$ ) or vehicle. Four hours later, mice were administered vehicle (SL327, 0 $\mathrm{mg} / \mathrm{kg}$ ) or SL327 (50 mg/kg), $60 \mathrm{~min}$ before the $5 \mathrm{~min}$ exposure to the opposite compartment. Upon removal from the apparatus, i.e. before being returned to their home cage, mice were administered the second injection (ethanol 0 or $2 \mathrm{~g} / \mathrm{kg}$ ). During conditioning days for both CPP and CPA the order of vehicle and ethanol administration was counterbalanced [i.e. the order of the combined pretreatment/treatment [SL327 $(50-100$ or $0 \quad \mathrm{mg} / \mathrm{kg}) /$ ethanol $(0$ or $2 \mathrm{~g} / \mathrm{kg})$ ] administrations was opposite on even days with respect to that one on odd days]; similarly, the number of mice receiving saline and ethanol was counterbalanced over the four days of conditioning. The same counterbalanced design was also applied to the assignment of mice to compartments $A$ and $B$. As a result of these conditioning schedules, saline (ethanol, $0 \mathrm{~g} / \mathrm{kg}$ ) and ethanol $(2 \mathrm{~g} / \mathrm{kg}$ ) were paired four times with the given compartment. The four hours interval between conditioning sessions was chosen in order to avoid carryover effects of both SL327, whose ability to prevent MAPK activation is most effective between $30 \mathrm{~min}$ and 2 hours (Selcher et al. 1999), and ethanol. During the third phase of both CPP and CPA experiments (post-conditioning test), $24 \mathrm{~h}$ after the last conditioning treatment, the guillotine door was kept raised and the time spent by each mouse in the drug-paired (backward conditioning, CPP) and in the drug-assigned (forward conditioning, CPA) compartment during 15 min was recorded. The conditions of the post-conditioning test were identical to those of the pre-conditioning test. Pre- and post-conditioning recordings were done with stop watch by observers blind to pharmacological treatments. Hence, a statistically significant difference between the time spent during pre- and post-conditioning tests of the drug group with respect to that of the saline group was taken as indication of the development of place conditioning. 
A

\section{Conditioned Place Preference (CPP)}

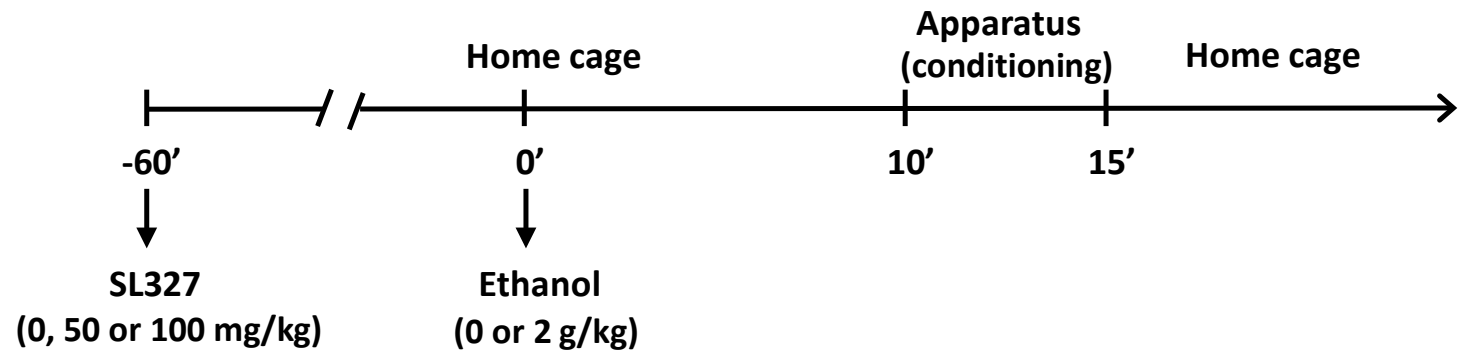

B

\section{Conditioned Place Aversion (CPA)}

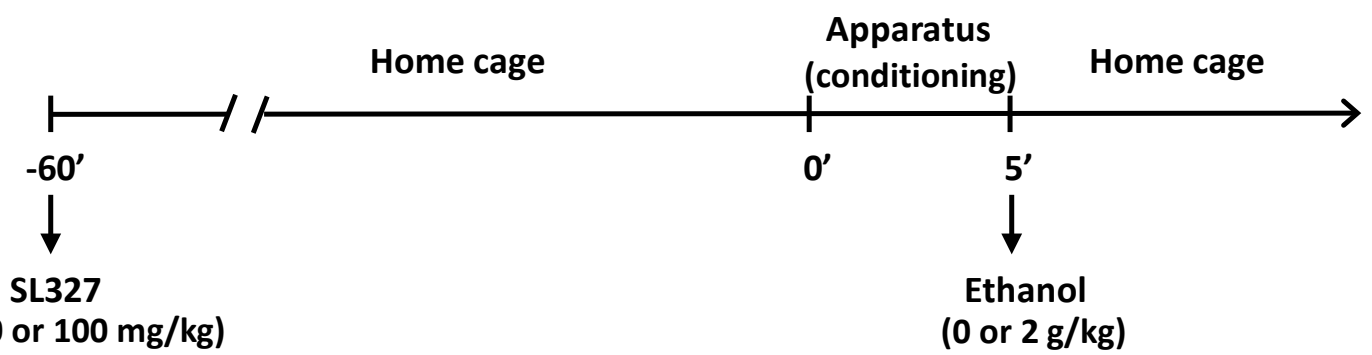

Figure 1. CPP and CPA conditioning procedures. Diagrammatic representation of the place conditioning procedures used in the CPP (A) and CPA (B) experiments. (A) Mice were administered vehicle (SL327 0 $\mathrm{mg} / \mathrm{kg}$ ) or $S L 327$ (50 and $100 \mathrm{mg} / \mathrm{kg}) 60 \mathrm{~min}$ before administration of saline or EtOH $(2 \mathrm{~g} / \mathrm{kg})$ and were returned to their home cage. After $10 \mathrm{~min}$ of saline or EtOH administration, mice were exposed for $5 \mathrm{~min}$ to the given compartment of the conditioning apparatus and returned to their home cage. (B) Mice were administered vehicle (SL327 $0 \mathrm{mg} / \mathrm{kg}$ ) or SL327 (50 and $100 \mathrm{mg} / \mathrm{kg}$ ) and returned to their home cage for $60 \mathrm{~min}$. At the end of this period, each mouse was exposed for $5 \mathrm{~min}$ to the given compartment of the conditioning apparatus. Upon removal from the apparatus, i.e. before being returned to their home cage, mice were administered saline $(\mathrm{Og} / \mathrm{kg} \mathrm{EtOH})$ or EtOH $(2 \mathrm{~g} / \mathrm{kg} \mathrm{EtOH})$.

\section{Expression of Conditioned Place Preference and Conditioned Place Aversion}

In the expression experiments, in agreement with Cunningham et al. (1997), $60 \mathrm{~min}$ before the beginning of the post-conditioning test, distinct groups of ethanolconditioned mice were administered SL327 (0, 50 and $100 \mathrm{mg} / \mathrm{kg})$. Testing for CPP or CPA expression was done on the first day following conditioning in the time frame corresponding to the interval between "morning" and "afternoon" conditioning sessions of days 2-5. The difference between the time spent in the drug-paired (CPP) and drug-assigned (CPA) compartments during the post-conditioning test and that 
spent during the pre-conditioning test (side preference shift) was taken as a measure of the degree of place conditioning induced by the drug (Carr et al. 1989). Hence, a statistically significant difference between the time spent during pre- and postconditioning tests of the drug group with respect to that of the saline group indicates the development of place conditioning.

\section{Immunohistochemistry}

For these experiments mice of distinct experimental groups were anesthetized with sodium pentobarbital (Valjent et al. 2001) 15 min after the administration of saline or ethanol (Ibba et al. 2009). Doses and timing of pre-treatment and treatment administrations exactly reproduced those followed on day 2 (first conditioning day) of the behavioral experiments. Following pretreatment administrations, mice were placed back in their home cages with their cage-mates. Under deep anesthesia, animals were subjected to trans-cardiac perfusion with ice-cold Phosphate Buffered Saline (PBS): $137 \mathrm{mM} \mathrm{NaCl}, 2.7 \mathrm{mM} \mathrm{KCl}, 10 \mathrm{mM} \mathrm{Na2HPO4,} 2 \mathrm{mM} \mathrm{KH2PO4,} \mathrm{and} \mathrm{4 \%}$ paraformaldehyde (PFA). After perfusion, brains were removed and post-fixed overnight in 4\% PFA. Brain slices $(40 \mu \mathrm{m})$ of the regions of interest were cut, on icecold PBS with a vibratome (Leica VT1000, Leica, Germany) according to the mouse brain atlas (Paxinos \& Franklin 2001). Slices were kept in ice-cold PBS and processed for immunohistochemistry according to a protocol for free-floating slices. Immunoreactions for PERK-positive cells detection were applied to at least two every other slices obtained from each brain. After incubation for $30 \mathrm{~min}$ in $1 \% \mathrm{H}_{2} \mathrm{O}_{2}$, slices were incubated for 1 hour with 3\% BSA. The incubation with the primary anti pERK antibody (phosphorylated ERK, Cell Signalling Technology, Beverly, MA, USA (1:350)) was conducted overnight. On the following day, after rinsing, slices were incubated for 1 hour with the biotinylated secondary antibody (1:800). After three rinses the slices were incubated in avidin biotin peroxidase complex prepared according to the manufacturer's suggestions (Vectastain ABC kit, Vector Laboratories, Burlingame, CA, USA) and a 3-3'-diaminobenzidine solution (10 mg/mL) was added until development of brown staining. Slices were rinsed and mounted onto gelatine-coated slides and processed through alcohol-xylene for light microscopy examination. pERK-positive neurons were identified in the regions of interest of both hemispheres at the lowest 
magnification (10X) and quantitative analysis was performed using a Zeiss Axioskop 40 light microscope, equipped with PL Fluotar 10X (na=0.3), 40X (na=1.00-0.5) and 100X oil (na=1.3) objectives, coupled with a digital camera (Nikon D5000, Melville, NY, USA). Images of the regions of interest were obtained at the lowest magnification (10X) from at least two every other $40 \mu \mathrm{m}$ thick slices, according to the atlas Paxinos and Franklin (2001), and used to automatically count the number of pERK-positive neurons/area (pERK expression) by application of the software ImageJ (v. 1.42, National Institutes of Health sponsored image analysis program) in conjunction with automated background to avoid experimenter bias, and entropy threshold plug-in. pERK-positive neurons/area were counted in the regions of interest whose borders in the slices were depicted/recognized according to plates 15-17 (approximately from AP 1.94 to AP 1.70 $\mathrm{mm}$ from bregma for the prefrontal cortex), to plates 21-23 (approximately from AP 1.18 to AP $0.98 \mathrm{~mm}$ from bregma for the nucleus accumbens), to plates $31-32$ (approximately from AP 0.02 to AP $-0.1 \mathrm{~mm}$ from bregma for the bed nucleus of stria terminalis) and to plates $36-38$ (approximately from AP -0.58 to AP $-0.82 \mathrm{~mm}$ from bregma for the central nucleus of the amygdala) of the Paxinos and Franklin (2001) brain atlas. These brain regions were selected for their involvement in learning and motivation and their relationship with pERK in these processes (Valjent et al. 2004; Ibba et al. 2009; Marotta et al. 2014). The reported numbers for each brain region (table 1 and figure 6 ) are the average \pm SEM of average counts/slice from each animal.

\section{Statistical analysis}

To determine statistically significant differences between pre-conditioning values of the experimental groups depicted in figures 2-5, one-way Analysis of Variance (ANOVA) was applied (Statistica, v. 8.0, StatSoft Inc., Tulsa (OK), USA). To determine the effect of pre-treatment (2 levels: SL327 0 or 50 (or 100) $\mathrm{mg} / \mathrm{kg}$ ) on conditioning and those of treatment ( 2 levels: EtOH 0 or $2 \mathrm{~g} / \mathrm{kg}$ ) on acquisition of ethanol-elicited CPP or CPA, data were analyzed by three-way ANOVAs with pre-treatment and treatment as independent factors (between subjects) and with pre-conditioning and post-conditioning values as a within-subjects factor (repeated measures). Two-way ANOVA, with pre-treatment as an independent factor (between subjects) and preconditioning and post-conditioning values as within subjects factors (repeated 
measures), was also applied to assess the statistical significance of data from the expression experiments. All statistical analyses were carried out using data from the experimental groups depicted in each figure. Post hoc analyses (with multiple comparisons), carried out using Newman-Keuls tests, were undertaken if significant effects were found $(p<0.05)$.

pERK-positive neurons/area following each treatment were expressed as the average number of pERK-positive neurons/area of each experimental group and indicated as pERK-positive neurons/area ( $p$ ERK expression). These values were used as dependent variables for statistical analyses by one-, two- and three-way ANOVAs with pERKpositive neurons/area as dependent variables and with the factors brain area (2 levels: shell and core), pre-treatment (2 levels: vehicle or SL327) and treatment (2 levels: $\mathrm{EtOH} 0$ or $2 \mathrm{~g} / \mathrm{kg}$ ) used as independent variables. Newman-Keuls post-hoc analyses, whereby allowed by ANOVAs significant main effects, were applied for multiple comparisons, with the statistical significance set at $p<0.05$.

\section{RESULTS}

Effects of SL327 on acquisition of ethanol-elicited CPP and ethanol-elicited CPA

Figure 2 shows the effects of pre-treatment with SL327 (0 or $50 \mathrm{mg} / \mathrm{kg}$ ), $60 \mathrm{~min}$ before the administration of ethanol ( 0 and $2 \mathrm{~g} / \mathrm{kg}$ ) and $10 \mathrm{~min}$ before exposure to the assigned compartment for $5 \mathrm{~min}$ (see figure 1A). Pre-conditioning preference times did not significantly differ between experimental groups $\left[F_{3,38}=1.52\right.$, NS]. Repeated measures, three-way ANOVA revealed significant effects of pre-treatment $\left[F_{1,38}=9.52\right.$, $p<0.05]$, time $\left[F_{1,38}=22.28, p<0.001\right]$ and treatment $\left[F_{1,38}=8.23, p<0.05\right]$, and significant pre-treatment by time $\left[F_{1,38}=11.46, p<0.001\right]$, treatment by time $\left[F_{1,38}=7.849, p<0.05\right]$ and pre-treatment by treatment by time $\left[\mathrm{F}_{1,38}=8.76, \mathrm{p}<0.05\right]$ interactions. NewmanKeuls' post hoc analysis revealed a significant difference in the time spent in drugpaired compartment in post-conditioning between the group SL327 $(0 \mathrm{mg} / \mathrm{kg}) /$ ethanol $(0 \mathrm{~g} / \mathrm{kg})$ and the group SL327 (0 mg/kg)/ethanol $(2 \mathrm{~g} / \mathrm{kg})(\mathrm{p}<0.05)$. 


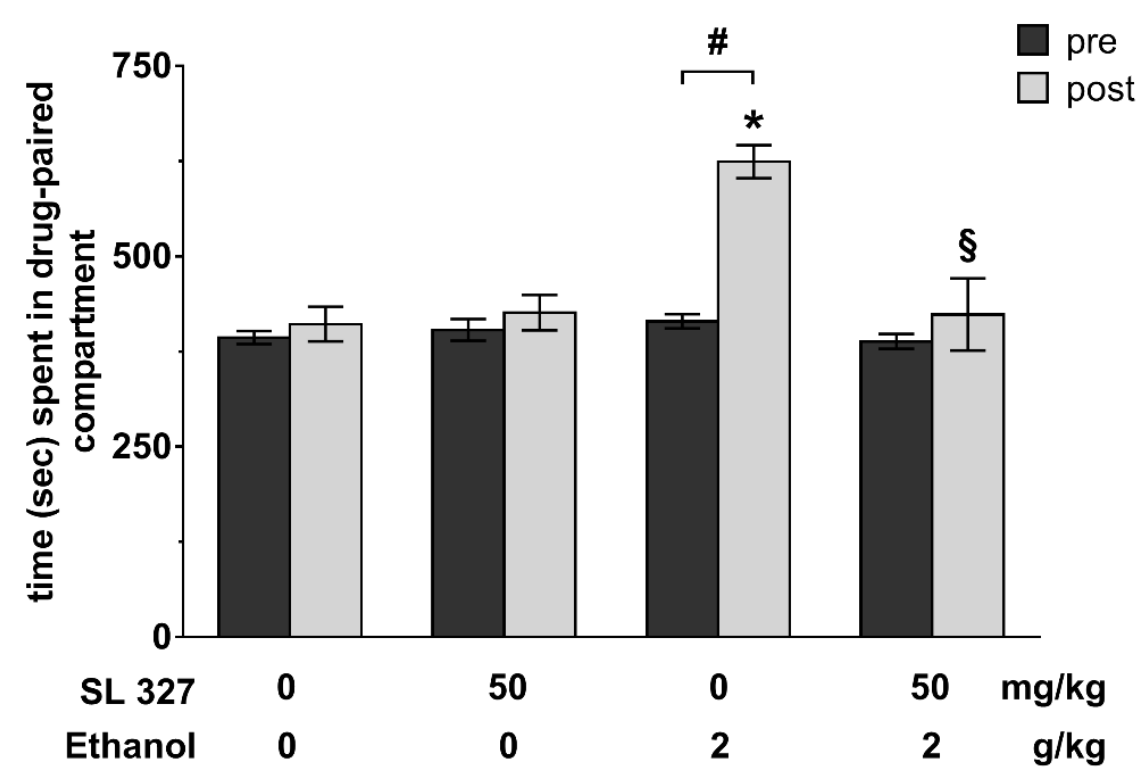

Figure 2. Effects of SL327 pre-treatment on acquisition of ethanol-elicited CPP. Data are shown as average time spent (sec.) $\pm S E M$ in the drug-paired compartment. Pre-conditioning preference times were $393 \pm 8$ for SL327 (0 mg/kg) + ethanol $(0 \mathrm{~g} / \mathrm{kg})(\mathrm{n=12}), 403 \pm 14$ for SL327 (50 mg/kg) + ethanol (0 $\mathrm{g} / \mathrm{kg})(\mathrm{n}=7), 414 \pm 9$ for SL327 (0 mg/kg) + ethanol $(2 \mathrm{~g} / \mathrm{kg})(\mathrm{n=13})$ and $388 \pm 9$ for SL327 $(50 \mathrm{mg} / \mathrm{kg})+$ ethanol $(2 \mathrm{~g} / \mathrm{kg})(n=10)$ groups. *Indicates a significant difference $(p<0.05)$ of time spent during postconditioning test as compared to $S L 327(0 \mathrm{mg} / \mathrm{kg})+$ ethanol $(0 \mathrm{~g} / \mathrm{kg})$ group; Sindicates a significant difference $(p<0.05)$ of time spent during post-conditioning test as compared to $S L 327(0 \mathrm{mg} / \mathrm{kg})+$ ethanol $(2 \mathrm{~g} / \mathrm{kg}$ ) group; \#indicates a significant difference $(p<0.05)$ between pre-and post-conditioning.

Figure 3 shows the effects of pre-treatment with $\operatorname{SL327}(0,50$ and $100 \mathrm{mg} / \mathrm{kg}), 60 \mathrm{~min}$ before the exposure to the assigned compartment for $5 \mathrm{~min}$, and of ethanol $(0$ and 2 $\mathrm{g} / \mathrm{kg}$ ) administration upon removal from the place conditioning apparatus (see figure 1B). Pre-conditioning preference times did not significantly differ between experimental groups $\left[\mathrm{F}_{5,44}=0.99, \mathrm{NS}\right]$. Repeated measures, three-way ANOVA revealed significant effects of pre-treatment $\left[F_{1,44}=46.44, p<0.001\right]$ and time $\left[F_{1,44}=56.66\right.$, $p<0.001]$, and significant pre-treatment by time $\left[F_{1,44}=63.53, p<0.001\right]$ and treatment by time $\left[F_{2,44}=3.99, p<0.05\right]$ interactions. Newman-Keuls' post hoc analysis revealed a significant difference in the time spent in drug-paired compartment in postconditioning between the group SL327 $(0 \mathrm{mg} / \mathrm{kg}) /$ ethanol $(0 \mathrm{~g} / \mathrm{kg})$ and the group SL327 (0 mg)/kg/ethanol (2 g/kg), that SL327 (50 and $100 \mathrm{mg} / \mathrm{kg}$ ) was devoid of motivational properties and that SL327 (50 and $100 \mathrm{mg} / \mathrm{kg}$ ) failed to prevent, but significantly $(p<0.05)$ reduced, the acquisition of ethanol-elicited CPA. 


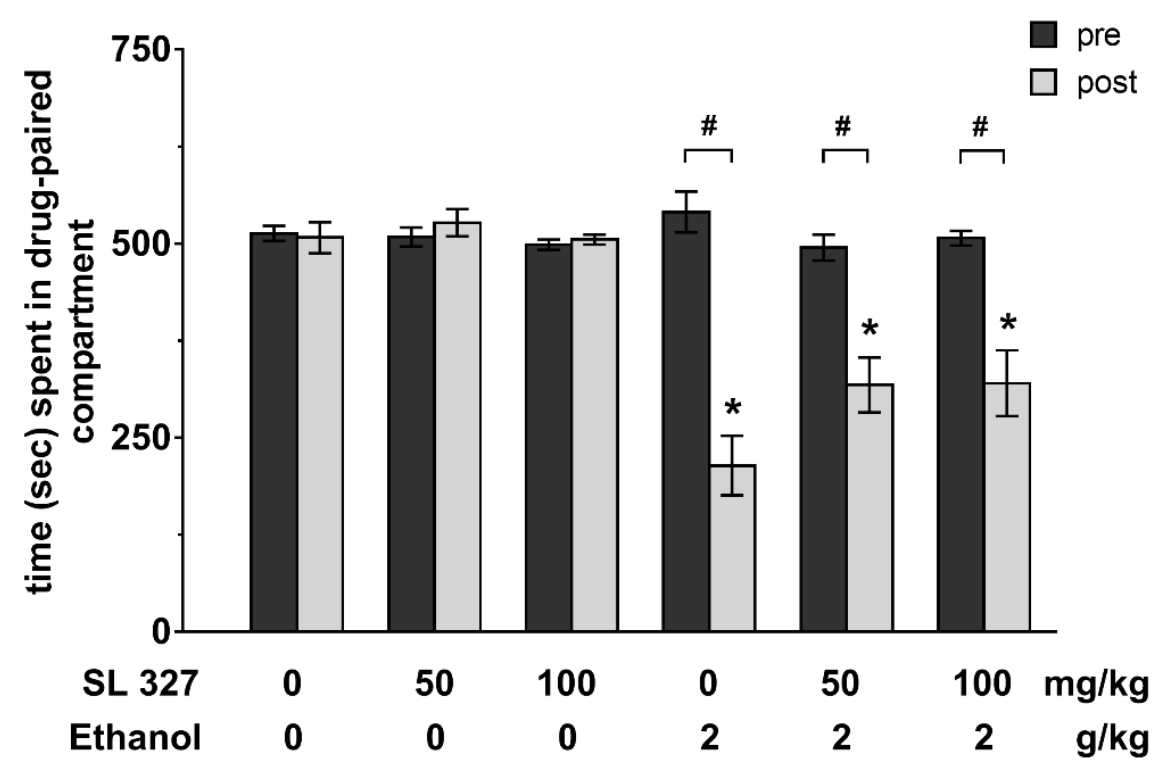

Figure 3. Effects of SL327 pre-treatment on acquisition of ethanol-elicited CPA. Data are shown as average time spent (sec.) \pm SEM in the drug-paired compartment. Pre-conditioning preference times were $513 \pm 9$ for SL327 $(0 \mathrm{mg} / \mathrm{kg})$ + ethanol $(0 \mathrm{~g} / \mathrm{kg})(\mathrm{n=10}), 508 \pm 1$ for SL327 $(50 \mathrm{mg} / \mathrm{kg})+$ ethanol (0 $\mathrm{g} / \mathrm{kg})(\mathrm{n}=7), 498 \pm 6$ for SL327 (100 mg/ $\mathrm{kg})+$ ethanol $(0 \mathrm{~g} / \mathrm{kg})(\mathrm{n}=6), 540 \pm 2$ for SL327 $(0 \mathrm{mg} / \mathrm{kg})$ + ethanol $(2 \mathrm{~g} / \mathrm{kg})(\mathrm{n=11}), 494 \pm 1$ for SL327 $(50 \mathrm{mg} / \mathrm{kg})+$ ethanol $(2 \mathrm{~g} / \mathrm{kg})(\mathrm{n=10})$ and $507 \pm 9$ for SL327 (100 mg/kg) + ethanol $(2 \mathrm{~g} / \mathrm{kg})(\mathrm{n}=6)$ groups. *Indicates a significant difference $(p<0.05)$ of time spent during postconditioning test as compared to SL $327(0 \mathrm{mg} / \mathrm{kg})$ + ethanol $(0 \mathrm{~g} / \mathrm{kg})$ group; \#indicates a significant difference $(p<0.05)$ between pre- and post-conditioning.

\section{Effects of SL327 on expression of ethanol-elicited CPP and ethanol-elicited CPA}

Figure 4 shows the effects of SL327 (0,50 and $100 \mathrm{mg} / \mathrm{kg}$ ) administered $60 \mathrm{~min}$ before the post-conditioning test of mice of three independent SL327 $(0 \mathrm{mg} / \mathrm{kg})$ + ethanol ( 2 $\mathrm{g} / \mathrm{kg}$ ) conditioned groups. Repeated measures, two-way ANOVA revealed significant effects of time $\left[F_{1,43}=56.54, p<0.001\right]$ and pre-treatment $\left[F_{2,43}=5.48, p<0.05\right]$ and $a$ significant time by pre-treatment $\left[F_{2,43}=5.13, p<0.05\right]$ interaction. Newman-Keuls' post hoc analysis revealed that ethanol elicited a significant CPP, that SL327 pre-treatment (50 and $100 \mathrm{mg} / \mathrm{kg}$ ) failed to prevent, but significantly $(\mathrm{p}<0.05)$ reduced, ethanolelicited CPP expression.

Figure 5 shows the effects of pre-treatment with $\operatorname{SL327}(0,50$ and $100 \mathrm{mg} / \mathrm{kg}$ ) administered 60 min before the post-conditioning test of mice of three independent SL327 (0 mg/kg) + ethanol ( $2 \mathrm{~g} / \mathrm{kg}$ ) conditioned groups. Repeated measures, two-way ANOVA of the effects of SL327 revealed a significant effect of time $\left[F_{1,37}=110.39\right.$, $p<0.001]$ and a significant time by pre-treatment $\left[F_{2,37}=3.45, p<0.05\right]$ interaction. 
Newman-Keuls' post hoc analysis revealed that ethanol elicited a significant CPA and that SL327 pre-treatment at the doses of 50 and $100 \mathrm{mg} / \mathrm{kg}$ failed to affect the expression of ethanol-elicited CPA.

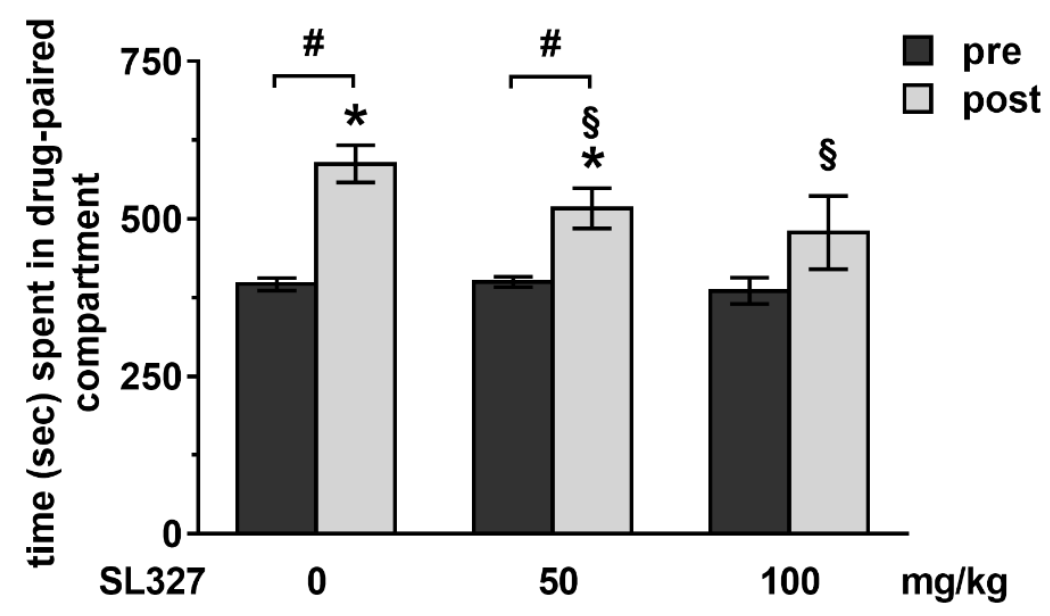

Figure 4. Effects of SL327 pre-treatment on expression of ethanol-elicited CPP. Data are shown as average time spent (sec.) \pm SEM in the drug-paired compartment. Pre-conditioning preference times were $400 \pm 8(n=18), 396 \pm 10(n=17)$ and $385 \pm 21(n=11)$ for $S L 327(0,50$ and $100 \mathrm{mg} / \mathrm{kg}$, respectively, on $S L 327(0 \mathrm{mg} / \mathrm{kg})+$ ethanol $(2 \mathrm{~g} / \mathrm{kg})$-conditioned groups). *Indicates a significant difference $(p<0.05)$ of time spent during post-conditioning test as compared to pre-conditioning test of SL327 (0 and $50 \mathrm{mg} / \mathrm{kg}$ ) + ethanol $(2 \mathrm{~g} / \mathrm{kg})$ conditioned groups; Sindicates a significant difference $(p<0.05)$ of time spent during post-conditioning test between SL327 $(0 \mathrm{mg} / \mathrm{kg}$ ) and SL327 (50 and $100 \mathrm{mg} / \mathrm{kg}$ ) groups; \#indicates a significant difference $(p<0.05)$ between pre- and post-conditioning.

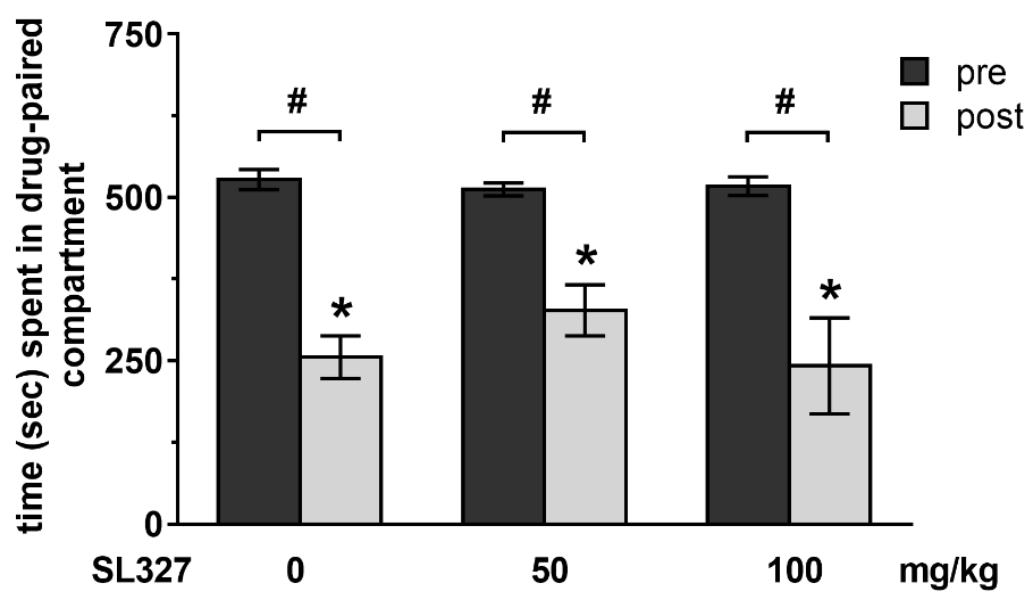

Figure 5. Effect of SL327 pre-treatment on the expression of ethanol-elicited CPA. Data are shown as average time spent (sec.) \pm SEM in the assigned compartment. Pre-conditioning preference times were $527 \pm 15(n=21) 512 \pm 10(n=11)$ and $517 \pm 14(n=8)$ for $S L 327(0,50$ and $100 \mathrm{mg} / \mathrm{kg}$, respectively, on SL327 $(0 \mathrm{mg} / \mathrm{kg})$ + ethanol $(2 \mathrm{~g} / \mathrm{kg})$ conditioned groups. *Indicates $(p<0.05)$ of time spent during postconditioning test as compared to pre-conditioning test of $S L 327(0,50$ and $100 \mathrm{mg} / \mathrm{kg})+$ ethanol $(2 \mathrm{~g} / \mathrm{kg})$ conditioned groups; \#indicates a significant difference $(p<0.05)$ between pre-and post-conditioning. 


\section{Effects of SL327 on the expression of ethanol-elicited pERK-positive neurons}

Figure 6 shows the effects of 60 min pretreatment with SL327 (0 and $50 \mathrm{mg} / \mathrm{kg}$ ) on the expression of ethanol $(2 \mathrm{~g} / \mathrm{kg}$ )-elicited pERK-positive neurons in the shell and core of the nucleus accumbens. Three-way ANOVA of the results of ethanol administration in the shell and core of the nucleus accumbens, revealed a main effect of pre-treatment $\left[F_{1,49}=46.29, p<0.001\right]$, treatment $\left[F_{1,49}=9.02, p<0.05\right]$ and brain region $\left[F_{1,49}=8.56\right.$, $p<0.05]$ and a significant pre-treatment by treatment interaction $\left[F_{1,49}=41.00\right.$, $p<0.001]$. Newman-Keuls' post-hoc test revealed that ethanol increased pERK-positive neurons/area with respect to saline in the shell and core of the nucleus accumbens. Moreover, one-way ANOVA of the results of SL327 administration followed by saline (ethanol vehicle group) administration in the shell and core of the nucleus accumbens

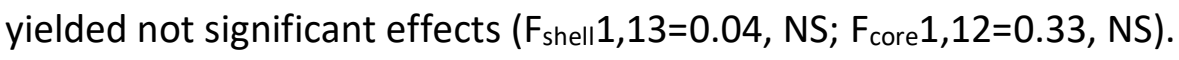

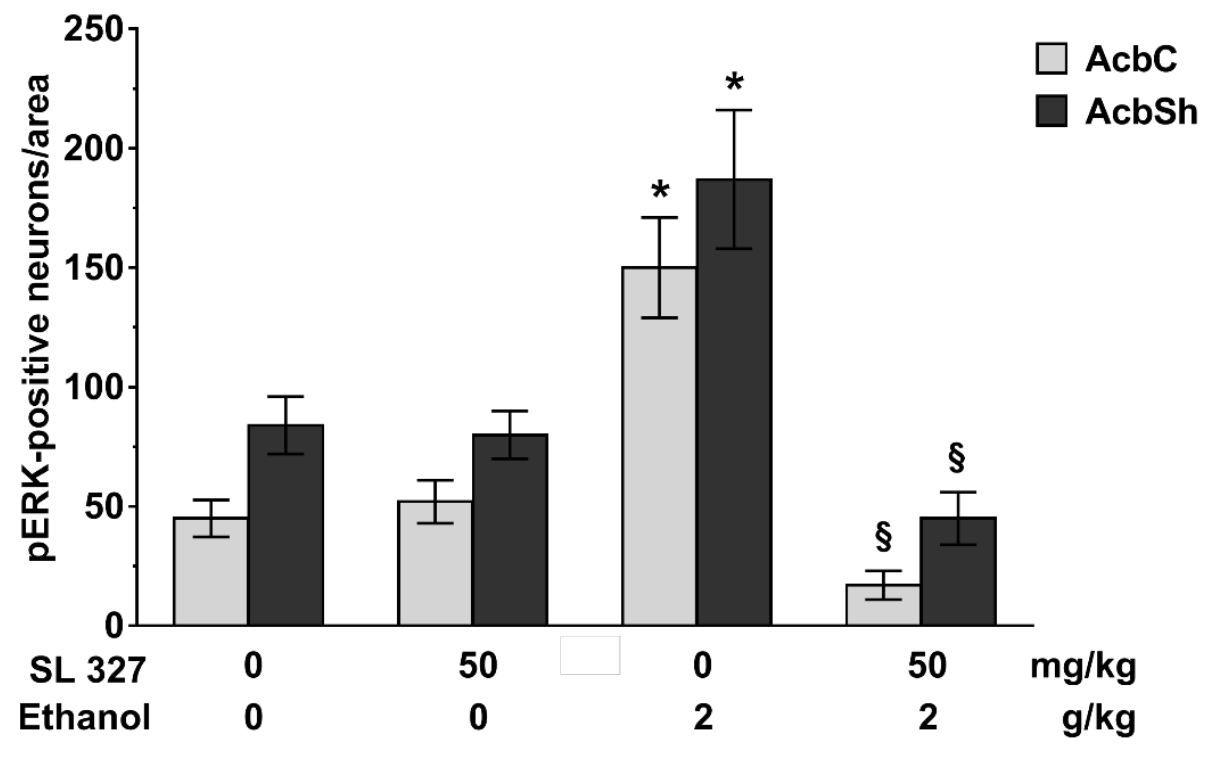

Figure 6. Effect of SL327 on the expression of ethanol-elicited pERK-positive neurons in the nucleus accumbens. Data are shown as mean \pm SEM of pERK-positive neurons/area. Effects of pre-treatment with SL327 (O and $50 \mathrm{mg} / \mathrm{kg}$ ) on ethanol (EtOH O (sal) and $2 \mathrm{~g} / \mathrm{kg}$ ) -elicited pERK-positive neurons/area in the shell (AcbSh) and core (AcbC) of the nucleus accumbens [ $n=9$, for the group veh/sal; $n=6$, for the group SL327/sal; $n=5$, for the group veh/EtOH; $n=7$, for the group SL327/EtOH]. *indicates a significant difference $(p<0.05)$ with respect to veh/sal (same brain region); sindicates a significant difference $(p<0.05)$ with respect to veh/EtOH (same brain region).

In addition, table 1 shows the effects of 60 min pretreatment with SL327 (0 and 50 $\mathrm{mg} / \mathrm{kg}$ ) on the expression of ethanol ( $2 \mathrm{~g} / \mathrm{kg}$ )-elicited pERK-positive neurons in the 
prefrontal cortex (prelimbic and infralimbic), bed nucleus of stria terminalis and central nucleus of the amygdala. One-way ANOVA of the results of SL327 administration followed by saline (ethanol vehicle group) administration in the prefrontal cortex (prelimbic and infralimbic), bed nucleus of stria terminalis and central nucleus of the

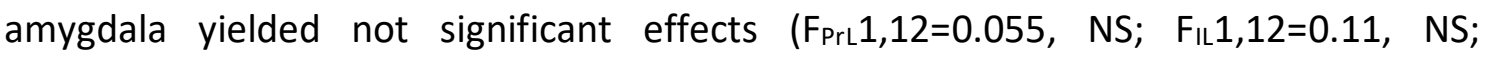
$F_{B S T L} 1,12=0.25$, NS and $F_{C e A} 1,12=0.09$, NS). Furthermore, two-way ANOVAs, followed by Newman-Keuls' post-hoc tests revealed that SL327 significantly prevented the expression of ethanol-elicited pERK-positive neurons/area in all brain regions.

\begin{tabular}{|c|c|c|c|c|c|}
\hline & \multicolumn{5}{|c|}{ pERK-positive neurons/area } \\
\hline & veh/sal & SL327/sal & veh/EtOH & SL327/EtOH & Two-way ANOVAs \\
\hline & & & & & $F_{\text {pre-treament }(1.26)}=11.05 p<0.05$ \\
\hline \multirow[t]{3}{*}{ PrL } & $42 \pm 10$ & $38.2 \pm 10.9$ & $156 \pm 23.2$ & $54 \pm 13 * *$ & $F_{\text {treatment }(1.26)}=16.5, p<0.001$ \\
\hline & & & & & $F_{\text {interaction }(1.26)}=9.62, p<0.05$ \\
\hline & & & & & $F_{\text {pre-treament }(1.26)}=7.27, p<0.05$ \\
\hline \multirow[t]{2}{*}{ IL } & $33 \pm 8$ & $29.5 \pm 7.9$ & $93.5 \pm 1 *$ & $39 \pm 10 * *$ & $F_{\text {treatment }(1.26)}=10.6, p<0.05$ \\
\hline & & & & & $F_{\text {interaction }(1.26)}=5.48, p<0.05$ \\
\hline \multirow{3}{*}{ BNST } & & & & & $F_{\text {pre-treament }(1.26)}=14.5, p<0.001$ \\
\hline & $25 \pm 8$ & $18.9 \pm 8.2$ & $102 \pm 14^{*}$ & $29 \pm 10 * *$ & $F_{\text {treatment(1.26) }}=17.77, p<0.001$ \\
\hline & & & & & $F_{\text {interaction }(1.26)}=10.62, p<0.05$ \\
\hline \multirow{3}{*}{$\mathrm{CeA}$} & & & & & $F_{\text {pre-treament(1.26) }}=6.6, p<0.05$ \\
\hline & $3 \pm 1$ & $9.3 \pm 5.7$ & $55 \pm 10^{*}$ & $13 \pm 6 * *$ & $F_{\text {treatment }(1.26)}=15.95, p<0.001$ \\
\hline & & & & & $F_{\text {interaction(1.26) }}=11.94, p<0.05$ \\
\hline
\end{tabular}

Table 1. Effects of $S L 327(0$ and $50 \mathrm{mg} / \mathrm{kg}$ ) on ethanol $(2 \mathrm{~g} / \mathrm{kg}$ )-elicited pERK-positive neurons in the pre-limbic (PrL); and infralimbic (IL) prefrontal cortex, in the bed nucleus of stria terminalis (BNST) and in the central nucleus of the amygdala (CeA). Data are the average \pm SEM raw numbers of $p E R K$ positive neurons/area from at least three every other slices. For all the brain regions the number of animals was: $n=7$, for the group veh/sal; $n=7$, for the group SL327/sal; $n=8$, for the group veh/EtOH; $n=8$, for the group SL327/EtOH. *indicates $p<0.05$ at Newman-Keuls post hoc test with respect to veh/sal; ${ }^{*} *_{\text {indicates }} p<0.05$ at Newman-Keuls post hoc test with respect to veh/EtOH. 


\section{DISCUSSION}

In agreement with Cunningham and Co-workers (1997), the results of this study confirm the ability of ethanol to elicit CPP and CPA (figure 1). Furthermore, the results demonstrate the differential involvement of MEK/ERK cascade in the acquisition and expression of place conditioning as the consequence of the of the blood brain barrierpenetrant compound, SL327 (Selcher et al. 1999), ability to block some of these effects (figures 2-5). The immunohistochemistry experiments also establish that SL327 significantly reduces the MEK mediated expression of $\mathrm{pERK}$-positive neurons elicited by ethanol in the nucleus accumbens shell and core and in other nuclei of extended amygdala, at the same doses and timing of place conditioning experiments (table 1 and figure 6).

\section{Effects on CPP and CPA Acquisition}

The administration of $\mathrm{SL327}(50 \mathrm{mg} / \mathrm{kg})$ significantly prevents the acquisition of ethanol-elicited CPP, whereas its administration (50 and $100 \mathrm{mg} / \mathrm{kg}$ ) is not able to prevent, but significantly reduces, the acquisition of ethanol-elicited CPA. The result that pre-treatment with SL327 affects the ability of ethanol to elicit CPP (figure 2) is in agreement with several studies (Valjent et al. 2000, 2001; Salzmann et al. 2003; Gerdjikov et al. 2004; Spina et al. 2010). In fact, it has been demonstrated that the local administration of MEK inhibitors, PD98059 in the nucleus accumbens (Gerdjikov et al. 2004) or U0126 in the VTA (Lin et al. 2010), during conditioning phase, precludes d-amphetamine- and morphine-elicited CPP, respectively. On the same vein, in another study the intracerebroventricular administration of PD98059 impairs the acquisition of morphine-elicited CPP (Spina et al. 2010). Moreover, the acute administration of ethanol (Ibba et al. 2009; Rosas et al. 2014; Agoglia et al. 2015) is able to increase the phosphorylation of ERK in the nucleus accumbens, brain region which has been shown to be involved in the acquisition of CPP (Di Chiara 2002; Gerdjikov et al. 2004). The involvement of MEK/ERK pathway is also in agreement with self-administration experiments in which the administration of SL327 at a low dose (30 $\mathrm{mg} / \mathrm{kg})$ increases the operant behavior, whereas at a higher dose $(100 \mathrm{mg} / \mathrm{kg})$ prevents it (Faccidomo et al. 2009). Furthermore, it has also been shown that the voluntary consumption of ethanol enhances pERK expression in medial prefrontal cortex, nucleus 
accumbens and amygdala (Faccidomo et al. 2015). Although different circuits are involved in the self-administration experiments, it is demonstrated that the neurobiological mechanisms and the brain regions that underlie the learning process of operant behavior are in common with Pavlovian learning (Sanchis-segura \& Spanagel 2006) and are triggered by the pharmacological effects of ethanol. In this regard, our result that MEK blockade prevents the acquisition of CPP is in agreement with the hint of a pivotal role of the MEK/ERK cascade in positive reinforcement mediated by ethanol (Faccidomo et al. 2009, 2015). However, this suggestion appears in contrast with the study of Groblewski, Franken and Cunnigham (2011) reporting that administration of SL327 (50 mg/kg) before two conditioning sessions failed to affect acquisition of ethanol ( $2 \mathrm{~g} / \mathrm{kg}$ i.p.)-elicited CPP. These differences could be due to different experimental schedules [unbiased (Groblewski et al. 2011) vs biased design (present data)], different strain of animals (DBA/2J), different vehicle for the dissolution of SL327 and time intervals ( $90 \mathrm{~min}$ vs $60 \mathrm{~min}$ in the present study) before the exposure to the conditioning apparatus.

Regarding the results of the CPA acquisition, SL327 is unable to fully prevent, but significantly reduces, the ability of ethanol to elicit CPA (figure 3 ) appears in contrast with the ability of SL327 to prevent the acquisition of ethanol-elicited CPP. The effects of SL327 on the acquisition of ethanol-elicited CPA appear also at variance with the results of Cao and Co-workers (2009) in which the local administration of MEK inhibitor, U0126, in the anterior cingulate cortex, affects the acquisition of CPA induced by intra-plantar formalin (Cao et al. 2009). Also, in this case the differences between this study and present data could be due to different routes of administration (local vs systemic) of the MEK inhibitors and nature and strength (pharmacological vs nociceptive) of the US, that play a critical role in determining the ability of MEK blockade to affect CPA acquisition. Similar, but opposite, results on the role of MEK blockade on CPA acquisition were reported by Cao et al. (2009) by showing that other MEK inhibitors prevent intra-plantar formalin- but not foot-shock or U69,593-elicited CPA. Moreover, the immunohistochemical data (table 1 and figure 6), in agreement with Valjent et al. (2000), clearly demonstrate that, at the same dose and timing observed in the place conditioning experiments, SL327 totally prevents the activation 
of ERK in brain regions involved in the acquisition of associative learning (Marotta et al. 2014) and positive (Gerdjikov et al. 2004) and negative conditioning (Deyama et al. 2007). However, due to a significantly different experimental design, the immunohistochemical data cannot be offered to provide a consistent explanation about the effect of SL327 on ERK phosphorylation in animals exposed to the CS, but only the effects of SL327 on pERK expression induced by an acute administration of ethanol. Hence, we can only assume that SL327 may prevent ethanol-elicited ERK phosphorylation in the following conditioning sessions as in the first one.

Thus, in light of the ability of SL327 to prevent the acquisition of ethanol-elicited CPP, these observations overall suggest that learning the aversive US-CS association encompasses differentially the MEK/ERK cascade so that its involvement may or may not result critical for the specific behavioral outcome.

In summary, while we cannot offer any conclusive interpretation that may comprehensively explain such experimental differences, including the finding of a significant reduction by SL327 of the acquisition of ethanol-elicited CPA, these observations suggest that MEK blockade may represent the necessary but not sufficient condition to prevent aversive associative learning.

\section{Effects on CPP and CPA Expression}

The expression phase of the place conditioning experiments allows establishing whether drug-associated affective memories are able, in a drug-free state and in a state of free choice between CS+ and CS-, to direct animals' behavior toward preferring or avoiding the CS+. This indicates that measurements of place conditioning expression may be the result of both attraction to the CS+ or aversion/avoidance of the CS-. The finding that SL327 significantly reduces, although not fully preventing (figure 4), the expression of ethanol-elicited CPP is in agreement with previous studies showing that MEK inhibitors could prevent retrieval of cocaine (Miller \& Marshall 2005) and morphine (Lin et al. 2010)-elicited CPP and with the observation that presentation of conditioned stimuli, either in CPP (Nygard et al. 2015) and in selfadministration experiments (Radwanska et al. 2008; Peana et al. 2013; Faccidomo et al. 2015) is associated with an increased expression of phosphorylated ERK. However, 
these studies, at least in terms of brain structures involved, fail to provide a view that may sustain a unifying hypothesis on the role of MEK and the significance of activated ERK in the expression of responses to conditioned stimuli. In fact, the critical involvement of this kinase pathway has been reported in different brain structures such as the VTA (Lin et al. 2010), the medial prefrontal cortex (Faccidomo et al. 2015), the amygdala (Radwanska et al. 2008) and the core of the nucleus accumbens (Miller \& Marshall 2005) whereby its blockade results in prevention to express the acquired association.

In contrast with the observation that SL327 significantly reduces CPP expression (figure 4), we found, in agreement with Longoni et al. (2011), that its administration before the post-conditioning test to rats undergone the schedule of aversive conditioning, fails to affect the ability of the CS+ to elicit place aversion (figure 5). Interestingly, although ERK phosphorylation has been reported under a number of experimental conditions related to the establishment of aversive memories such as conditioned taste aversion (Marotta et al. 2014) and opiate withdrawal (Wang et al. 2015) to our knowledge only few studies, Cao et al. (2009) and Longoni et al. (2011), have addressed, with opposite results, the issue of the role of MEK in the ability of a CS+ to evoke aversive memories. A number of methodological differences might be responsible for discrepancies between these studies and the present data and we can only state at the present that recalling aversive memories by a CS+ may or may not require the involvement of MEK/ERK cascade as a function of the US.

In summary, since the acquisition is more sensitive to MEK/ERK disruption, these results suggest that the signaling kinase under study may be more involved in the initial learning than in the expression of a previously learned association as well as that it may be more involved in appetitive (present data; Salzmann et al. (2003); Valjent et al. 2000 and 2001)) than in aversive motivation. Furthermore, the observation that SL327 (50 and $100 \mathrm{mg} / \mathrm{kg}$ ) significantly reduces the expression of ethanol-elicited CPP whereas fully fails to affect the expression of ethanol-elicited CPA allows also to speculate that in CPP expression experiments the attraction toward the CS+ succeeds over the repulsion from the CS-. 
In conclusion, given the significance of the place conditioning model, i.e. to highlight the appetitive or aversive motivational properties of USs on one side, and to characterize the strength of CSs to evoke responses of attraction to, or repulsion from, the USs, on the other, the present study provides new insight on the complexity of the involvement of MEK in the establishment of associative learning and in the expression of the acquired responses. 


\section{REFERENCES}

Agoglia AE, Sharko AC, Psilos KE, Holstein SE, Reid GT, Hodge CW, Hill C \& Carolina N (2015) Alcohol Alters the Activation of ERK1/2, a Functional Regulator of Binge Alcohol Drinking in Adult C57BL/6J Mice. Alcohol Exp Res 39:463-475.

Atkins CM, Selcher JC, Petraitis JJ, Trzaskos JM \& Sweatt JD (1998) The MAPK cascade is required for mammalian associative learning. Nat Neurosci 1:602-609.

Blum S, Moore AN, Adams F \& Dash PK (1999) A mitogen-activated protein kinase cascade in the CA1/CA2 subfield of the dorsal hippocampus is essential for longterm spatial memory. J Neurosci 19:3535-3544.

Cao H, Gao Y, Ren W, Li T, Duan K, Cui Y, Cao X, Zhao Z, Ji R \& Zhang Y (2009) Activation of Extracellular Signal-Regulated Kinase in the Anterior Cingulate Cortex Contributes to the Induction and Expression of Affective Pain. 29:3307-3321.

Carr G, Fibiger H \& Phillips A (1989) Conditioned place preference as a measure of drug reward, Liebman JM. C. Press (ed). Oxford.

Di Chiara G (2002) Nucleus accumbens shell and core dopamine: Differential role in behavior and addiction. Behav Brain Res 137:75-114.

Cunningham CL, Okorn DM \& Howard CE (1997) Interstimulus interval determines whether ethanol produces conditioned place preference or aversion in mice. Anim Learn Behav 25:31-42.

Faccidomo S, Besheer J, Stanford PC \& Hodge CW (2009) Increased operant responding for ethanol in male $\mathrm{C} 57 \mathrm{BL} / 6 \mathrm{~J}$ mice : specific regulation by the ERK $1 / 2$, but not JNK , MAP kinase pathway. Psychopharmacology (Berl):135-147.

Faccidomo S, Salling MC, Galunas C \& Hodge CW (2015) Operant ethanol selfadministration increases extracellular-signal regulated protein kinase (ERK) phosphorylation in reward-related brain regions: Selective regulation of positive reinforcement in the prefrontal cortex of C57BL/6J mice. Psychopharmacology (Berl) 232:3417-3430.

Gerdjikov T V., Ross GM \& Beninger RJ (2004) Place preference induced by nucleus accumbens amphetamine is impaired by antagonists of ERK or p38 MAP kinases in rats. Behav Neurosci 118:740-750.

Girault J, Valjent E, Caboche J \& Herve D (2007) ERK2 : a logical AND gate critical for drug-induced plasticity ? Curr Opin Pharmacol:77-85.

Groblewski PA, Franken FH \& Cunningham CL (2011) Inhibition of extracellular signalregulated kinase (ERK) activity with SL327 does not prevent acquisition, expression, and extinction of ethanol seeking behavior in mice. Behav Brain Res 217:399-407.

Ibba F, Vinci S, Spiga S, Peana AT, Assaretti AR, Spina L, Longoni R \& Acquas E (2009) Ethanol-induced extracellular signal regulated kinase: Role of dopamine $D 1$ 
receptors. Alcohol Clin Exp Res 33:858-867.

Kelly A, Laroche S \& Davis S (2003) Activation of mitogen-activated protein kinase/extracellular signal-regulated kinase in hippocampal circuitry is required for consolidation and reconsolidation of recognition memory. J Neurosci 23:535460 .

Kirschmann EKZ, Mauna JC, Willis CM, Foster RL, Chipman AM \& Thiels E (2014) Appetitive cue-evoked ERK signaling in the nucleus accumbens requires NMDA and D1 dopamine receptor activation and regulates CREB phosphorylation. Learn Mem 21:606-615.

Lin X, Wang Q, Ji J \& Yu L (2010) Role of MEK-ERK Pathway in Morphine-Induced Conditioned Place Preference in Ventral Tegmental Area of Rats. J Neurosci Res 1604:1595-1604.

Longoni R, Spina L \& Vinci S (2011) The MEK inhibitor SL327 blocks acquisition but not expression of lithium-induced conditioned place aversion: a behavioral and immunohistochemical study. Psychopharmacology (Berl):63-73.

Marotta R, Fenu S, Scheggi S, Vinci S, Rosas M, Falqui A, Gambarana C, De Montis MG \& Acquas E (2014) Acquisition and expression of conditioned taste aversion differentially affects extracellular signal regulated kinase and glutamate receptor phosphorylation in rat prefrontal cortex and nucleus accumbens. Front Behav Neurosci 8:153.

Mazzucchelli C, Vantaggiato C, Ciamei A, Fasano S, Pakhotin P, Krezel W, Welzl H, Valverde O, Wolfer DP, Page G, Marowsky A, Porrazzo A, Orban PC, Maldonado R, Ehrengruber MU, Cestari V, Lipp H, Chapman PF, Neuroscienze I \& Psicobiologia S (2002) Knockout of ERK1 MAP Kinase Enhances Synaptic Plasticity in the Striatum and Facilitates Striatal-Mediated Learning and Memory. Neuron 34:807-820.

Miller CA \& Marshall JF (2005) Molecular substrates for retrieval and reconsolidation of cocaine-associated contextual memory. Neuron 47:873-884.

Nygard SK, Klambatsen A, Balouch B \& Jenab S (2015) Region and context-specific intracellular responses associated with cocaine-induced conditioned place preference expression. Neuroscience 287:1-8.

Paxinos G \& Franklin K (2001) The mouse brain in stereotaxic coordinates, 2nd editio. Academic (ed). Sydney.

Peana AT, Giugliano V, Rosas M, Sabariego M \& Acquas E (2013) Effects of I-Cysteine on Reinstatement of Ethanol-Seeking Behavior and on Reinstatement-Elicited Extracellular Signal-Regulated Kinase Phosphorylation in the Rat Nucleus Accumbens Shell. Alcohol Clin Exp Res 37.

Radwanska K, Wrobel E, Korkosz A, Rogowski A, Kostowski W, Bienkowski P \& Kaczmarek L (2008) Alcohol relapse induced by discrete cues activates components of AP-1 transcription factor and ERK pathway in the rat basolateral and central amygdala. Neuropsychopharmacology 33:1835-1846. 
Rosas M, Porru S, Sabariego M, Piludu MA, Giorgi O, Corda MG \& Acquas E (2018) Effects of morphine on place conditioning and ERK1/2 phosphorylation in the nucleus accumbens of psychogenetically selected Roman low- and high-avoidance rats. Psychopharmacology (Berl) 235:59-69.

Rosas M, Zaru A, Sabariego M, Giugliano V, Carboni E, Colombo G \& Acquas E (2014) Differential sensitivity of ethanol-elicited ERK phosphorylation in nucleus accumbens of Sardinian alcohol-preferring and -non preferring rats. Alcohol 48:471-6.

Salzmann J, Marie-Claire C, Le Guen S, Roques BP \& Noble F (2003) Importance of ERK activation in behavioral and biochemical effects induced by MDMA in mice. $\mathrm{Br} \mathrm{J}$ Pharmacol 140:831-838.

Sanchis-segura C \& Spanagel R (2006) Behavioural assessment of drug reinforcement and addictive features in rodents : an overview. Addict Biol Review:2-38.

Selcher JC, Atkins CM, Trzaskos JM, Paylor R \& Sweatt JD (1999) A necessity for MAP kinase activation in mammalian spatial learning. Learn Mem 6:478-90.

Shiflett MW \& Balleine BW (2011) Contributions of ERK signaling in the striatum to instrumental learning and performance. Behav Brain Res 218:240-247.

Spina L, Longoni R, Vinci S, Ibba F, Peana AT, Muggironi G, Spiga S \& Acquas E (2010) Role of dopamine $D 1$ receptors and extracellular signal regulated kinase in the motivational properties of acetaldehyde as assessed by place preference conditioning. Alcohol Clin Exp Res 34:607-616.

Tzschentke TM (2007) Measuring reward with the conditioned place preference (CPP) paradigm: Update of the last decade. Addict Biol 12:227-462.

Valjent E, Caboche J \& Vanhoutte P (2001) Mitogen-Activated Protein Kinase / Extracellular Signal-Regulated Kinase Induced Gene Regulation in Brain. Mol Neurobiol 23:83-99.

Valjent E, Corbillé AG, Bertran-Gonsalez J, Hervé D \& Girault JA (2006) Inhibition of ERK pathway or protein synthesis during reexposure to drugs of abuse erases previously learned place preference. Proc Natl Acad Sci U S A 103:2932-2937.

Valjent E, Corvol J, Page C, Besson M, Maldonado R, Curie M, Neurofarmacologia L De \& De F (2000) Involvement of the Extracellular Signal-Regulated Kinase Cascade for Cocaine-Rewarding Properties. J Neurosci 20:8701-8709.

Valjent E, Pagès C, Hervé D, Girault JA \& Caboche J (2004) Addictive and non-addictive drugs induce distinct and specific patterns of ERK activation in mouse brain. Eur $J$ Neurosci 19:1826-1836.

Villarreal JS \& Barea-Rodriguez EJ (2006) ERK phosphorylation is required for retention of trace fear memory. Neurobiol Learn Mem 85:44-57.

Vinci S, Ibba F, Longoni R, Spina L, Spiga S \& Acquas E (2010) Acetaldehyde elicits ERK 
phosphorylation in the rat nucleus accumbens and extended amygdala. Synapse 64:916-927.

Wang W, Chen Z, Liu W \& Chi Z (2015) Dorsal hippocampal NMDA receptor blockade impairs extinction of naloxone- precipitated conditioned place aversion in acute morphine-treated rats by suppressing ERK and CREB phosphorylation in the basolateral amygdala. Br J Pharmacol:482-491. 


\section{Experimental Studies Chapter 2}





\section{CHAPTER 2: Caffeine prevents ethanol-elicited place preference and aversion and ERK phosphorylation in the nucleus accumbens and other areas of the extended amygdala}

\section{ABSTRACT}

Although several epidemiological studies focus on the consequences of the association between caffeinated and alcoholic beverages, the effects of the combination of caffeine and ethanol in animal models of drug addiction are currently still underexplored.

To characterize the pharmacological interaction between caffeine and ethanol and establish if caffeine can affect the ability of ethanol $(2 \mathrm{~g} / \mathrm{kg})$ of eliciting conditioned place preference (CPP) and conditioned place aversion (CPA), we administered caffeine ( 3 or $15 \mathrm{mg} / \mathrm{kg}$ ) to male CD-1 mice before saline or ethanol. Moreover, we assessed whether caffeine, at doses at which fails to affect the expression of Extracellular-signal Regulated Kinase (ERK) phosphorylation (pERK) in the nucleus accumbens, bed nucleus of stria terminalis, central and basolateral amygdala, could prevent ethanol $(2 \mathrm{~g} / \mathrm{kg})$ elicited pERK expression in these brain regions.

In the place conditioning paradigm, caffeine was devoid of reinforcing properties whereas ethanol elicited significant CPP and CPA. Moreover, caffeine (15 mg/kg) significantly prevented ethanol-elicited CPP and at both doses also ethanol-elicited CPA. Caffeine ( 3 and $15 \mathrm{mg} / \mathrm{kg}$ ) also prevented ethanol-elicited pERK expression in all brain areas examined.

These results, that could be interpreted as due to the functional antagonistic action of caffeine and ethanol on the adenosine-mediated regulation of associative learning and motivated behaviors, disclose exciting insights on the consequences of the acute interaction between two of the most used psychotropic substances and provide exciting grounds to further study their pharmacological interaction. 


\section{INTRODUCTION}

Ethanol and caffeine are two of the most widely consumed substances in the world. Ethanol is a sedative/hypnotic drug that is recognized as being responsible for initiating and sustaining a wide array of conditions that are fundamental to alcohol use disorders, including alcohol dependence, a progressive escalation from low or moderate to high doses, and compulsive ethanol intake (Koob \& Volkow 2009). Caffeine is a minor stimulant that is often consumed in the form of drinks like tea or coffee, but in recent years also as an ingredient in "energy drinks" that contain relatively high caffeine concentrations (e.g., 50-500 mg caffeine per serving) (Scholey \& Kennedy 2004; Reissig et al. 2009; Peacock et al. 2015). Energy drinks are frequently consumed by teenagers and young adults in order to increase athletic performance by reducing fatigue, and/or to improve cognitive performance by increasing memory and concentration (Lalanne et al. 2017). Furthermore, the combined intake of alcohol and energy drinks is an emerging phenomenon. The tendency to combine caffeine with ethanol during binge drinking may be due to the popular belief that caffeine antagonizes intoxicating effects of alcohol, and improves social interactions (Weitzman et al. 2003; Reissig et al. 2009; Marczinski 2011).

Caffeine and ethanol both act on adenosine function, but in opposite ways. Specifically, caffeine acts as a non-selective antagonist of $A_{1}$ and $A_{2 A}$ adenosine receptors (Cauli \& Morelli 2005; Ferré et al. 2008), while ethanol acts indirectly via the production of its second metabolite, acetate, to increase adenosine levels (Nagy et al. 1990; Nagy 1992; Fredholm \& Wallman-Johansson 1996). Interestingly, although epidemiological studies have shown that there can be a positive correlation between the consumption of caffeine and that of ethanol (Marczinski \& Fillmore 2014; Kristjansson et al. 2015), the results reported in the preclinical literature are often complex and contradictory, and the nature of the interaction varies across the doses and behavioral tasks used. Administration of caffeine at the dose of $5.0 \mathrm{mg} / \mathrm{kg}$ to rats subsequently given access to ethanol $(10 \% \mathrm{v} / \mathrm{v})$ facilitated its ingestion, while the administration of doses of 2.5 and $10.0 \mathrm{mg} / \mathrm{kg}$ failed to increase ethanol intake (Kunin et al. 2000). In mice, high doses of caffeine $(20 \mathrm{mg} / \mathrm{kg})$ reduced ethanol intake under restricted access conditions, but increased it when ethanol was available 24 hours. 
Lower doses of caffeine $(5-10 \mathrm{mg} / \mathrm{kg})$ did also increase ethanol consumption under unrestricted access conditions (SanMiguel et al. 2019). Moreover, high doses of ethanol are known to cause amnesia and learning impairments, which are frequently associated with episodes of binge drinking (Wetherill \& Fromme 2016), whereas caffeine at moderate doses $(5.0-10.0 \mathrm{mg} / \mathrm{kg}$ ) was able to improve memory acquisition and retention in different learning models (Angelucci et al. 2002; Dash et al. 2004; Spinetta et al. 2008). However, caffeine $(5.0-40.0 \mathrm{mg} / \mathrm{kg}$ ) did not reverse the learning deficits caused by ethanol (1.0-1.4 g/ $\mathrm{kg})$ in a plus-maze discriminative avoidance task (Gulick \& Gould 2009) or in a social interaction three-chamber test (López-cruz et al. 2016). Low doses of ethanol that did not impair social interaction reduced social recognition 24 hours later, and co-administration of caffeine was unable to block these amnesic effects (López-cruz et al. 2016).

Ethanol has motivational properties that are consistently highlighted in studies of place conditioning, such as conditioned place preference (CPP) and conditioned place aversion (CPA) (Cunningham et al., 2002, 2003; Cunningham and Henderson, 2000; Font et al., 2006; Rosas et al., 2017; Spina et., 2015), as well as voluntary intake and ethanol-induced reinforcement of operant behavior (Bassareo et al., 2017; Faccidomo et al., 2015; Lorrai et al., 2019; Peana et al., 2014). In contrast, the motivational effects of caffeine are not well characterized. In fact, the few studies focusing on caffeineinduced CPP have reported inconclusive results, mostly due to substantially different doses and schedules of administration across studies (Brockwell et al. 1991; Brent Bedingfield et al. 1998; Patkina \& Zvartau 1998; Hsu et al. 2009). Moreover, the studies that investigated the effects of caffeine and ethanol co-administration on place conditioning reported that caffeine, administered either alone $(3.0 \mathrm{mg} / \mathrm{kg}$ ) (Brockwell et al. 1991) or in the same injection as ethanol $(3.0 \mathrm{mg} / \mathrm{kg}$ of caffeine and $1.75 \mathrm{~g} / \mathrm{kg}$ of ethanol), did induce a significant CPP, although this effect was more modest than that of ethanol itself (Hilbert et al. 2013). In addition, a single administration of caffeine $(3.0 \mathrm{mg} / \mathrm{kg}$ ) was reported as being able to reduce the expression of ethanol-elicited CPP and its reinstatement (Okhuarobo et al. 2019).

The Extracellular signal-Regulated Kinase (ERK) is part of the Mitogen-Activated Protein Kinase (MAPK)-signaling cascade that plays a critical role in neuroplasticity, gene 
expression, and behavioral changes underlying the reinforcing processes induced by substances of abuse (Valjent et al. 2005). The active form of this protein, phosphorylated ERK (pERK), plays a key role in the acute effects of ethanol. Increases in ERK expression following acute ethanol administration has been demonstrated in several brain areas, including both the core $(\mathrm{AcbC})$ and shell (AcbSh) subregions of the nucleus accumbens, nuclei that are part of the extended amygdala (bed nucleus of stria terminalis (BNST) and central nucleus of the amygdala (CeA)) (Ibba et al. 2009), and basolateral amygdala (Spanos et al. 2012). These brain areas are involved in positive and negative effects of ethanol reinforcement and in the development of dependence (Koob et al. 1998). Moreover, ERK expression is related to the motivational properties of drugs as demonstrated by CPP experiments (Valjent et al. 2000, 2001; Salzmann et al. 2003; Gerdjikov et al. 2004; Lu et al. 2006; Spina et al. 2010). ERK appears to be involved in the acquisition of motivational valence by neutral stimuli paired with the primary effects of addictive drugs (Valjent et al. 2001; Gerdjikov et al. 2004).

In order to shed light on the interaction between low but pharmacologically significant doses of caffeine and the motivational properties of ethanol, the aims of this study were: 1) determining if pre-treatment with different doses of caffeine (3.0 and 15.0 $\mathrm{mg} / \mathrm{kg}$ ) may affect the acquisition of ethanol $(2 \mathrm{~g} / \mathrm{kg})$-elicited CPP and CPA (Cunningham et al. 1997; Spina et al. 2015; Rosas et al. 2017), and 2) investigating if caffeine has the ability to affect the increases of pERK expression elicited by ethanol in the nucleus accumbens, extended amydgala (bed nucleus of stria terminalis and central nucleus of the amygdala), and basolateral amygdala. Moreover, the study was also undertaken to verify if the stimuli (positive or negative) associated with ethanol may induce a differential expression of pERK in the brain areas examined, and if the effects of caffeine on the acquisition of place conditioning may also be reflected in the differential expression of ERK in brain areas involved in ethanol-conditioned reinforcement. 


\section{MATERIALS AND METHODS}

\section{Animals}

Adult male CD-1 mice (22-24 g, Charles River, Calco, Italy) were housed in groups of four per cage for at least 6 days before use and maintained on a 12:00/12:00 $\mathrm{h}$ light/dark cycle (lights on at 08:00 a.m.) with food and water ad libitum. All the experiments were carried out during the light phase, between 09:00 and 16:00 h. The total numbers of mice were $n=89$ and $n=80$ in the CPP and CPA experiments, respectively, and $n=19$ and $n=20$ in the immunohistochemistry experiments after CPP and CPA expression, respectively. Finally, the total number of mice used in the immunohistochemical experiments were $n=19$.

All the experimental procedures were performed in accordance with the Principles of laboratory animal care and with the guidelines and protocols approved by the European Union (2010/63/UE L 276 20/10/2010). Every possible effort was made to minimize animal pain and discomfort and to reduce the number of experimental subjects.

\section{Drugs}

Ethanol (Sigma-Aldrich, Milan, Italy) $20 \%$ (v/v) in isotonic saline, was administered at the dose of $2 \mathrm{~g} / \mathrm{kg}$ (12 ml/kg volume injection). Caffeine (Sigma-Aldrich, Milan, Italy) was dissolved in isotonic saline (10 ml/kg volume injection) and was administered at the doses of 3 and $15 \mathrm{mg} / \mathrm{kg}$. All drugs and vehicle (saline) were administered intraperitoneally (IP).

\section{Apparatus}

The apparatus consisted of two rectangular Plexiglas boxes $(48 \mathrm{~L} \times 20 \mathrm{~W} \times 30 \mathrm{H} \mathrm{cm})$ separated by a guillotine door. The apparatus was placed in a sound-proof room with a constant light of 37.5 Lux (ELD 9010 Luxmeter, Eldes Instruments, Italy) provided by a 40W lamp placed above each compartment. Different visual and tactile cues distinguished the two compartments: vertically striped black and white walls and white smooth floor for one compartment (A) and horizontally striped black and gray walls and fine grid floor for the other compartment (B). The spontaneous preference was randomly distributed between compartments (45,4\% for compartment $A$ and $54,6 \%$ 
for compartment B in CPP experiments; $49 \%$ for compartment $A$ and $51 \%$ for compartment B in CPA experiments). Moreover, mice whose spontaneous preference times, at the pre-conditioning test, were between 441 and $459 \mathrm{sec}$ were randomly assigned half to compartment $A$ and half to compartment $B$.

\section{Conditioned Place Preference and Conditioned Place Aversion: procedure and experimental design}

Each experiment consisted of three phases. During the first phase (pre-test, day 1), the guillotine door was kept raised and each mouse was placed randomly in one or the other compartment and given access to both compartments of the apparatus for 15 minutes $(900 \mathrm{sec})$. The time spent in one compartment was recorded and taken as indication of spontaneous preference. Behavioral schedules for backward (CPP) and forward (CPA) conditioning (figure $1 \mathrm{~A}$ and $1 \mathrm{~B}$, respectively) were designed after Rosas et al. (2017) and Spina et al. (2015) with some modifications related to the timing of pre-treatment with caffeine. In particular, during the second phase (conditioning, days 2-5) of CPP experiments, mice of distinct experimental groups, were administered caffeine ( 3 or $15 \mathrm{mg} / \mathrm{kg}$ ) or saline 20 min before ethanol $(2 \mathrm{~g} / \mathrm{kg}$ ) or saline, and were returned to their home cage. $10 \mathrm{~min}$ after ethanol administration mice were exposed for $5 \mathrm{~min}$ to a given compartment and returned to their home cage. 6 hours later mice were administered saline or caffeine ( 3 or $15 \mathrm{mg} / \mathrm{kg}$ ), then returned to their home cage 20 min before the second administration (ethanol, 0 or $2 \mathrm{~g} / \mathrm{kg}$ ). $10 \mathrm{~min}$ after this second administration mice were placed (for $5 \mathrm{~min}$ ) in the compartment opposite to that of the morning exposure.

During the second phase (conditioning, days 2-5) of CPA experiments, mice of distinct experimental groups were administered caffeine ( 3 or $15 \mathrm{mg} / \mathrm{kg}$ ) or saline and returned to their home cage for $30 \mathrm{~min}$. At the end of this period mice were exposed for $5 \mathrm{~min}$ to the given compartment. Upon removal from the compartment (i.e. immediately before being returned to their home cage) mice were administered the second injection (ethanol, 0 or $2 \mathrm{~g} / \mathrm{kg}$ ). 6 hours later, mice were administered caffeine $(0,3$ or $15 \mathrm{mg} / \mathrm{kg})$ or saline $30 \mathrm{~min}$ before the $5 \mathrm{~min}$ exposure to the opposite compartment. Upon removal from the apparatus (i.e. before being returned to their home cage) mice were administered the second injection (ethanol 0 or $2 \mathrm{~g} / \mathrm{kg}$ ). 
During conditioning days for both CPP and CPA the order of saline and ethanol administration was counterbalanced [i.e. the order of the combined pretreatment/treatment [caffeine $(0,3$ and $15 \mathrm{mg} / \mathrm{kg}) /$ ethanol $(0$ or $2 \mathrm{~g} / \mathrm{kg})$ ] administrations was opposite on even days with respect to that one on odd days]; similarly, the number of mice receiving saline and ethanol was counterbalanced over the 4 days of conditioning. The same counterbalanced design was also applied to the assignment of mice to compartments $A$ and $B$. As a result of these conditioning schedules, saline (ethanol, $0 \mathrm{~g} / \mathrm{kg}$ ) and ethanol $(2 \mathrm{~g} / \mathrm{kg}$ ) were paired four times with the given compartment.

A

\section{Conditioned Place Preference (CPP)}

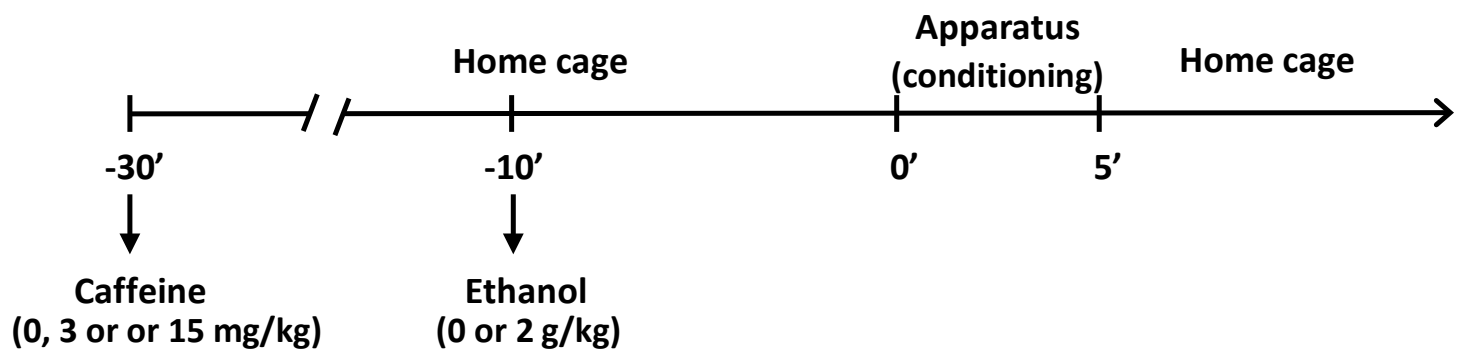

B

\section{Conditioned Place Aversion (CPA)}

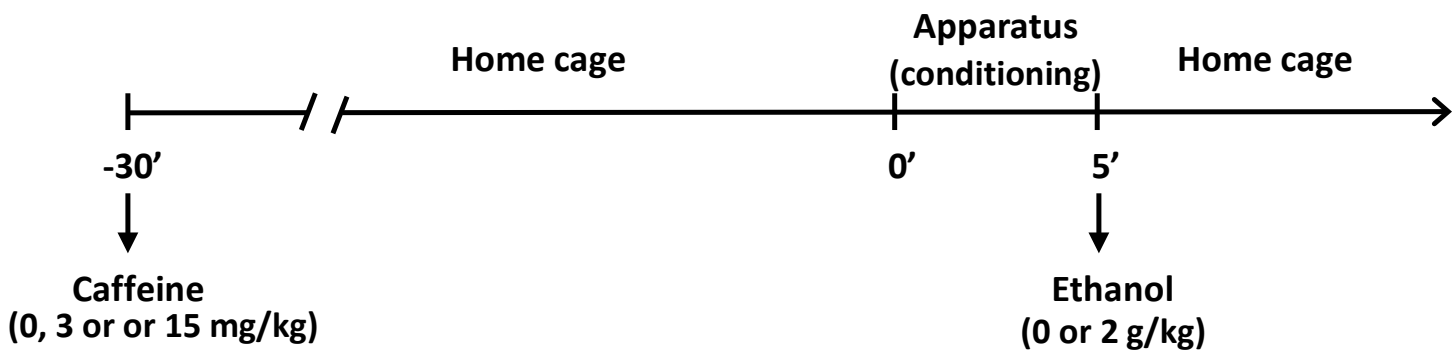

Figure 1. CPP and CPA conditioning procedures. Schematic representation of the place conditioning procedures used in the CPP $(A)$ and CPA $(B)$ experiments. $(A)$ Mice were administered caffeine $(0,3$ or 15 $\mathrm{mg} / \mathrm{kg}) 20 \mathrm{~min}$ before administration of ethanol $(0$ or $2 \mathrm{~g} / \mathrm{kg}$ ) and were returned to their home cage. 10 min after ethanol (0 or $2 \mathrm{~g} / \mathrm{kg}$ ) administration, mice were exposed for 5 min to the given compartment of the conditioning apparatus and returned to their home cage. (B) Mice were administered caffeine $(0$, 3 or $15 \mathrm{mg} / \mathrm{kg}$ ) and returned to their home cage for $30 \mathrm{~min}$. At the end of this period, each mouse was exposed for $5 \mathrm{~min}$ to the given compartment of the conditioning apparatus. Upon removal from the apparatus, i.e. before being returned to their home cage, mice were administered ethanol (0 or $2 \mathrm{~g} / \mathrm{kg}$ ). 
During the third phase of both CPP and CPA experiments (post-conditioning test, day 6), $24 \mathrm{~h}$ after the last conditioning treatment, the guillotine door was kept raised and the time spent by each mouse in the drug-paired (backward conditioning, CPP) and in the drug-assigned (forward conditioning, CPA) compartment during 15 min was recorded. The conditions of the post-conditioning test were identical to those of the pre-conditioning test. Pre- and post-conditioning recordings were done with stop watch by observers blind to pharmacological treatments. Hence, a statistically significant difference between the time spent during pre- and post-conditioning tests of the drug group with respect to that of the saline group was taken as indication of the development of place conditioning (Carr et al. 1989).

\section{Immunohistochemistry}

For these experiments mice of distinct experimental groups were administrated caffeine $(0,3$ or $15 \mathrm{mg} / \mathrm{kg}, \mathrm{IP}) 20 \mathrm{~min}$ before ethanol $(0$ or $2 \mathrm{~g} / \mathrm{kg}, \mathrm{IP}$ ) and deeply anesthetized $15 \mathrm{~min}$ after the last administration (Ibba et al. 2009). Under deep anesthesia, animals were subjected to trans-cardiac perfusion with ice-cold PBS (Phosphate Buffered Saline: $137 \mathrm{mM} \mathrm{NaCl}, 2.7 \mathrm{mM} \mathrm{KCl}, 10 \mathrm{mM} \mathrm{Na} 2 \mathrm{HPO}_{4}, 2 \mathrm{mM}$ $\mathrm{KH}_{2} \mathrm{PO}_{4}, \mathrm{pH}$ 7.4) and $4 \%$ paraformaldehyde (PFA) solutions. After perfusion, brains were removed and post-fixed overnight in 4\% PFA. Brain slices $(40 \mu \mathrm{m})$ of the regions of interest were cut, on ice-cold PBS with a vibratome (Leica VT1000, Leica, Germany) according to plates 21-23 (approximately from AP 1.18 to AP $0.98 \mathrm{~mm}$ from bregma for the nucleus accumbens core and shell), to plates 30-32 (approximately from AP 0.14 to AP $-0.10 \mathrm{~mm}$ from bregma for the bed nucleus of stria terminalis) and to plates $40-41$ (approximately from AP -1.06 to AP $-1.34 \mathrm{~mm}$ from bregma for the basolateral and central nucleus of the amygdala) of the mouse brain atlas (Paxinos \& Franklin 2001). Slices were kept in ice-cold PBS and processed for immunohistochemistry according to a protocol for free-floating slices. Immunoreactions for pERK-positive cells detection were applied to at least two every other slice obtained from each brain. After an incubation for 30 min in $1 \% \mathrm{H}_{2} \mathrm{O}_{2}$, slices were incubated for 1 hour with $3 \%$ BSA. The incubation with the primary anti pERK antibody (phosphorylated ERK, Cell Signalling Technology, Beverly, MA, USA (1:350)) was conducted overnight. On the following day, after rinsing, slices were incubated for 1 hour with the biotinylated secondary antibody 
(1:800). After three rinses the slices were incubated in avidin biotin peroxidase complex prepared according to the manufacturer's suggestions (Vectastain ABC kit, Vector Laboratories, Burlingame, CA, USA) and a 3-3'-diaminobenzidine solution (10 $\mathrm{mg} / \mathrm{mL}$ ) was added until development of brown staining. Slices were rinsed and mounted onto gelatine-coated slides and processed through alcohol-xylene for light microscopy examination. pERK-positive neurons were identified in the regions of interest of both hemispheres at the lowest magnification (10X) and quantitative analysis was performed using a Zeiss Axioskop 40 light microscope, equipped with PL Fluotar 10X (na=0.3), 40X (na=1.00-0.5) and 100X oil (na=1.3) objectives, coupled with a Nikon D5000 digital camera (Melville, NY, USA). Images of the regions of interest were obtained at the lowest magnification (10X) from at least three every other $40 \mu \mathrm{m}$ thick slices and used to automatically count the number of pERK-positive neurons/area (pERK expression) by application of the software ImageJ (v. 1.42, National Institutes of Health sponsored image analysis program).

\section{Statistical analysis}

To determine statistically significant differences between pre-conditioning values of the experimental groups depicted in figures 2-6, one-way Analysis of Variance (ANOVA) was applied (Statistica v. 8.0, StatSoft Inc., Tulsa (OK), USA). To determine the effect of pre-treatment ( 3 levels: caffeine 0,3 or $15 \mathrm{mg} / \mathrm{kg}$ ) on conditioning and those of treatment (2 levels: EtOH 0 or $2 \mathrm{~g} / \mathrm{kg}$ ) on acquisition of ethanol-elicited CPP or CPA, data were analyzed by three-way ANOVAs with pre-treatment and treatment as independent factors (between subjects) and with pre-conditioning and postconditioning values as a within-subjects factor (repeated measures). All statistical analyses were carried out using data from the experimental groups depicted in each figure. Post hoc analyses (with multiple comparisons), carried out using Newman-Keuls post-hoc analyses, were undertaken if significant effects were found $(p<0.05)$.

pERK-positive neurons/area following each treatment were expressed as the average number of pERK-positive neurons/area of each experimental group and indicated as pERK-positive neurons/area ( $p E R K$ expression). These values were used as dependent variables for statistical analyses by one-way ANOVAs with pERK-positive neurons/area as dependent variables and with pre-treatment (3 levels: caffeine 0,3 or 15 
$\mathrm{mg} / \mathrm{kg}$ )/treatment (2 levels: EtOH 0 or $2 \mathrm{~g} / \mathrm{kg}$ ) used as independent variable. Fishers Least Significant Difference (LSD) post-hoc analyses, whereby allowed by ANOVAs significant main effects, were applied for multiple comparisons, with the statistical significance set at $p<0.05$.

\section{RESULTS}

\section{Effects of caffeine on acquisition of ethanol-elicited CPP}

Figure 2 shows the effects of pre-treatment with caffeine $(0,3$ or $15 \mathrm{mg} / \mathrm{kg}) 20 \mathrm{~min}$ before the administration of ethanol $(\mathrm{EtOH}, 0$ or $2 \mathrm{~g} / \mathrm{kg}$ ) and exposure to the associated compartment for $5 \mathrm{~min}$ (see figure 1A). Pre-conditioning preference times did not significantly differ between experimental groups $\left[\mathrm{F}_{5,81}=0.06, \mathrm{NS}\right]$. Repeated measures three-way ANOVA with preference times (pre- and post-conditioning) as dependent factors and with pre-treatment (caffeine 0,3 or $15 \mathrm{mg} / \mathrm{kg}$ ) and treatment (EtOH 0 or $2 \mathrm{~g} / \mathrm{kg}$ ) doses as independent factors, revealed a significant effect of time $\left[F_{1,83}=19.21, p<0.001\right]$, and significant treatment by time $\left[F_{1,83}=10.37, p<0.05\right]$ and pretreatment by treatment by time $\left[\mathrm{F}_{2,83}=7.24, \mathrm{p}<0.05\right]$ interactions. Post-hoc analysis according to Newman-Keuls test revealed 1) that EtOH stimulates a significant preference shift from $343 \pm 15$ to $528 \pm 23 \mathrm{sec} / 900(p<0.05), 2)$ that caffeine 3 and 15 $\mathrm{mg} / \mathrm{kg}$ is devoid of motivational properties and 3) that caffeine 15 but not $3 \mathrm{mg} / \mathrm{kg}$ significantly prevents the acquisition of CPP induced by EtOH $(p<0.05)$. 


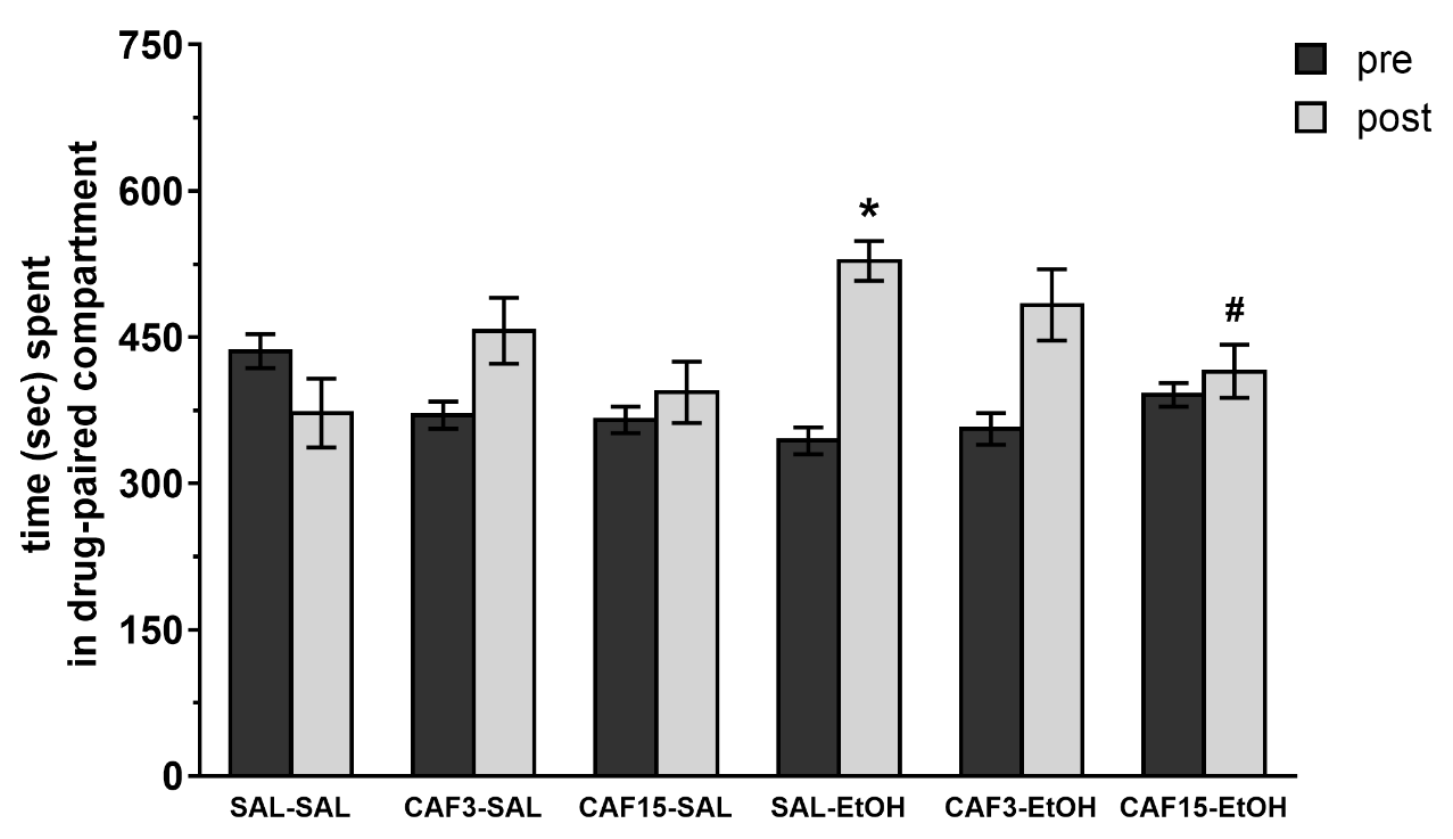

Figure 2. Effects of caffeine pre-treatment on acquisition of ethanol-elicited CPP. Data are shown as average time spent (sec.) \pm SEM in the drug-paired compartment. *Indicates a significant difference $(p<0.05)$ of time spent during post-conditioning test as compared to caffeine $(0 \mathrm{mg} / \mathrm{kg})+\mathrm{EtOH}(0 \mathrm{~g} / \mathrm{kg})$ group; \#Indicates a significant difference $(p<0.05)$ in time spent during the post-conditioning test as compared to caffeine $(0 \mathrm{mg} / \mathrm{kg})+\mathrm{EtOH}(2 \mathrm{~g} / \mathrm{kg})$ group.

\section{Effects of caffeine on acquisition of ethanol-elicited CPA}

Figure 3 shows the effects of pre-treatment with caffeine $(0,3$ or $15 \mathrm{mg} / \mathrm{kg}) 30 \mathrm{~min}$ before the exposure to the assigned compartment for $5 \mathrm{~min}$, and of ethanol (EtOH 0 or $2 \mathrm{~g} / \mathrm{kg}$ ) administration upon removal from the place conditioning apparatus (see figure 1B). Pre-conditioning preference times did not differ significantly between experimental groups $\left[\mathrm{F}_{5,74}=0.03, \mathrm{NS}\right]$. Repeated measures three-way ANOVA with preference times (pre- and post-conditioning) as dependent factors and with pretreatment (caffeine 0,3 or $15 \mathrm{mg} / \mathrm{kg}$ ) and treatment (EtOH 0 and $2 \mathrm{~g} / \mathrm{kg}$ ) doses as independent factors, revealed significant effects of pre-treatment $\left[F_{2,74}=3.51, p<0.05\right]$, treatment $\left[F_{1,74}=13.10, p<0.001\right]$ and time $\left[F_{1,74}=8.87, p<0.05\right]$, and significant pretreatment by time $\left[\mathrm{F}_{2,74}=3.83, \mathrm{p}<0.05\right]$ and treatment by time $\left[\mathrm{F}_{1,74}=14.54, \mathrm{p}<0.001\right]$ interactions. Post-hoc analysis according to Newman-Keuls test revealed that 1) EtOH stimulated a significant CPA from $513 \pm 13$ to $269 \pm 38 \mathrm{sec} / 900(p<0.001) 2$ ) caffeine (3 and $15 \mathrm{mg} / \mathrm{kg}$ ) is devoid of motivational properties and 3) caffeine ( 3 and $15 \mathrm{mg} / \mathrm{kg}$ ) significantly prevents the acquisition of CPA induced by EtOH $(p<0.05)$. 


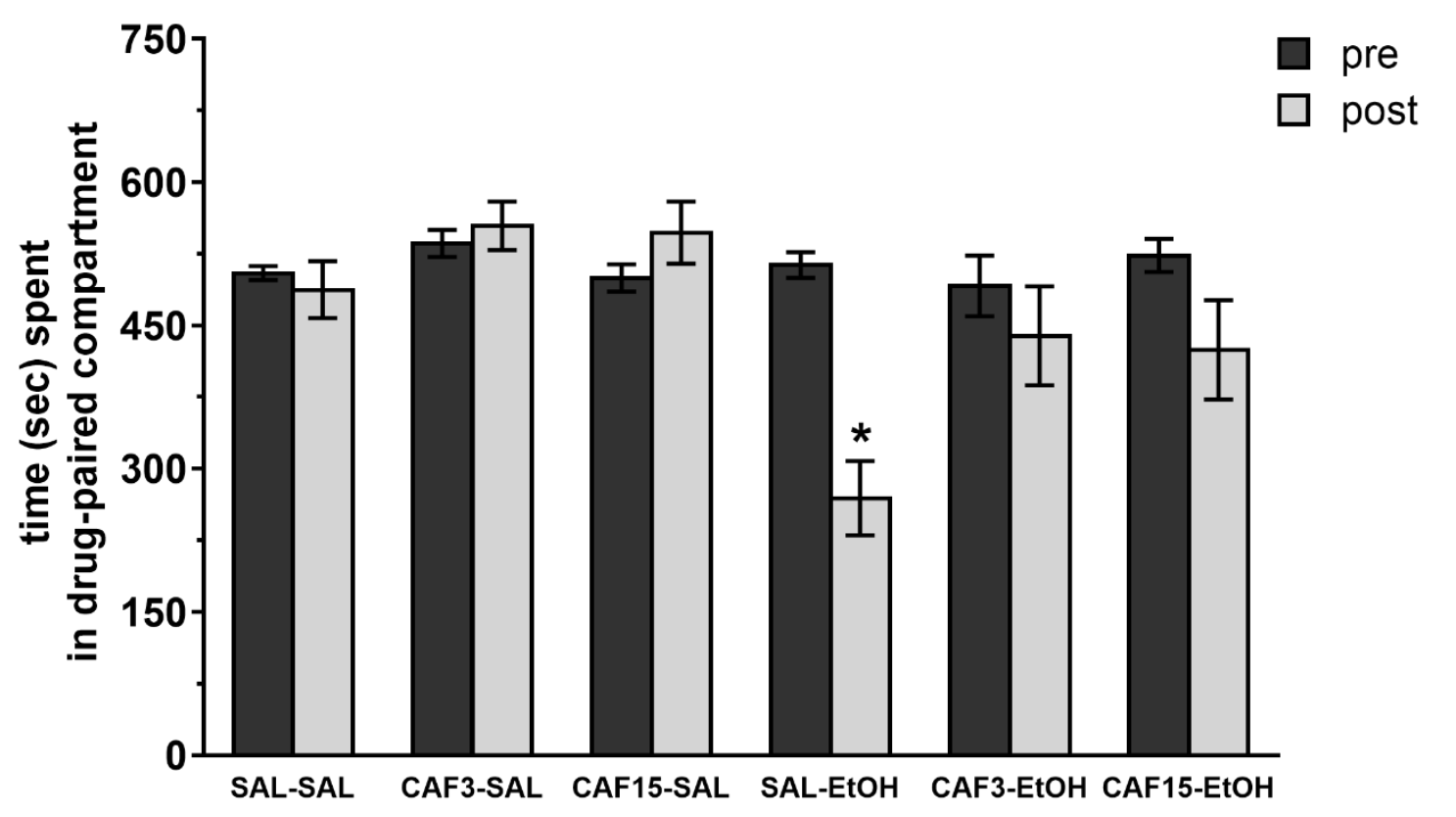

Figure 3. Effects of caffeine pre-treatment on acquisition of ethanol-elicited CPA. Data are shown as average time spent (sec.) \pm SEM in the drug-paired compartment. *Indicates a significant difference $(p<0.05)$ of time spent during the post conditioning test between caffeine $(0 \mathrm{mg} / \mathrm{kg})+\mathrm{EtOH}(2 \mathrm{~g} / \mathrm{kg})$ group and all other groups.

Effects of acute administration of caffeine on the expression of ethanolelicited pERK-positive neurons

Figure 4 shows the effects of pre-treatment with caffeine $(0,3$ or $15 \mathrm{mg} / \mathrm{kg}) 20 \mathrm{~min}$ before the administration of ethanol (EtOH 0 or $2 \mathrm{~g} / \mathrm{kg}$ ) on the number of pERKpositive neurons in $\mathrm{AcbC}$ and $\mathrm{AcbSh}, \mathrm{BNST}, \mathrm{CeA}$ and BLA.

The administration of EtOH ( $2 \mathrm{~g} / \mathrm{kg}$ ), according to previous studies (Ibba et al. 2009) increases the number of pERK-positive cells in the AcbC and AcbSh $(p<0.05)$ (from $41 \pm 2$ and $50 \pm 10$ to $149 \pm 13$ and $168 \pm 34$, respectively) and caffeine pretreatment reduces to $78 \pm 10$ and $101 \pm 21$ at the doses of $3 \mathrm{mg} / \mathrm{kg}$ and to $51 \pm 3$ and $82 \pm 15$ at the dose of 15 $\mathrm{mg} / \mathrm{kg}$, the ability of EtOH to stimulate ERK phosphorylation in both Acb subregions (figure 4A). One-way ANOVA, with pre-treatment/treatment factor as independent variable and with the number of pERK-positive cells/area as dependent variable, revealed significant pre-treatment/treatment effects in $A c b C\left[F_{3,15}=6.91, p<0.05\right]$ and AcbSh $\left[F_{3,15}=5.12, p<0.05\right]$. Post hoc analysis according to Fishers Least Significant Difference (LSD) test revealed that 1 ) EtOH stimulates a significant increase of the 
number of pERK-positive neurons both in the AcbC and in the AcbSh $(p<0.05)$ and 2$)$ pre-treatment with caffeine at both doses significantly reduces this effect in both areas.

Moreover, the administration of EtOH $(2 \mathrm{~g} / \mathrm{kg})$ increases pERK-positive cells in the BNST $(p<0.05$ ) (respectively from $23 \pm 3$ to $103 \pm 9$ and caffeine pretreatment reduces, to $77 \pm 3$ at the dose of $3 \mathrm{mg} / \mathrm{kg}$ and to $72 \pm 6$ at the dose of $15 \mathrm{mg} / \mathrm{kg}$, the ability of EtOH to stimulate ERK phosphorylation in this area (figure 4B). One-way ANOVA, with pretreatment/treatment as independent variable and with the number of $p E R K$-positive cells/area as dependent variable, revealed significant effects of pretreatment/treatment $\left[\mathrm{F}_{3,15}=28.04, \mathrm{p}<0.001\right]$. Post hoc analysis according to Fishers Least Significant Difference (LSD) test revealed 1) that EtOH stimulates a significant increase of the number of pERK-positive neurons in the BNST $(p<0.001)$ and 2$)$ that pre-treatment with caffeine at both doses significantly reduces $(p<0.05)$ this effect. 
A

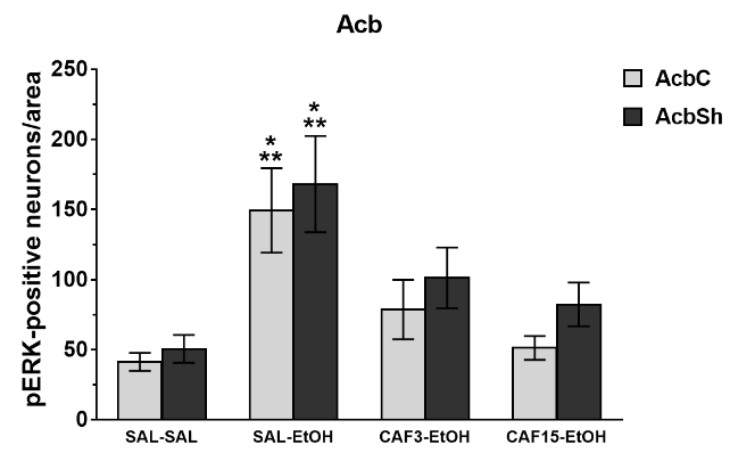

C

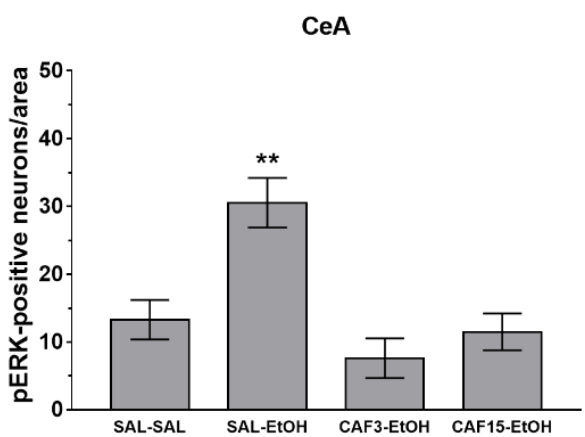

B

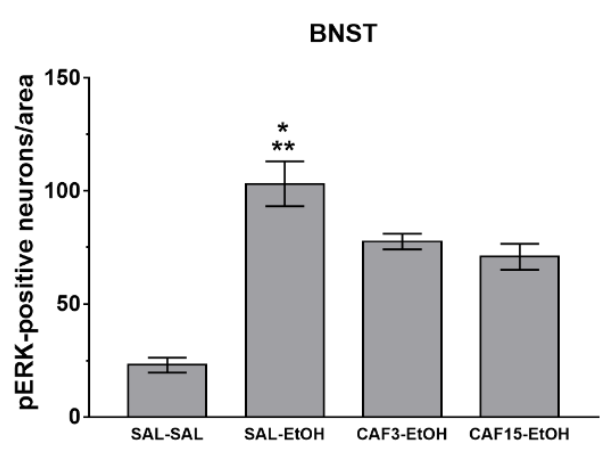

D

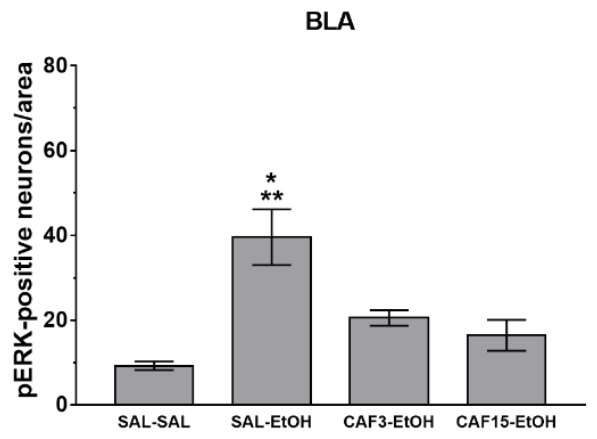

Figure 4. Effects of acute administration of caffeine on the expression of ethanol-elicited pERK-positive neurons in the Acb, BNST, CeA and BLA. Data are shown as mean \pm SEM of $p E R K$-positive neurons/area. Figure 4A: *indicates a significant difference $(p<0.05)$ between caffeine $(0 \mathrm{mg} / \mathrm{kg})+E t O H(2 \mathrm{~g} / \mathrm{kg})$ and caffeine (3 and $15 \mathrm{mg} / \mathrm{kg})+E t O H(2 \mathrm{~g} / \mathrm{kg})$ groups in AcbC and AcbSh; **indicates a significant difference $(p<0.001)$ between caffeine $(0 \mathrm{mg} / \mathrm{kg})+E$ tOH $(2 \mathrm{~g} / \mathrm{kg})$ and caffeine $(0 \mathrm{mg} / \mathrm{kg})+$ EtOH $(0 \mathrm{~g} / \mathrm{kg})$ groups in $A c b C$ and AcbSh. Figure 4B: *indicates a significant difference $(p<0.05)$ between caffeine $(0 \mathrm{mg} / \mathrm{kg})+$ $\mathrm{EtOH}(2 \mathrm{~g} / \mathrm{kg})$ and caffeine (3 and $15 \mathrm{mg} / \mathrm{kg})+E t O H(2 \mathrm{~g} / \mathrm{kg})$ groups in BNST; **indicates a significant difference $(p<0.001)$ between caffeine $(0 \mathrm{mg} / \mathrm{kg})+E t O H(2 \mathrm{~g} / \mathrm{kg})$ and caffeine $(0 \mathrm{mg} / \mathrm{kg})+E t O H(0 \mathrm{~g} / \mathrm{kg})$ groups in BNST. Figure 4C: ${ }^{*}$ indicates a significant difference $(p<0.001)$ between caffeine $(0 \mathrm{mg} / \mathrm{kg})+$ $\mathrm{EtOH}(2 \mathrm{~g} / \mathrm{kg})$ and all other groups in CeA. Figure 4D: *indicates a significant difference $(p<0.05)$ between caffeine $(0 \mathrm{mg} / \mathrm{kg})+$ EtOH $(2 \mathrm{~g} / \mathrm{kg})$ and caffeine $(3$ and $15 \mathrm{mg} / \mathrm{kg})+E t O H(2 \mathrm{~g} / \mathrm{kg})$ groups in BLA; $* *$ indicates a significant difference $(p<0.001)$ between caffeine $(0 \mathrm{mg} / \mathrm{kg})+E \mathrm{EOOH}(2 \mathrm{~g} / \mathrm{kg})$ and caffeine $(0$ $\mathrm{mg} / \mathrm{kg})+E t O H(\mathrm{Og} / \mathrm{kg})$ groups in BLA.

Finally, the administration of EtOH $(2 \mathrm{~g} / \mathrm{kg})$ also increases the number of pERK-positive cells in the CeA and BLA ( $p<0.05)$, respectively, from $13 \pm 2$ to $30 \pm 3$ in the CeA and from $9 \pm 1$ to $39 \pm 6$ in the BLA; pretreatment with caffeine, at the doses of 3 and $15 \mathrm{mg} / \mathrm{kg}$, reduces to $7 \pm 2$ and $11 \pm 3$ respectively, in the $\mathrm{CeA}$ and to $20 \pm 1$ and $16 \pm 4$, respectively, in the BLA, the number of pERK-positive neurons elicited by ethanol (figures $\mathbf{4 C}$ and 4D). One-way ANOVA, with pre-treatment/treatment as independent variables and with the number of pERK-positive cells/area as dependent variable, revealed 
significant effects of pre-treatment/treatment $\left[\mathrm{F}_{3,15}=10.76, p<0.05\right]$. Post hoc analysis according to Fishers Least Significant Difference (LSD) test revealed that 1) EtOH stimulates a significant increase of the number of pERK-positive neurons in the CeA and BLA $(p<0.05)$ and 2$)$ pre-treatment with caffeine at both doses significantly reduces $(p<0.001)$ this effect in both areas. Representative images of these results are shown in Figure 5.

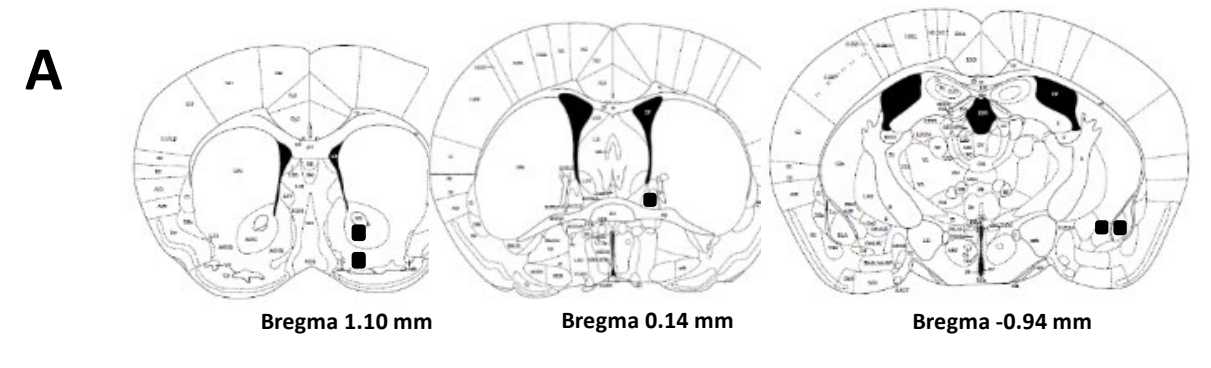

B

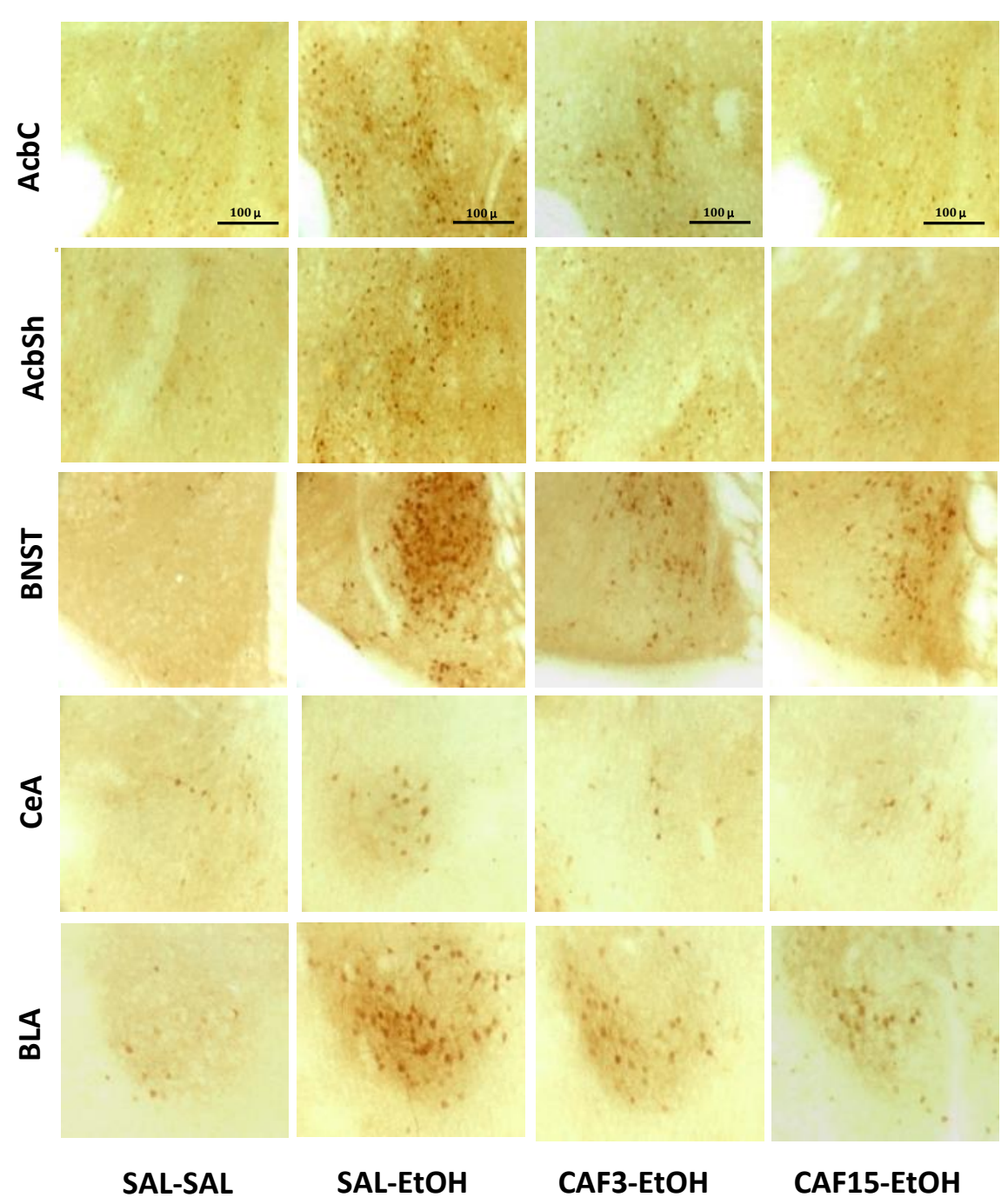

Figure 5. Coronal sections with bregma coordinates taken from the mouse brain atlas of Paxinos and Franklin (2001) showing the location of the areas (AcbC and AcbSh, BNST, CeA and BLA) for pERK immunoreactivity counting (figure 5A). Low (20X) magnification images of $p E R K$-positive neurons from mice representative of each treatment group (figure 5B). 


\section{Effects of the expression of ethanol-elicited CPP on ERK phosphorylation}

Figure 6 shows the effects of ethanol-elicited CPP expression behavior on the number of pERK-positive neurons/area in AcbC and AcbSh, BNST, CeA and BLA.

A

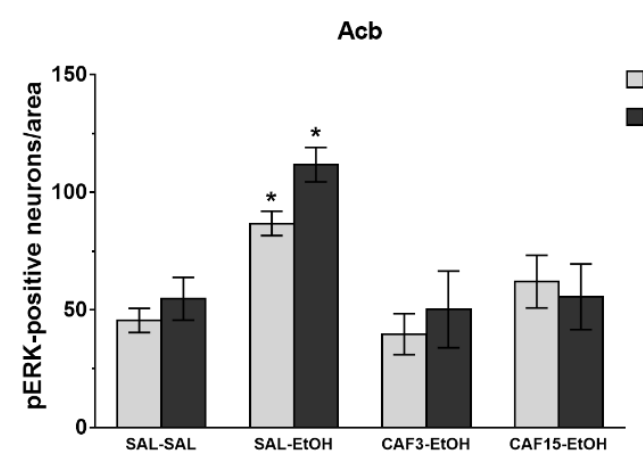

C

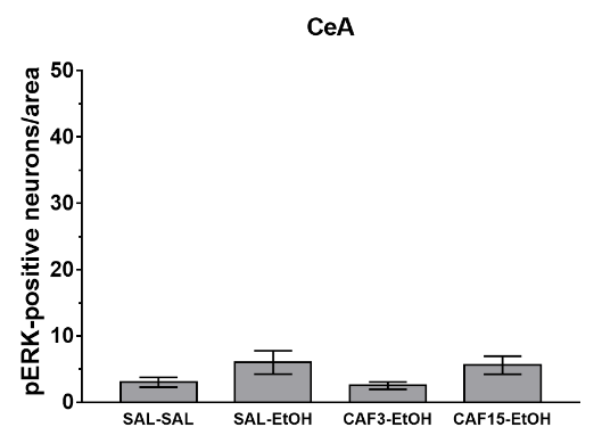

B

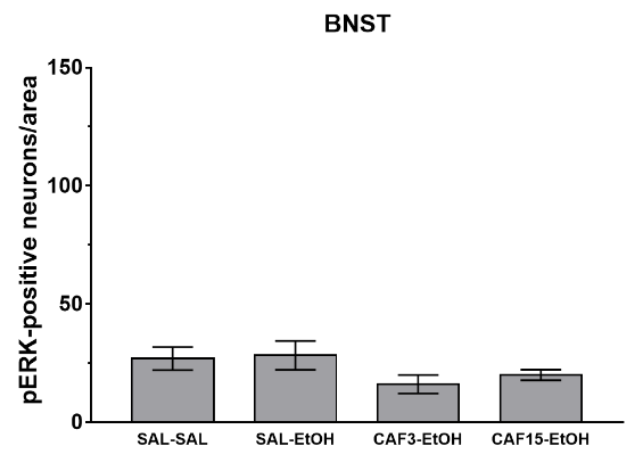

D

BLA

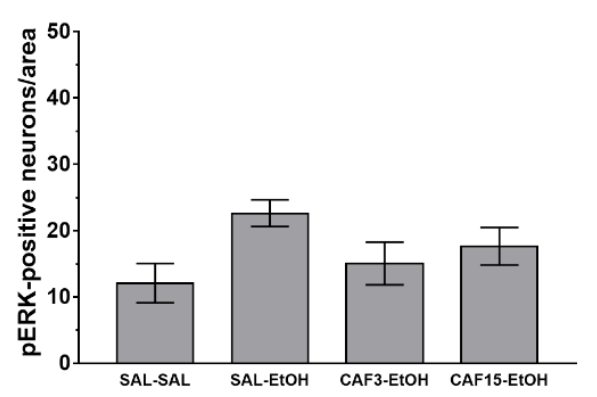

Figure 6. Effects of the expression of ethanol-elicited CPP on ERK phosphorylation in the Acb, BNST, CeA and BLA. Animals of each group, in a drug-free state, performed the post-conditioning test (15 min) and immediately afterwards were anesthetized and perfused for immunohistochemical analysis. Data are shown as mean \pm SEM of $p E R K$-positive neurons/area. Figure $6 A$ : *indicates a significant difference $(p<0.05)$ between caffeine $(0 \mathrm{mg} / \mathrm{kg})+E t O H(2 \mathrm{~g} / \mathrm{kg})$ and caffeine $(0 \mathrm{mg} / \mathrm{kg})+E t O H(0 \mathrm{~g} / \mathrm{kg})$ groups and between caffeine $(0 \mathrm{mg} / \mathrm{kg})+E t O H(2 \mathrm{~g} / \mathrm{kg})$ and caffeine $(3$ and $15 \mathrm{mg} / \mathrm{kg})+E t O H(0 \mathrm{~g} / \mathrm{kg})$ groups in $A c b C$ and $A c b S h$.

The administration of ethanol $(2 \mathrm{~g} / \mathrm{kg}$ ) during conditioning, according to the schedule depicted in figure $1 \mathrm{~A}$, resulted, as also shown in figure 2 , in a significant CPP; the expression of this acquired preference during the post conditioning test, in turn, increases the number of pERK-positive cells in the AcbC and AcbSh $(p<0.05)$, respectively from $45 \pm 2$ to $86 \pm 2$ and from $54 \pm 9$ to $111 \pm 7$; pretreatment with caffeine during conditioning reduces to $39 \pm 6$ in $A c b C$ and to $50 \pm 16$ in AcbSh at the dose of

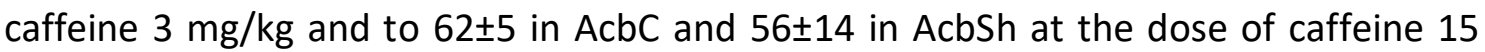


$\mathrm{mg} / \mathrm{kg}$, the ability of the EtOH-conditioned stimulus to increase ERK phosphorylation in both subregions of nucleus accumbens (figure 6A). One-way ANOVA, considering pretreatment/treatment as independent variables and the number of pERK-positive neurons/area as dependent variable, revealed significant pre-treatment/treatment effects in the $A c b C\left[F_{3,15}=5.98, p<0.05\right]$ and $A c b S h\left[F_{3,15}=4.62, p<0.05\right]$ but not significant effects in BNST $\left[F_{3,15}=2.04, N S\right], C e A\left[F_{3,15}=2.41, N S\right]$ and $B L A\left[F_{3,15}=2.23, N S\right]$. Post-hoc analysis according to Fishers Least Significant Difference (LSD) test for the Acb revealed that 1 ) the expression of $\mathrm{EtOH}$-elicited CPP is associated with a significant increase of the number of pERK-positive neurons/area both in the AcbC and in the AcbSh $(p<0.05)$ and that 2$)$ caffeine at both doses, during conditioning, significantly reduced this effect.

\section{Effects of ethanol-elicited CPA expression on ERK phosphorylation}

Figure 7 shows the effects of ethanol-elicited CPA expression behavior on the number of pERK-positive neurons/area (pERK expression) in AcbC and AcbSh, BNST, CeA and BLA.

The administration of ethanol $(2 \mathrm{~g} / \mathrm{kg}$ ) during conditioning, according to the schedule depicted in figure $1 \mathrm{~B}$, resulted, as also shown in figure 3 , in a significant CPA; the expression of this acquired aversion during the post conditioning test, fails to increase the number of pERK-positive cells in the AcbC and AcbSh ( $p>0.05$ ) (figure 7A). One-way ANOVA, considering the number of pERK-positive neurons/area as a dependent variable, and pretreatment/treatment as independent variables, reveled significant pre-treatment and treatment effects in the $A c b C\left[F_{1,16}=4.25, p<0.05\right]$ but not in the AcbSh $\left[\mathrm{F}_{3,16}=1.30, \mathrm{NS}\right]$ (figure $7 \mathrm{~A}$ ). Post-hoc test according to Fishers Least Significant Difference (LSD) revealed that 1 ) the expression of ethanol-elicited CPA is not associated with a significant increase of the number of pERK-positive neurons/area in AcbSh and AcbC $(p>0.05)$ with respect to caffeine $(0 \mathrm{mg} / \mathrm{kg})+\mathrm{EtOH}(0 \mathrm{~g} / \mathrm{kg})$ conditioned group.

However, the expression of the acquired aversion during the post conditioning test, increases the number of pERK-positive cells in the BNST $(p<0.001)$ (respectively from $37 \pm 4$ to $85 \pm 14$ ) and caffeine pretreatment at both doses reduces, to $49 \pm 7$ (caffeine 3 
$\mathrm{mg} / \mathrm{kg}$ ) and $28 \pm 4$ (caffeine $15 \mathrm{mg} / \mathrm{kg}$ ) pERK-positive cells/area, the ability of EtOHelicited CPA expression to stimulate ERK phosphorylation in this area (figure 7B). Oneway ANOVA, with pre-treatment/treatment as independent variable and with the number of pERK-positive cells/area as dependent variable, revealed significant pretreatment and treatment effects $\left[F_{3,16}=9.06, p<0.001\right]$. Post hoc analysis according to Fishers Least Significant Difference (LSD) test revealed that 1) expression of EtOHelicited CPA stimulated a significant increase of the number of $p E R K$-positive neurons in the BNST $(p<0.001)$ and that 2$)$ pre-treatment with caffeine at both doses significantly reduced $(p<0.001)$ this effect.

Finally, the expression of the acquired aversion during the post conditioning test, increases of pERK-positive cells in the CeA $(p<0.001)$ and BLA $(p<0.05)$ of the amygdala complex (respectively from $7 \pm 1$ to $17 \pm 1$ for the CeA and from $18 \pm 2$ to $31 \pm 4$ for BLA) and caffeine pretreatment at both doses, during conditioning, significantly reduces it to $3 \pm 1$ and $5 \pm 1$ for the doses of caffeine of 3 and $15 \mathrm{mg} / \mathrm{kg}$, respectively in the CeA and to $21 \pm 1$ and $16 \pm 2$ for the doses of caffeine of 3 and $15 \mathrm{mg} / \mathrm{kg}$, respectively, in the BLA (figure 7C and 7D). One-way ANOVA, with pre-treatment/treatment as independent variable and with the number of pERK-positive cells/area as dependent variable, revealed a significant pre-treatment and treatment effects in CeA $\left[F_{3,16}=79.57\right.$, $p<0.001]$ and $B L A\left[F_{3,16}=5.52, p<0.05\right]$. Post hoc analysis according to Fishers Least Significant Difference (LSD) test revealed that 1 ) expression of EtOH-elicited CPA stimulates a significant increase of the number of pERK-positive neurons in both regions of amygdala complex $(p<0.05)$ and that 2$)$ pre-treatment with caffeine at both doses significantly reduced $(p<0.05)$ this effect. 
A

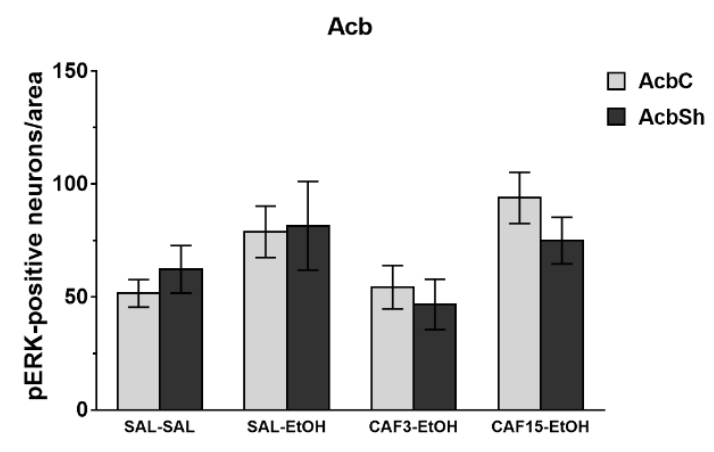

C

CeA

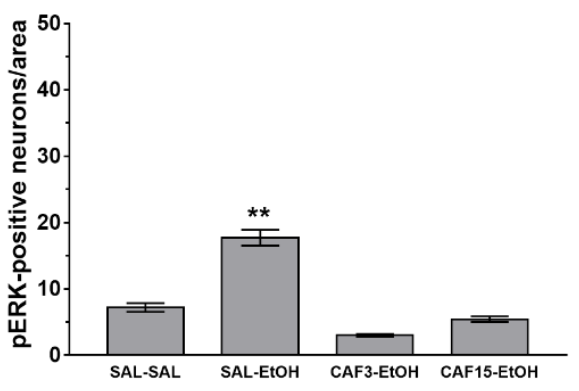

B

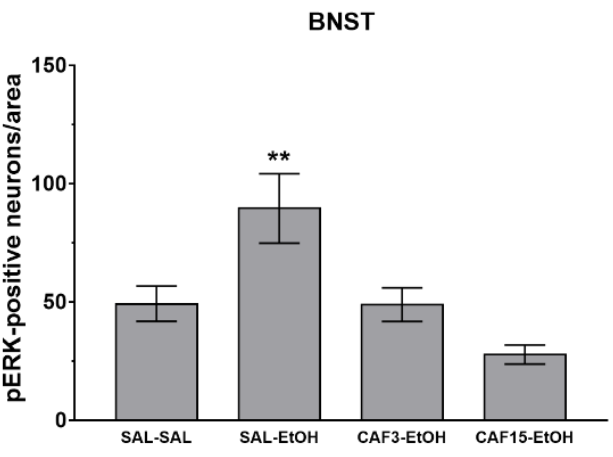

D

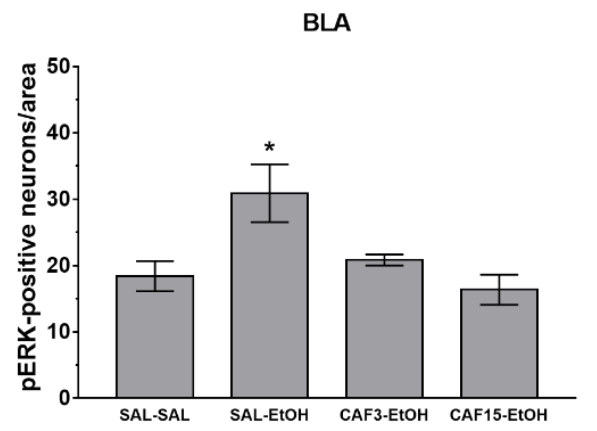

Figure 7. Effects of ethanol-elicited CPA expression on ERK phosphorylation in the Acb, BNST, CeA and BLA. Animals of each group, in a drug-free state, performed the post-conditioning test (15 min) and immediately afterwards were anesthetized and perfused for immunohistochemical analysis. Data are shown as mean \pm SEM of $p E R K$-positive neurons/area. Figures $\mathbf{Z B}$ and $\mathbf{7 C}$ : ${ }^{*}$ indicates a significant difference $(p<0.001)$ between caffeine $(0 \mathrm{mg} / \mathrm{kg})+E t O H(2 \mathrm{~g} / \mathrm{kg})$ and all other groups in BNST and CeA. Figure 7D: *indicates a significant difference $(p<0.05)$ between caffeine $(0 \mathrm{mg} / \mathrm{kg})+E t O H(2 \mathrm{~g} / \mathrm{kg})$ and all other groups in BLA.

\section{DISCUSSION}

The consequences of drug interactions have an enormous importance both for substance abuse and therapeutic practice. Depending on the substances these interactions can lead to numerous and, a priori unsuspected, problems that can occur from pharmacokinetic, pharmacodynamic, metabolic and toxicological factors. The interaction between caffeine and ethanol is no exception in this regard. Moreover, not only does this interaction involve a very large number of individuals all over the world, but it also involves the functional antagonistic effects of two substances that share a pharmacological target represented by the adenosinergic system (López-Cruz et al. 2013). The present work was designed and carried out in order to start laying a 
foundation for systematically studying the consequences of the interaction between these two broadly-used psychoactive substances, especially with specific reference to the motivational effects descending from such interaction.

In particular, the study was aimed at establishing whether the administration of caffeine at low to moderate doses that are thought to be on the borderline for altering behavior in terms of eliciting arousal (Acquas et al., 2002; De Luca et al., 2007; Hasenfratz et al., 1993) and locomotor activity (Dar 1988; López-Cruz et al. 2013) could affect the reinforcing properties of a moderate dose of ethanol $(2.0 \mathrm{~g} / \mathrm{kg})$ as measured by the place conditioning method in adult male CD-1 mice (Cunningham et al. 2006; Spina et al. 2015; Rosas et al. 2017). To this end we adopted a dual approach, currently applied in our laboratory, which involves both behavioral and biochemical determinations. For the behavioral measure we assessed spontaneous preference for a given environment in terms of place conditioning (Acquas et al. 1989; Spina et al. 2015; Rosas et al. 2017). The neurochemical measure involved the detection of pERK expression in specific brain regions involved in the affective and motivational responses to drug stimuli. Phosphorylated ERK is important to assess because it is a cellular marker related to neural plasticity and short- and long-term adaptive responses to substances of abuse (Sweatt 2001, 2004; Gerdjikov et al. 2004; Acquas et al. 2007, 2010; Ibba et al. 2009; Sun et al. 2016; Rosas et al. 2017).

Our behavioral model, which involved slight modifications of the methods introduced by Cunningham and Colleagues (Cunningham et al. 2003, 2006), had the added benefit of highlighting the fact that the same dose of the unconditioned stimulus (ethanol), can have both positive and negative motivational properties. This is useful for characterizing the opposite motivational aspects elicited by the same substance. In agreement with previous data (Cunningham \& Henderson 2000; Cunningham et al. 2002, 2003; Spina et al. 2015; Rosas et al. 2017), the results of the behavioral experiments confirmed that ethanol at the dose of $2.0 \mathrm{~g} / \mathrm{kg}$ elicits strong and significant CPP (figure 2) and CPA (figure 3). The study also reports that caffeine at either dose $(3.0$ and $15.0 \mathrm{mg} / \mathrm{kg}$ ) failed to alter the spontaneous preference of the animals as shown by the results of the post-conditioning tests of the caffeine 13.0 $\mathrm{mg} / \mathrm{kg})+\mathrm{EtOH}(0 \mathrm{~g} / \mathrm{kg})$ and caffeine $(15.0 \mathrm{mg} / \mathrm{kg})+\mathrm{EtOH}(0 \mathrm{~g} / \mathrm{kg})$ groups. Nevertheless, the combination of caffeine and ethanol administration significantly altered the 
outcome of ethanol elicited conditioning. In particular, $15.0 \mathrm{mg} / \mathrm{kg}$ caffeine significantly prevented the acquisition of ethanol-elicited CPP (figure 2), and both doses significantly prevented the acquisition of ethanol-elicited CPA (figure 3). These results appear at variance with those of the study of Hilbert and Colleagues (2013), who found that caffeine $(3.0 \mathrm{mg} / \mathrm{kg}$ ) exerted reinforcing effects in $\mathrm{C} 57 \mathrm{BL} / 6 \mathrm{~J}$ mice that were generally weaker compared to ethanol $(1.75 \mathrm{~g} / \mathrm{kg})$ and that their combination resulted in motivational properties indistinguishable from those of ethanol alone. Moreover, our results are also partly at variance with those of the study by Zuniga and Cunningham (2019), who reported that caffeine $(3.0$ or $30.0 \mathrm{mg} / \mathrm{kg}$ ) administered in combination with ethanol $(2.0 \mathrm{~g} / \mathrm{kg})$ fails to affect ethanol-elicited CPP. However, a number of significant differences may be taken into account to interpret these discrepant results. For example, the experimental design of the studies by Hilbert and Colleagues (2013) and Zuniga and Cunningham (2019) were quite different than that of the present one, including a different route of administration (single injection vs two separate injections at different times), different strains of animals (C57BL/6J or DBA/2J vs CD-1), different acquisition times (16 vs 8 conditioning sessions), different time intervals between administration of the US and exposure to the conditioning apparatus, and different numbers of post-conditioning tests. These substantial experimental differences could reasonably have led to different results. In addition, the significant CPP elicited by caffeine was observed only after test one in the study by Hilbert et al., (2013) and only after test three in the study by Zuniga and Cunningham (2019), while that for ethanol remained constant across tests (Hilbert et al. 2013; Zuniga \& Cunningham 2019), and in this regard these results overall confirmed that caffeine has weak reinforcing properties (Liu et al. 2008).

The results of our study on the whole indicate that the combination of appropriate doses of caffeine with the $2.0 \mathrm{~g} / \mathrm{kg}$ of ethanol, a dose of ethanol which was capable of exerting motivational properties, prevented the establishment of learning the CS-US association and consequently its expression. This suggests that the acute effect of ethanol, i.e. its ability to transfer motivational properties to the environment (acquisition of place conditioning), is prevented by the blockade of $A_{1}$ and/or $A_{2 A}$ adenosinergic receptors by caffeine. In other words, these data show for the first time 
that the acute administration of caffeine can interfere with the motivationally relevant conditioning effects of ethanol.

Moreover, these present results also appear at variance with those of the recent study by SanMiguel et al., (2019) reporting that low to moderate doses of caffeine actually increased ethanol intake, in particular, in moderate ethanol-consumers (on average between 10.0 to $15.0 \mathrm{~g} / \mathrm{kg} / 24$ hours) in C57BL6J mice. However, in the same study, a high dose of caffeine was indeed able to reduce high levels of ethanol intake in the drinking in the dark paradigm (SanMiguel et al. 2019).

The results of the immunohistochemical experiments revealed that, consistent with previous studies (Ibba et al. 2009), ethanol stimulated a significant increase of the number of pERK-positive neurons both in the $\mathrm{AcbC}$ and in the AcbSh, and that pretreatment with caffeine at both doses significantly reduced these effects. These results also extend to the other brain areas examined (figures $4 A-D$ ), thus providing a possible interpretative mechanism for the behavioral results illustrated in figures 2 and 3 of this work. These findings also are in agreement with the observations that the expression of this phosphorylated kinase is, in fact, increased in the Acb and in other nuclei of the extended amygdala (central nucleus of the amygdala, bed nucleus of the stria terminalis) following the administration of numerous substances with addictive properties (Valjent et al. 2004) but not following that of other psychopharmacologically active, but not addictive, substances such as caffeine itself (Valjent et al. 2004; Acquas et al. 2010).

In the present study, we also aimed to evaluate the expression of pERK in the core and shell of the Acb, and in the amygdala, after exposure to the conditioned stimulus. The results clearly demonstrate the dissociation between behavioral expression (preference shift compared to pre-test) and the brain regions showing increased expression of ERK phosphorylation in relation to the affective value acquired by the conditioned stimulus. These data also strongly support the specificity of the effects of caffeine on ethanol's ability to activate the behavior (figures 2 and 3 ) and to elicit expression of phosphorylated ERK in the AcbC, AcbSh, CeA and BLA (figure 4) after acute administration (Ibba et al. 2009).

As previously mentioned, caffeine and ethanol act in opposite directions on the adenosinergic system. Caffeine is a non-selective antagonist of the $A_{1}$ and $A_{2 A}$ 
adenosine receptors (Cauli \& Morelli 2005; Ferré et al. 2008). In contrast, ethanol increases the levels of the endogenous agonist, adenosine, through different mechanisms that include the stimulation of its release, the reduction of its reuptake through inhibition of nucleoside transporter, and the promotion of its synthesis through the increased availability of acetate, an intermediate of adenosine biosynthesis, that accumulates in the cells upon ethanol's oxidative metabolism (Nagy et al. 1990; Nagy 1992; Fredholm \& Wallman-Johansson 1996). These biochemical actions could provide the basis of the results on pERK expression in animals that received combined administration of caffeine and ethanol, and in fact it can be hypothesized that the increase in adenosine concentrations induced by ethanol is the main factor responsible of the increased stimulation of adenosine $A_{1}$ receptor activity. Adenosine $A_{1}$ and $A_{2 A}$ receptors are co-localized with dopaminergic $D_{1}$ and $D_{2}$ receptors, respectively, in several areas of the brain including the mesolimbic dopaminergic system (Fuxe et al. 2003; Nunes et al. 2013). Thus, it is possible that ethanol activates pERK expression in both subregions of Acb, and in the amygdala, through a mechanism mediated by $D_{1}$ receptors (Ibba et al. 2009). Otherwise ethanol increases alongside dopaminergic transmission in the AcbC and in the AcbSh, either after contingent (Bassareo et al. 2017) and non-contingent administration (Bassareo et al. 2003, 2019). Thus, a functional antagonism between caffeine and ethanol that is related to actions on adenosine receptors might be at least partially responsible for the behavioral interactions between these two substances seen in the present studies.

Furthermore, the data shown in Figures 6 and 7 indicate that the conditioned stimulus (environment associated with ethanol, CPP; environment assigned to ethanol, CPA) has a different impact on the phosphorylation of ERK in these brain areas. In other words, the same conditioned stimulus, but with opposite motivational properties, stimulated the phosphorylation of ERK in a differential manner in the AcbC and AcbSh. Previous evidence demonstrated that a conditioned aversive stimulus (expression of lithium-elicited CPA) (Longoni et al. 2011) was not associated with increased ERK phosphorylation in the Acb. However, pERK expression is activated in nuclei in the amygdala complex, suggesting an involvement of these areas in associative learning and reinforcement (McDonald et al. 2010; Pati et al. 2019; Wscieklica et al. 2019). Thus, the results from the experiments on the effects of conditioned stimuli on pERK 
expression appear in agreement with the role attributed to the activation of this kinase in the acquisition and expression of motivated behaviors (Gerdjikov et al. 2004; Zhai et al. 2008; Sun et al. 2016).

Overall, these results cast fresh light on a critical topic that has considerable translational significance. Future experiments need to identify and further characterize the significance of the interaction between caffeine and ethanol. 


\section{REFERENCES}

Acquas E, Carboni E, Leone P \& Di Chiara G (1989) SCH 23390 blocks drug-conditioned place-preference and place-aversion: anhedonia (lack of reward) or apathy (lack of motivation) after dopamine-receptor blockade? Psychopharmacology (Berl) 99:151-5.

Acquas E, Pisanu A, Spiga S, Plumitallo A, Zernig G \& Chiara G Di (2007) Differential effects of intravenous R,S-( \pm )-3,4- methylenedioxymethamphetamine (MDMA, Ecstasy) and its $\mathrm{S}(+)$ - and $\mathrm{R}(-)$-enantiomers on dopamine transmission and extracellular signal regulated kinase phosphorylation (pERK) in the rat nucleus accumbens shell and core. J Neurochem 102:121-132.

Acquas E, Tanda G \& Di Chiara G (2002) Differential Effects of Caffeine on Dopamine and Acetylcholine Transmission in Brain Areas of Drug-naive and Caffeinepretreated Rats. Neuropsychopharmacology 27:182-193.

Acquas E, Vinci S, Ibba F, Spiga S, De Luca MA \& Di Chiara G (2010) Role of dopamine D1 receptors in caffeine-mediated ERK phosphorylation in the rat brain. Synapse 64:341-349.

Angelucci MEM, Cesário C, Hiroi RH, Rosalen PL \& Da Cunha C (2002) Effects of caffeine on learning and memory in rats tested in the Morris water maze. Brazilian J Med Biol Res 35:1201-1208.

Bassareo V, Cucca F, Frau R \& Di Chiara G (2017) Changes in dopamine transmission in the nucleus accumbens shell and core during ethanol and sucrose selfadministration. Front Behav Neurosci 11.

Bassareo V, De Luca MA, Aresu M, Aste A, Ariu T \& Di Chiara G (2003) Differential adaptive properties of accumbens shell dopamine responses to ethanol as a drug and as a motivational stimulus. Eur J Neurosci 17:1465-72.

Bassareo V, Talani G, Frau R, Porru S, Rosas M, Kasture SB, Peana AT, Loi E, Sanna E \& Acquas E (2019) Inhibition of morphine-and ethanol-mediated stimulation of mesolimbic dopamine neurons by withania somnifera. Front Neurosci 13.

Brent Bedingfield J, King DA \& Holloway FA (1998) Cocaine and caffeine: Conditioned place preference, locomotor activity, and additivity. Pharmacol Biochem Behav 61:291-296. 
Brockwell NT, Eikelboom R \& Beninger RJ (1991) Caffeine-induced place and taste conditioning: Production of dose-dependent preference and aversion. Pharmacol Biochem Behav 38:513-517.

Cauli O \& Morelli M (2005) Caffeine and the dopaminergic system. Behav Pharmacol 16:63-77.

Cunningham CL, Clemans JM \& Fidler TL (2002) Injection timing determines whether intragastric ethanol produces conditioned place preference or aversion in mice. Pharmacol Biochem Behav 72:659-668.

Cunningham CL, Ferree NK \& Howard MA (2003) Apparatus bias and place conditioning with ethanol in mice. Psychopharmacology (Berl) 170:409-422.

Cunningham CL, Gremel CM \& Groblewski PA (2006) Drug-induced conditioned place preference and aversion in mice. Nat Protoc 1:1662-1670.

Cunningham CL \& Henderson CM (2000) Ethanol-induced conditioned place aversion in mice. Behav Pharmacol 11:591-602.

Cunningham CL, Okorn DM \& Howard CE (1997) Interstimulus interval determines whether ethanol produces conditioned place preference or aversion in mice. Anim Learn Behav 25:31-42.

Dar MS (1988) The Biphasic Effects of Centrally and Peripherally Administered Caffeine on Ethanol-induced Motor Incoordination in Mice. J Pharm Pharmacol 40:482487.

Dash PK, Moore AN, Moody MR, Treadwell R, Felix JL \& Clifton GL (2004) Post-trauma administration of caffeine plus ethanol reduces contusion volume and improves working memory in rats. J Neurotrauma 21:1573-1583.

Faccidomo S, Salling MC, Galunas C \& Hodge CW (2015) Operant ethanol selfadministration increases extracellular-signal regulated protein kinase (ERK) phosphorylation in reward-related brain regions: Selective regulation of positive reinforcement in the prefrontal cortex of C57BL/6J mice. Psychopharmacology (Berl) 232:3417-3430.

Ferré S, Ciruela F, Borycz J, Solinas M, Quarta D, Antoniou K, Quiroz C, Justinova Z, Lluis C, Franco R \& Goldberg SR (2008) Adenosine A1-A2A receptor heteromers: new targets for caffeine in the brain. Front Biosci 13:2391-9.

Font L, Aragon CMG \& Miquel M (2006) Ethanol-induced conditioned place preference, 
but not aversion, is blocked by treatment with D-penicillamine, an inactivation agent for acetaldehyde. Psychopharmacology (Berl) 184:56-64.

Fredholm BB \& Wallman-Johansson A (1996) Effects of ethanol and acetate on adenosine production in rat hippocampal slices. Pharmacol Toxicol 79:120-3.

Fuxe K, Agnati LF, Jacobsen K, Hillion J, Canals M, Torvinen M, Tinner-Staines B, Staines W, Rosin D, Terasmaa A, Popoli P, Leo G, Vergoni V, Lluis C, Ciruela F, Franco R \& Ferre S (2003) Receptor heteromerization in adenosine A2A receptor signaling: Relevance for striatal function and Parkinson's disease. Neurology 61:S19-S23.

Gerdjikov T V., Ross GM \& Beninger RJ (2004) Place preference induced by nucleus accumbens amphetamine is impaired by antagonists of ERK or p38 MAP kinases in rats. Behav Neurosci 118:740-750.

Gulick D \& Gould TJ (2009) Effects of Ethanol and Caffeine on Behavior in C57BL/6 Mice in the Plus-Maze Discriminative Avoidance Task. Behav Neurosci 123:12711278.

Hasenfratz M, Bunge A, Dal Prá G \& Bättig K (1993) Antagonistic effects of caffeine and alcohol on mental performance parameters. Pharmacol Biochem Behav 46:463465.

Hilbert MLT, May CE \& Griffin WC (2013) Conditioned Reinforcement and Locomotor Activating Effects of Caffeine and Ethanol Combinations in Mice. Pharmacol Biochem Behav 110:168-173.

Hsu CW, Chen CY, Wang CS \& Chiu TH (2009) Caffeine and a selective adenosine A2A receptor antagonist induce reward and sensitization behavior associated with increased phospho-Thr75-DARPP-32 in mice. Psychopharmacology (Berl) 204:313-325.

Ibba F, Vinci S, Spiga S, Peana AT, Assaretti AR, Spina L, Longoni R \& Acquas E (2009) Ethanol-induced extracellular signal regulated kinase: Role of dopamine D 1 receptors. Alcohol Clin Exp Res 33:858-867.

Koob GF, Sanna PP \& Bloom FE (1998) Neuroscience of addiction. Neuron 21:467-76.

Koob GF \& Volkow ND (2009) Neurocircuitry of Addiction. Neuropsychopharmacology 35:217-238.

Kristjansson AL, Mann MJ, Sigfusdottir ID \& James JE (2015) Mode of daily caffeine consumption among adolescents and the practice of mixing alcohol with energy 
drinks: Relationships to drunkenness. J Stud Alcohol Drugs 76:397-405.

Kunin D, Gaskin S, Rogan F, Smith BR \& Amit Z (2000) Caffeine promotes ethanol drinking in rats. Examination using a limited-access free choice paradigm. Alcohol 21:271-7.

Lalanne L, Lutz PE \& Paille F (2017) Acute impact of caffeinated alcoholic beverages on cognition: A systematic review. Prog Neuro-Psychopharmacology Biol Psychiatry 76:188-194.

Liu Y, Le Foll B, Liu Y, Wang X \& Lu L (2008) Conditioned Place Preference Induced by Licit Drugs: Establishment, Extinction, and Reinstatement. Sci World J 8:12281245.

Longoni R, Spina L \& Vinci S (2011) The MEK inhibitor SL327 blocks acquisition but not expression of lithium-induced conditioned place aversion: a behavioral and immunohistochemical study. Psychopharmacology (Berl):63-73.

López-Cruz L, Salamone JD \& Correa M (2013) The Impact of Caffeine on the Behavioral Effects of Ethanol Related to Abuse and Addiction: A Review of Animal Studies. J Caffeine Res 3:9-21.

López-cruz L, San-miguel N, Bayarri P, Baqi Y, Müller CE, Salamone JD \& Correa M (2016) Ethanol and Caffeine Effects on Social Interaction and Recognition in Mice : Involvement of Adenosine A 2A and A 1 Receptors. 10:1-15.

Lorrai I, Contini A, Gessa GL, Mugnaini C, Corelli F, Colombo G \& Maccioni P (2019) Operant, oral alcohol self-administration: Sex differences in Sardinian alcoholpreferring rats. Alcohol 79:147-162.

Lu L, Koya E, Zhai H, Hope BT \& Shaham Y (2006) Role of ERK in cocaine addiction. Trends Neurosci 29:695-703.

Marczinski CA (2011) Alcohol mixed with energy drinks: consumption patterns and motivations for use in U.S. college students. Int J Environ Res Public Health 8:3232-45.

Marczinski CA \& Fillmore MT (2014) Energy drinks mixed with alcohol: what are the risks? Nutr Rev 72 Suppl 1:98-107.

McDonald RJ, Yim TT, Lehmann H, Sparks FT, Zelinski EL, Sutherland RJ \& Hong NS (2010) Expression of a conditioned place preference or spatial navigation task following muscimol-induced inactivations of the amygdala or dorsal 
hippocampus: A double dissociation in the retrograde direction. Brain Res Bull 83:29-37.

Nagy LE (1992) Ethanol metabolism and inhibition of nucleoside uptake lead to increased extracellular adenosine in hepatocytes. Am J Physiol Physiol 262:C1175C1180.

Nagy LE, Diamond I, Casso DJ, Franklin C \& Gordon AS (1990) Ethanol increases extracellular adenosine by inhibiting adenosine uptake via the nucleoside transporter. J Biol Chem 265:1946-51.

Nunes EJ, Randall PA, Hart EE, Freeland C, Yohn SE, Baqi Y, Muller CE, Lopez-Cruz L, Correa M \& Salamone JD (2013) Effort-Related Motivational Effects of the VMAT2 Inhibitor Tetrabenazine: Implications for Animal Models of the Motivational Symptoms of Depression. J Neurosci 33:19120-19130.

Okhuarobo A, Igbe I, Yahaya A \& Sule Z (2019) Effect of caffeine on alcohol consumption and alcohol-induced conditioned place preference in rodents. $J$ Basic Clin Physiol Pharmacol 30:19-28.

Pati D, Pina MM \& Kash TL (2019) Ethanol-induced conditioned place preference and aversion differentially alter plasticity in the bed nucleus of stria terminalis. Neuropsychopharmacology 0:1-12.

Patkina NA \& Zvartau EE (1998) Caffeine place conditioning in rats: Comparison with cocaine and ethanol. Eur Neuropsychopharmacol 8:287-291.

Peacock A, Cash C \& Bruno R (2015) Cognitive impairment following consumption of alcohol with and without energy drinks. Alcohol Clin Exp Res 39:733-742.

Peana AT, Muggironi G, Spina L, Rosas M, Kasture SB, Cotti E \& Acquas E (2014) Effects of Withania somnifera on oral ethanol self-administration in rats. Behav Pharmacol 25:618-628.

Reissig CJ, Strain EC \& Griffiths RR (2009) Caffeinated energy drinks--a growing problem. Drug Alcohol Depend 99:1-10.

Rosas M, Porru S, Longoni R, Spina L, Peana AT, Collu M \& Acquas E (2017) Differential effects of the MEK inhibitor SL327 on the acquisition and expression of ethanolelicited conditioned place preference and aversion in mice. J Psychopharmacol 31:105-114.

Salzmann J, Marie-Claire C, Le Guen S, Roques BP \& Noble F (2003) Importance of ERK 
activation in behavioral and biochemical effects induced by MDMA in mice. $\mathrm{Br} \mathrm{J}$ Pharmacol 140:831-838.

SanMiguel N, López-Cruz L, Müller CE, Salaemone JD \& Correa M (2019) Caffeine modulates voluntary alcohol intake in mice depending on the access conditions: Involvement of adenosine receptors and the role of individual differences. Pharmacol Biochem Behav 186:172789.

Scholey AB \& Kennedy DO (2004) Cognitive and physiological effects of an 'energy drink': an evaluation of the whole drink and of glucose, caffeine and herbal flavouring fractions. Psychopharmacology (Berl) 176:320-30.

Spanos M, Besheer J \& Hodge CW (2012) Increased sensitivity to alcohol induced changes in ERK Map kinase phosphorylation and memory disruption in adolescent as compared to adult C57BL/6J mice. Behav Brain Res 230:158-166.

Spina L, Longoni R, Rosas M, Collu M, Peana AT, Espa E, Kasture S, Cotti E \& Acquas E (2015) Withania somnifera Dunal (Indian ginseng) impairs acquisition and expression of ethanol-elicited conditioned place preference and conditioned place aversion. J Psychopharmacol 29:1191-1199.

Spina L, Longoni R, Vinci S, Ibba F, Peana AT, Muggironi G, Spiga S \& Acquas E (2010) Role of dopamine D 1 receptors and extracellular signal regulated kinase in the motivational properties of acetaldehyde as assessed by place preference conditioning. Alcohol Clin Exp Res 34:607-616.

Spinetta MJ, Woodlee MT, Feinberg LM, Stroud C, Schallert K, Cormack LK \& Schallert T (2008) Alcohol-induced retrograde memory impairment in rats: Prevention by caffeine. Psychopharmacology (Berl) 201:361-371.

Sun W, Quizon PM \& Zhu J (2016) Molecular Mechanism: ERK Signaling , Drug Addiction, and Behavioral Effects Molecular Mechanism : ERK Signaling, Drug Addiction, and Behavioral Effects. Prog Mol Biol Sci 137.

Sweatt JD (2004) Mitogen-activated protein kinases in synaptic plasticity and memory. Curr Opin Neurobiol:311-317.

Sweatt JD (2001) The neuronal MAP kinase cascade : a biochemical signal integration system subserving synaptic plasticity and memory. J Neurochem 76:1-10.

Valjent E, Caboche J \& Vanhoutte P (2001) Mitogen-Activated Protein Kinase / Extracellular Signal-Regulated Kinase Induced Gene Regulation in Brain. Mol 
Neurobiol 23:83-99.

Valjent E, Corvol J, Page C, Besson M, Maldonado R, Curie M, Neurofarmacologia L De \& De F (2000) Involvement of the Extracellular Signal-Regulated Kinase Cascade for Cocaine-Rewarding Properties. J Neurosci 20:8701-8709.

Valjent E, Pagès C, Hervé D, Girault JA \& Caboche J (2004) Addictive and non-addictive drugs induce distinct and specific patterns of ERK activation in mouse brain. Eur J Neurosci 19:1826-1836.

Valjent E, Pascoli V, Corvol J, Svenningsson P, Paul S, Stipanovich A, Caboche J, Lombroso PJ, Nairn AC, Greengard P, Herve D \& Girault J (2005) Regulation of a protein phosphatase cascade allows convergent dopamine and glutamate signals to activate ERK in the striatum. PNAS 102:491-496.

Weitzman ER, Nelson TF \& Wechsler H (2003) Taking up binge drinking in college: The influences of person, social group, and environment. J Adolesc Heal 32:26-35.

Wetherill RR \& Fromme K (2016) Alcohol-Induced Blackouts: A Review of Recent Clinical Research with Practical Implications and Recommendations for Future Studies. Alcohol Clin Exp Res 40:922-935.

Wscieklica T, Le Sueur-Maluf L, Prearo L, Conte R, Viana M de B \& Céspedes IC (2019) Chronic intermittent ethanol administration differentially alters DeltaFosB immunoreactivity in cortical-limbic structures of rats with high and low alcohol preference. Am J Drug Alcohol Abuse 45:264-275.

Zhai H, Li Y, Wang X \& Lu L (2008) Drug-induced alterations in the extracellular signalregulated kinase (ERK) signalling pathway: implications for reinforcement and reinstatement. Cell Mol Neurobiol 28:157-72.

Zuniga A \& Cunningham CL (2019) Rewarding and aversive doses of caffeine alter activity but not conditioned place preference induced by ethanol in DBA/2J mice. Pharmacol Biochem Behav 187:172799. 


\section{Experimental Studies Chapter 3}





\section{CHAPTER 3: Impact of caffeine on ethanol induced sensitization: relation to dopamine metabotropic changes in ERK and DARPP-32}

\section{ABSTRACT}

In recreational contexts, caffeine is frequently consumed with ethanol to reduce psychomotor slowing, sedation and coordination induced by this drug of abuse. Both drugs modulate dopamine and adenosine receptors, which are co-localized in nucleus accumbens $(A c b)$, an area that regulates behavioral activation.

To determine if caffeine can reverse these ethanol-induced impairments we evaluated in adult male CD-1 mice novelty-induced exploration in an open field. Acute effects of caffeine $(7.5,15$ and $30 \mathrm{mg} / \mathrm{kg})$ were evaluated on horizontal and vertical exploration (locomotion and supported rearing) as well as rearing non-supported by the wall (a measure of incoordination) modulated by acute or repeated administration of ethanol $(1.5 \mathrm{~g} / \mathrm{kg})$. Phosphorylation of markers dependent on dopamine receptor activation were evaluated (increases in pERK and PDARPP-32(Thr75) related to $D_{1}$ and $D_{2}$ receptor activation, respectively) in Acb.

Acutely, ethanol decreased both types of rearing. Caffeine increased only supported rearing and also reversed ethanol-reduction in supported rearing. Both substances increased locomotion in a biphasic manner, and caffeine potentiated ethanol-induced locomotion. Ethanol administered repeatedly produced locomotion and supported rearing sensitization. However, caffeine administered acutely to those mice on an ethanol-free state, showed blunted stimulating effects compared to ethanol naïve mice. Finally, acute administration of ethanol increased pERK immunoreactivity in Acb, but co-administration with caffeine suppressed that increase. There were no effects on pDARPP-32(Thr75).

Caffeine potentiates stimulation and reduces acute ethanol effects on suppression of vertical exploration, but cannot reverse its incoordinating effects. In ethanolexperienced mice caffeine has a blunted or even impairing effect on horizontal and vertical exploration. Caffeine blocks dopaminergic $D_{1}$ receptor-dependent markers induced by ethanol in Acb. 


\section{INTRODUCTION}

Caffeine is a substance commonly used for its known psychostimulant properties (Temple et al. 2017). Preferentially in form of beverages, contained in tea, coffee or more recently in popular drinks rich in caffeine called "energy drinks", it is taken daily with the aim of improving cognitive and physical performance. A large number of studies in humans have highlighted its beneficial effects in terms of fatigue reduction, increase alertness and energy (Astorino \& Roberson 2010; Duncan et al. 2012, 2013; Smirmaul et al. 2017). Moreover, its use in association with ethanol has, in the last decades, become widespread in order to counteract the sedative effects and the locomotor impairment of high, intoxicating, doses of ethanol (Hasenfratz et al. 1993; Drake et al. 2003; Attwood et al. 2012). In animal studies, it has been shown that the administration of caffeine and ethanol affects in different manners behavioral stimulation evaluated as locomotion. In rodents, both ethanol and caffeine are able to stimulate or inhibit the motor activity in a dose dependent manner, typically with bellshaped (or inverted-U) dose-response functions (Correa et al. 2001a; Hilbert et al. 2013; López-Cruz et al. 2013). However, the long-term risks of repeated exposure to ethanol in interaction with caffeine are not yet well investigated. In animal models, the repeated administration of a stimulant substance may produce sensitization, measured as a progressive increase in locomotion (Steketee \& Kalivas 2011). It has been also described cross-sensitization when a new drug shows potentiated stimulating effects in subjects that show sensitization to another drug, for example among ethanol and cocaine in rats (Xu \& Kang 2017). Moreover, caffeine induces locomotor sensitization as well as cross-sensitization with other substances such as amphetamine and nicotine (Celik et al. 2006). Recently it has been reported the repeated intragastric coadministration of ethanol and caffeine induced significantly greater locomotor sensitization than the drugs alone (May et al. 2015). However, cross-sensitization between both drugs has not been assessed.

Sensitization in locomotor exploration is related to the motivational properties of drugs of abuse (Robinson \& Berridge 2000), such as the regulation of locomotion, behavioral activation, and processes such as incentive salience and vigor involved in goal directed responses, all of then regulated by the mesolimbic system; dopaminergic 
neurons that project from ventral tegmental area to the nucleus accumbens (Acb) (Robinson \& Berridge 2000; Salamone et al. 2016). Sensitization process may be considered as a drug-dependent behavioral plasticity that can lead to greater vulnerability to the development of addiction (Ferreira et al. 2013). Ethanol and caffeine act on the dopaminergic system via different mechanisms: ethanol preferentially increases the firing of dopaminergic neurons in the ventral tegmental area leading to an increase in dopamine (DA) transmission in Acb (Gessa et al. 1985; Di Chiara \& Imperato 1988; Carboni et al. 2000) while caffeine causes an increase of extracellular DA in prefrontal cortex, but not in Acb (Acquas et al. 2002, 2010). The two drugs act on the adenosinergic system; ethanol increases endogenous adenosine (López-Cruz et al. 2014), while caffeine is an antagonist of adenosine receptors (Ferré 2008). Adenosine $A_{1}$ and $A_{2 A}$ receptor subtypes, are highly expressed in brain areas rich in DA such as Acb (Ferré 2008; Nunes et al. 2013). In particular $A_{2 A}$ receptors and dopaminergic $D_{2}$ receptors are co-localized on encephalin-positive neurons, whereas adenosine $A_{1}$ are co-localized with DA $D_{1}$ receptors on substance P-positive neurons (Ferré et al. 2008). Adenosinergic and dopaminergic receptors converge on common mechanisms, showing opposite effects on metabotropic intracellular cascades (Agnati et al. 2003; Fuxe et al. 2003; Ferré 2008), such as Dopamine- and cAMP-regulated phosphoprotein Mr 32 kDa phosphorylated at the Threonine75 (Thr-75) site (pDARPP32-Thr75), which is associated with activation of $D^{A} D_{2}$ receptors (Svenningsson et al. 1999; Nunes et al. 2013). Their interaction can be studied also on the expression of biochemical parameters related to DA receptor activation such as Extracellular signalregulated kinase (ERK), protein-kinase important for long-term synaptic plasticity (Valjent et al. 2005).

Given these premises, the present experiments were developed with the purpose to determine the effects of acute administration of caffeine $(7.5,15$ or $30 \mathrm{mg} / \mathrm{kg})$, ethanol $(1.5,2.5$ or $3.5 \mathrm{~g} / \mathrm{kg})$ and their interaction on different indicators of novelty induced behavioral activation and exploration measured in an open field apparatus. In addition, we also studied if an acute administration of caffeine at different doses (15 and 30 $\mathrm{mg} / \mathrm{kg}$ ) can reverse the motor sensitization elicited by repeated administration of ethanol $(1.5 \mathrm{~g} / \mathrm{kg})$. Furthermore, we assessed the effects of an acute challenge with 
caffeine on ethanol-elicited pERK and pDARPP-32(Thr75) immunoreactivity in Acb core (AcbC) and shell (AcbSh), as a measure of neuronal markers of DA and adenosine receptor activation.

\section{MATERIALS AND METHODS}

\section{Animals}

Adult male CD-1 mice ( $n=277$ ) (30-40 g, Janvier, France S.A.) were 8-10 weeks old at the beginning of the study. Mice were housed in groups of three or four per cage, with standard laboratory rodent chow and tap water available ad libitum. The colony was

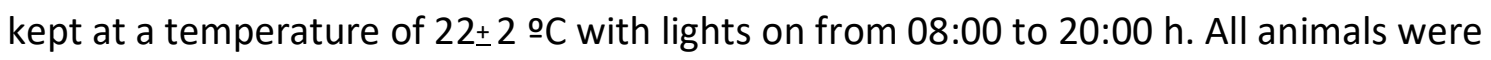
under a protocol approved by the Institutional Animal Care and Use committee of Universitat Jaume I. All experimental procedures complied with directive 2010/63/EU of the European Parliament and of the Council, and with the "Guidelines for the Care and Use of Mammals in Neuroscience and Behavioral Research", National Research Council 2003, USA. All efforts were made to minimize animal suffering and to reduce the number of animals used.

\section{Drugs}

Ethanol (Panreac Quimica S.A., Spain) 20\% (v/v) in isotonic saline $(0.9 \% \mathrm{w} / \mathrm{v})$ was administered intraperitoneally (IP) 10 minutes (min) before testing. Caffeine (SigmaAldrich, Spain) was dissolved in $0.9 \% \mathrm{w} / \mathrm{v}$ saline and administered IP $30 \mathrm{~min}$ before testing. Saline solution was used as vehicle. Doses and time leads were chosen based on previous studies (Correa et al. 2004; López-Cruz et al. 2016).

\section{Apparatus and testing procedures}

\section{Open Field (OF)}

The OF apparatus consists of a clear glass cylinder $25 \mathrm{~cm}$ in diameter and $30 \mathrm{~cm}$ high previously used to observe the effects of ethanol on spontaneous locomotion and locomotor sensitization (Correa et al. 2004). The floor of the cylinder was divided into four equal quadrants by two intersecting lines drawn on the floor. Animals were placed in the center of the cylinder and immediately observed for $10 \mathrm{~min}$. The behavioral test room was illuminated with a soft light, and external noise was attenuated. Horizontal and 
vertical locomotion in the OF were simultaneously recorded and registered manually. For horizontal locomotion, an activity count was registered each time the animal crossed from one quadrant to another with all four legs. A count of vertical locomotion was registered each time the animal raised its forepaws in the air higher than its back (unsupported rear) or rested them on the wall (supported rear).

\section{Blood ethanol determinations}

Additional mice were used to determine whether caffeine influenced blood ethanol levels at the high doses and times used in the behavioral studies. For that purpose, animals were injected with caffeine ( 0 or $30 \mathrm{mg} / \mathrm{kg}$ ) and with ethanol (1.5 or $2.5 \mathrm{~g} / \mathrm{kg}$ ). Trunk blood samples $(20 \mu \mathrm{l})$ were collected 10 and $20 \mathrm{~min}$ after ethanol and caffeine administration respectively. Following Boehm et al. (2000), each blood sample was immediately placed in a microcentrifuge tube containing $50 \mu \mathrm{l}$ of ice-cold $5 \% \mathrm{ZnSO}_{4}$ solution. A $50-\mu \mathrm{l}$ aliquot of $0.3 \mathrm{~N} \mathrm{Ba}(\mathrm{OH})_{2}$ and $300 \mu \mathrm{l}$ of deionized water was added. After centrifugation at $4^{\circ} \mathrm{C}(5 \mathrm{~min}, 12,000 \mathrm{rpm})$, the supernatant was removed and blood ethanol concentrations were determined by headspace gas chromatography with a flame-ionized detector (CE Instruments GC 8000, HS 850).

\section{pERK immunohistochemistry}

Mice were anesthetized with carbon dioxide for $30 \mathrm{~s}$ and perfused $15 \mathrm{~min}$ after the last treatment. The time interval between ethanol administration and anesthesia was selected on the basis of the time of the peak effect on DA transmission (Melis et al. 2007; Ibba et al. 2009). Brains were collected and stored in paraformaldehyde solution $3.7 \%$ during $24 \mathrm{~h}$ and refrigerated in sucrose (30\%), sodium azide (2\%) and phosphate buffer PB $(0.1 \mathrm{M})$ solution prior to slicing. Free floating coronal sections $(40 \mu \mathrm{m})$ were serially cut using a microtome cryostat (Weymouth, MA, USA) according to plates 21-23 (approximately from AP 1.18 to AP $0.98 \mathrm{~mm}$ from bregma for the nucleus accumbens core and shell) of the mouse brain atlas (Paxinos \& Franklin 2001). After rinsing in $0.01 \mathrm{M}$ $0.01 \mathrm{M}$ phosphate buffer saline (PBS) ( $\mathrm{pH} \mathrm{7.4)} \mathrm{(3} \mathrm{times} \mathrm{for} 10 \mathrm{~min}$ ) and incubating for 30 min with $1 \%$ hydrogen peroxide and after three rinses of 30 min each one, the slices were incubated for $1 \mathrm{hr}$ with $0.1 \%$ Triton X-100 (T.X) in TBS and 3\% Bovine Albumin serum (BSA). The incubation with the primary anti-pERK antibody (phosphorylated ERK, Cell 
Signaling Technology, Beverly, MA, USA) at 1:350 was conducted overnight at $4^{\circ} \mathrm{C}$. On the following day, after rinsing, the slices were incubated with the second antibody, the antirabbit HRP conjugate envision plus (DAKO) for $1.5 \mathrm{~h}$ on a rotating shaker at room temperature. Finally, sections were washed and rinsed for 1-3 $\min$ in 3,3diaminobenzidine chromagen (DAKO).

\section{pDARPP-32(Thr75) immunohistochemistry}

Other brain slices obtained from the same animals used for pERK immunohistochemistry were processed for pDARPP-32(Thr75) immunoreaction. Brain slices were rinsed in 0.01 M PBS ( $\mathrm{pH} 7.4$ ) and incubated in $1 \%$ hydrogen peroxide for 30 min to block endogenous staining. Sections were then rinsed in 0.01 M PBS ( $\mathrm{pH}$ 7.4) (3 times for $5 \mathrm{~min}$ ). To measure the immunoreactivity to pDARPP-32 nonspecific binding sites were blocked, and cells were permeabilized in a solution containing 0.1\% T.X and 3\% BSA in PBS for $1 \mathrm{~h}$ at room temperature on a rotating platform before primary antibody incubation. pDARPP-32 immunoreactivity was visualized with a polyclonal rabbit antibody for pDARPP-32 phosphorylated at the threonine 75 residue (pDARPP32-Thr75, 1:500; Cell Signaling Technology, Beverly, MA, USA). The antibody was dissolved in solutions that also contained $3 \% \mathrm{BSA}$ and $0.1 \%$ T.X in PBS for $24 \mathrm{~h}$ incubation at $4^{\circ} \mathrm{C}$. After the primary antibody treatment, the sections were rinsed in PBS (3 times for $5 \mathrm{~min}$ ) and incubated in the secondary antibody, anti-rabbit HRP conjugate envision plus (DAKO) for $1.5 \mathrm{~h}$ on a rotating shaker at room temperature. Finally, sections were washed and rinsed for 1-3 min in 3,3-diaminobenzidine chromagen (DAKO).

\section{Image analysis}

Processed brain sections were mounted to microscope slides (Menzel-Gläser, Superfrost ${ }^{\circledR}$ Plus, Thermo scientific), air dried, processed through alcohol-xylene and cover-slipped using Eukitt ${ }^{\circledR}$ (Sigma AldrichMerck KGaA) as a mounting medium. The sections were examined and photographed using a Nikon Eclipse E600 (Melville, NY, USA) upright microscope equipped with an Insight Spot digital camera (Diagnostic Instruments, Inc). Images of the regions of interest were magnified at 20X and captured digitally using Stereo Investigator software. Cells were quantified with ImageJ software (v. 1.42, 
National Institutes of Health sponsored image analysis program) in three sections per animal, and the average value per $\mathrm{mm}^{2}$ was used for statistical analysis.

\section{Statistical analysis}

One-way analysis of variance (ANOVA) was used to analyze the effect of drug administration on the different dependent variables; horizontal and vertical supported and unsupported locomotion. Two-way factorial ANOVA was used for the interaction studies. When the overall ANOVA was significant, non-orthogonal planned comparisons using the overall error term were used to compare each treatment with the control group (Keppel 1991). For these comparisons, a level was kept at 0.05 alpha because the number of comparisons was restricted to the number of treatments minus one. A probability level of 0.05 or smaller was used to indicate statistical significance. Statistics were done using STATISTICA 8 (StatSoft Inc., Tulsa (OK), USA) software.

\section{RESULTS}

\section{Effects of acute administration of caffeine on locomotion}

Figure 1 shows the effects of caffeine $(0.0,7.5,15.0$ or $30.0 \mathrm{mg} / \mathrm{kg}$ ) administered $30 \mathrm{~min}$ before OF test $(n=38)$. One way-ANOVA showed an overall effect of caffeine on horizontal crosses $\left(F_{3,30}=4.06, p<0.05\right)$, as well as on supported rear $\left[F_{3,30}=3.48, p<0.05\right]$. Planned comparisons revealed that caffeine at low and moderate doses $(7.5$ and $15 \mathrm{mg} / \mathrm{kg}$ ) significantly increased horizontal locomotion ( $p<0.05$ and $p<0.01$, respectively) (Fig 1A). These doses of caffeine also produced significant increases in the number of supported rears $(p<0.05)$ (Fig 1B). No significant effect of caffeine treatment on unsupported rear was observed $\left[\mathrm{F}_{3,30}=0.45, \mathrm{NS}\right]$ (Fig $\left.1 \mathrm{C}\right)$.

\section{Effects of acute administration of ethanol on locomotion}

Figure 2 shows the effects of ethanol $(0.0,1.5,2.5$ or $3.5 \mathrm{~g} / \mathrm{kg}$ ) administered $10 \mathrm{~min}$ before OF test $(n=40)$. One-way ANOVA revealed an overall effect of ethanol treatment on horizontal crosses $\left[F_{3,39}=3.75, p<0.05\right]$, supported rear $\left[F_{3,39}=24.11, p<0.01\right]$, and unsupported rear $\left[\mathrm{F}_{3,39}=19.13, \mathrm{p}<0.01\right]$. Planned comparisons showed that ethanol significantly increased horizontal crosses at the dose of $2.5 \mathrm{~g} / \mathrm{kg}(\mathrm{p}<0.05)$ (Fig 2A). Supported rear was decreased by the highest doses of ethanol $(2.5$ and $3.5 \mathrm{~g} / \mathrm{kg}$, 
$p<0.01)$ (Fig 2B). All ethanol doses significantly decreased unsupported rear $(p<0.01)$

(Fig 2C).

A

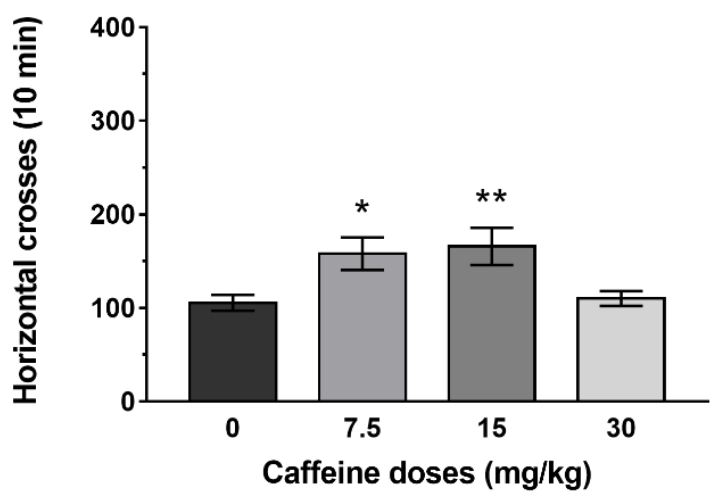

B

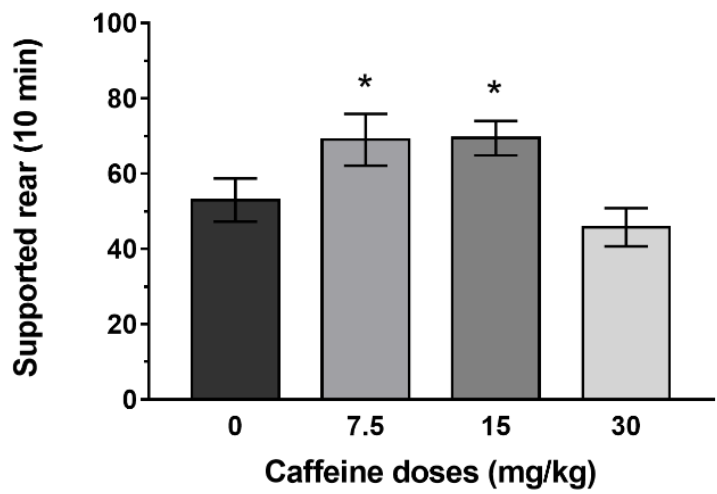

C

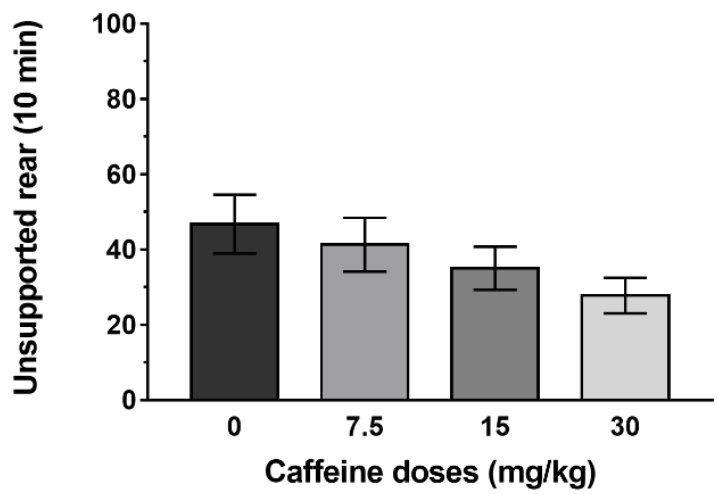

Figure 1. Effects of acute administration of caffeine $(0,7.5,15$ or $30 \mathrm{mg} / \mathrm{kg})$ on horizontal locomotion (A), supported rear (B), and unsupported rear (C) in the OF. Data are expressed as mean ( \pm SEM) number of counts during 10 minutes. ${ }^{* *} p<0.01,{ }^{*} p<0.05$ significantly different from vehicle (caffeine 0 $\mathrm{mg} / \mathrm{kg}$ ) control group. 
A

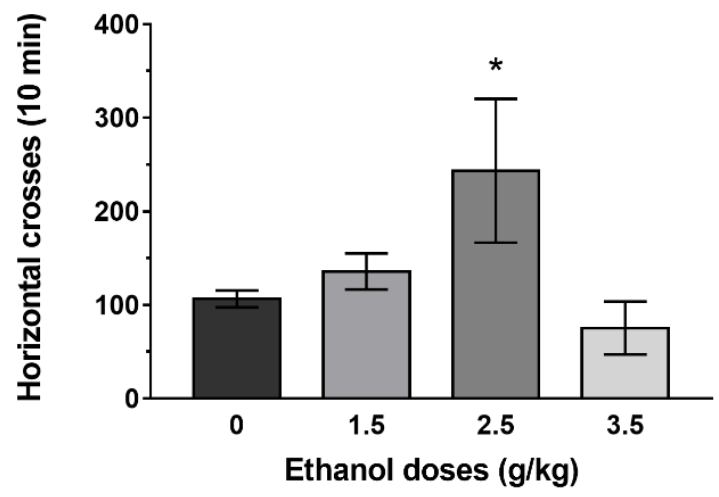

B

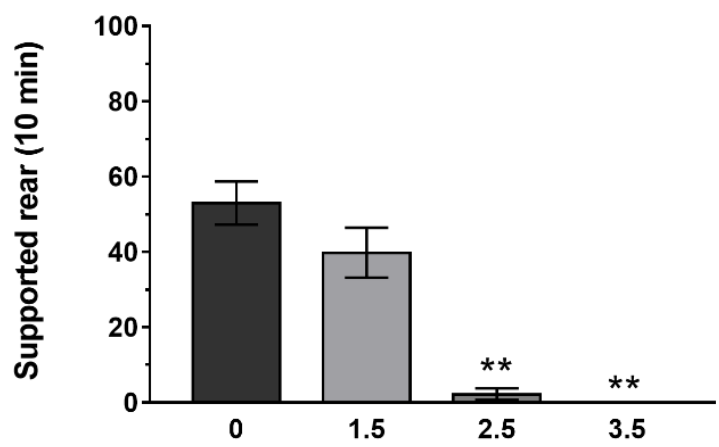

Ethanol doses $(\mathbf{g} / \mathbf{k g})$

C

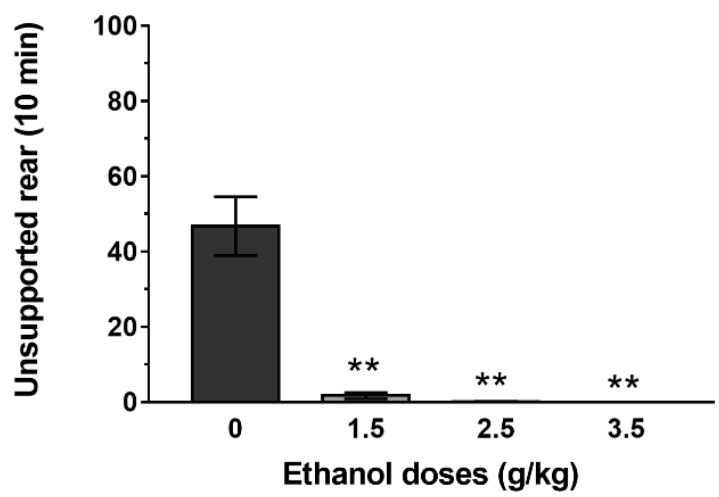

Figure 2. Effects of acute administration of ethanol $(0,1.5,2.5$ or $3.5 \mathrm{~g} / \mathrm{kg})$ on horizontal locomotion (A), supported rear (B), and unsupported rear (C) in the OF. Data are expressed as mean ( \pm SEM) number of counts during 10 minutes. ${ }^{* *} p<0.01,{ }^{*} p<0.05$ significantly different from vehicle (ethanol 0 $\mathrm{g} / \mathrm{kg}$ ) control group. 


\section{Effects of acute administration of caffeine and ethanol on locomotion}

Figure 3 shows the effects of caffeine $(0,15$ or $30 \mathrm{mg} / \mathrm{kg})$ and ethanol $(0.0,1.5,2.5$ or 3.5 $\mathrm{g} / \mathrm{kg}$ ) combination in mice $(\mathrm{n}=115)$ evaluated in the OF. Factorial ANOVA (Caffeine $\mathrm{x}$ Ethanol) showed an overall effect of caffeine $\left[F_{2,112}=11.18, p<0.01\right]$, ethanol $\left[F_{3,112}=59.35\right.$, $p<0.01]$ and caffeine-ethanol interaction $\left[F_{6,112}=6.64, p<0.01\right]$ on horizontal crosses in the OF. Planned comparisons revealed that in caffeine $30 \mathrm{mg} / \mathrm{kg}$ treated mice, ethanol 1.5 $\mathrm{g} / \mathrm{kg}$ produced a significant increase in locomotion compared to caffeine $(0 \mathrm{mg} / \mathrm{kg})+$ ethanol $(1.5 \mathrm{~g} / \mathrm{kg})$ treated mice $(\mathrm{p}<0.05)$. In addition, caffeine $(15$ and $30 \mathrm{mg} / \mathrm{kg})+$ ethanol $(2.5 \mathrm{~g} / \mathrm{kg})$ groups were significantly different from caffeine $(0 \mathrm{mg} / \mathrm{kg})+$ ethanol $(2.5 \mathrm{~g} / \mathrm{kg})$ treated mice $(p<0.01)$. Moreover, caffeine $(0 \mathrm{mg} / \mathrm{kg})+$ ethanol $(2.5 \mathrm{~g} / \mathrm{kg})$ was significantly different compared to vehicle control group $(p<0.01)$ (Fig $3 A$ ). The factorial ANOVA (Caffeine $x$ Ethanol) for the variable supported rear, as a measure of vertical locomotion, also showed an overall effect of caffeine $\left[F_{2,112}=3.81, p<0.05\right]$, ethanol $\left[F_{3,112}=62.26\right.$, $p<0.01]$ and their interaction $\left[F_{6,112}=2.29, p<0.05\right]$. Planned comparisons showed that in vehicle treated group, caffeine $15 \mathrm{mg} / \mathrm{kg}$ increased supported rear compared to control $(p<0.01)$. Among ethanol $1.5 \mathrm{~g} / \mathrm{kg}$ treated mice, both caffeine $(15$ and $30 \mathrm{mg} / \mathrm{kg})$ treated groups increased supported rearing compared to caffeine $(0 \mathrm{mg} / \mathrm{kg})+$ ethanol $(1.5 \mathrm{~g} / \mathrm{kg})$ group $(p<0.01)$ In addition, caffeine $(0 \mathrm{mg} / \mathrm{kg})$ + ethanol $(2.5$ and $3.5 \mathrm{~g} / \mathrm{kg}$ ) groups were significantly different from vehicle control group ( $<<0.01$ ) (Fig 3B). Finally, the factorial ANOVA (Caffeine $x$ Ethanol) for unsupported rear (Fig 3C) showed a significant effect of ethanol treatment $\left[\mathrm{F}_{3,112}=66.89, \mathrm{p}<0.01\right]$. However, there was no significant effect of caffeine $\left[F_{2,112}=0.94, N S\right]$, and no significant interaction $\left[F_{6,112}=0.83, N S\right]$.

\section{Effects of caffeine administration on blood ethanol levels}

Additional mice $(n=24)$ were used to determine whether caffeine influenced bloodethanol levels after motor stimulating doses. Animals received caffeine ( 0 or $30 \mathrm{mg} / \mathrm{kg}$ ) and 20 min later ethanol (1.5 or $2.5 \mathrm{~g} / \mathrm{kg}$ ) was administered. Two-way factorial ANOVA (Ethanol $x$ Caffeine) showed a significant effect of ethanol $\left[F_{1,25}=326.82, p<0.01\right]$, but no

significant effect of caffeine $\left[F_{1,25}=0.31, N S\right]$, nor of the interaction $\left[F_{1,25}=3.39, N S\right]$. These data suggest that the observed behavioral effects of ethanol co-administered with caffeine are not due to changes in blood ethanol concentration. 
A

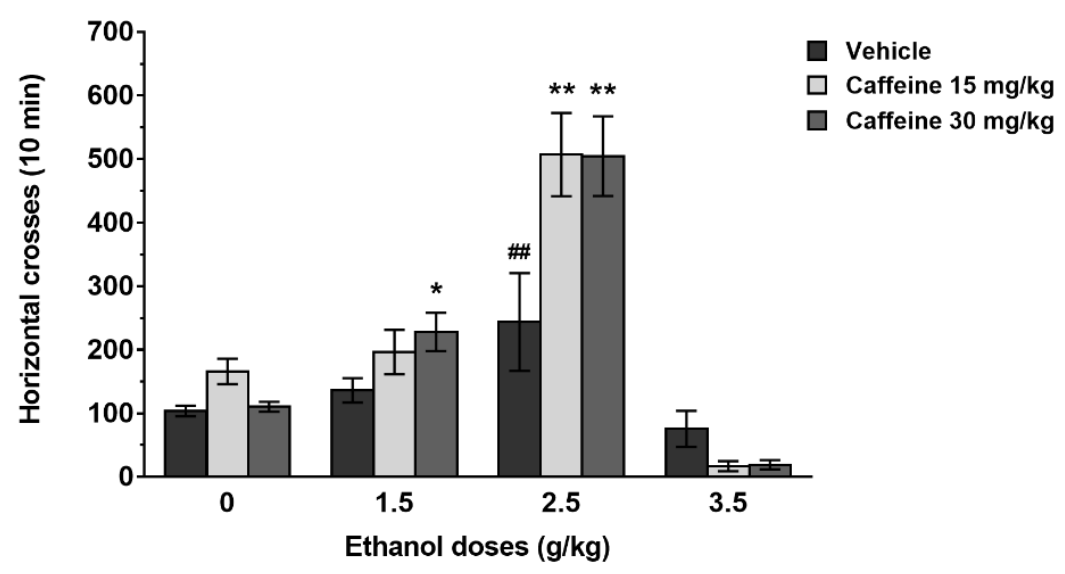

B

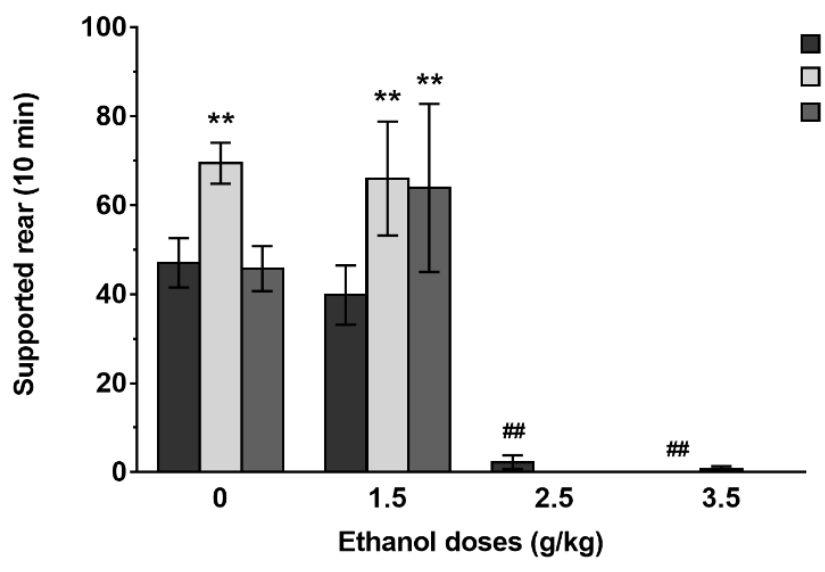

C

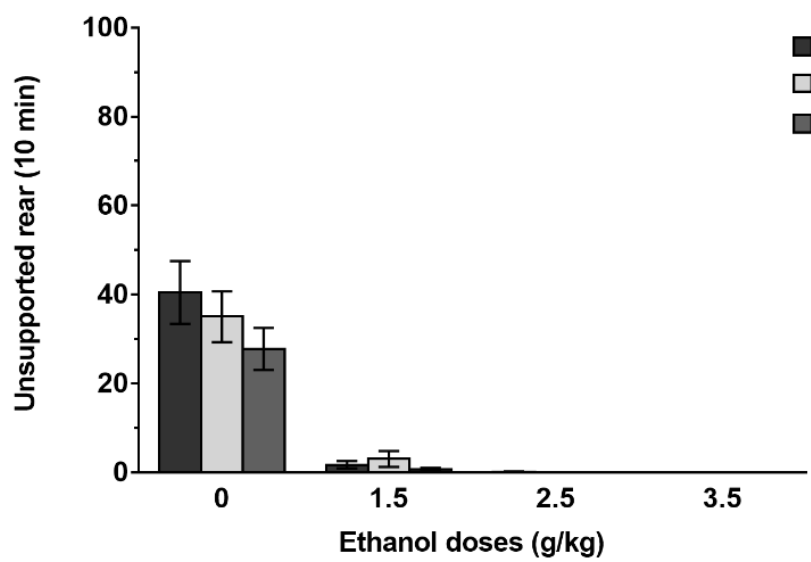

Figure 3. Effects of acute co-administration of caffeine $(0,15$ or $30 \mathrm{mg} / \mathrm{kg})$ and ethanol $(0,1.5,2.5$ or $3.5 \mathrm{~g} / \mathrm{kg}$ ) on horizontal locomotion (A), supported rear (B), and unsupported rear (C) in the OF. Mean ( \pm SEM) number of counts during 10 minutes. ${ }^{* *} p<0.01,{ }^{*} p<0.05$ significantly different from caffeine $(0$ $\mathrm{mg} / \mathrm{kg}$ ) in the same ethanol dose group; \#\#p<0.01 significantly different from vehicle (caffeine $0 \mathrm{mg} / \mathrm{kg}+$ ethanol $0 \mathrm{~g} / \mathrm{kg}$ ) control group. 


\begin{tabular}{ccc}
\hline \multirow{2}{*}{$\begin{array}{c}\text { EtOH } \\
(\mathrm{g} / \mathrm{kg})\end{array}$} & $\mathbf{0}$ & Caffeine $(\mathrm{mg} / \mathrm{kg})$ \\
\cline { 2 - 3 } & $0.89 \pm 0.04$ & $1.00 \pm 0.07$ \\
\hline 2.5 & $2.12 \pm 0.07$ & $2.03 \pm 0.05$ \\
\hline
\end{tabular}

Table 1. Effect of caffeine on blood ethanol levels. Mean \pm SEM of blood ethanol levels (in milligrams per deciliter) after acute IP administration of ethanol (1.5 or $2.5 \mathrm{~g} / \mathrm{kg}$ ) and caffeine (0 or $30 \mathrm{mg} / \mathrm{kg}$ ).

\section{Effects of repeated administration of ethanol on locomotion}

Figure 4 shows the effects of repeated ethanol ( 0 or $1.5 \mathrm{~g} / \mathrm{kg}$ ) administration in mice $(n=32)$ during 5 sessions in alternating days. Factorial ANOVA with a between factor (session: 1 and 5) and a within factor (ethanol dose: 0 or $1.5 \mathrm{~g} / \mathrm{kg}$ ethanol) showed a significant effect of treatment $\left[\mathrm{F}_{1,64}=30.87, \mathrm{p}<0.01\right]$, a significant effect of session $\left[F_{1,64}=18.15, p<0.01\right]$ and treatment $x$ session interaction $\left[F_{1,64}=8.24, p<0.01\right]$. Planned comparisons showed a locomotor stimulant effect of ethanol $(1.5 \mathrm{~g} / \mathrm{kg})$ compared with vehicle treated mice in the first session $(p<0.01)$. Ethanol treated group in session 5 was significantly different compared to vehicle group in the same session $(p<0.01)$. Moreover, ethanol in session 5 increased locomotion compared to session $1(p<0.01)$. This increase in locomotion over sessions was not observed in the vehicle treated groups, suggesting a sensitization of locomotion induced by ethanol (Fig 4A). The factorial ANOVA showed a significant effect of ethanol dose on supported rear $\left[F_{1,64}=6.42, p<0.01\right]$, no significant effect of session $\left[F_{1,64}=3.32, N S\right]$, but a significant effect of ethanol dose $x$ session interaction $\left[\mathrm{F}_{1,64}=4.61, \mathrm{p}<0.05\right]$ (Fig 4B). Planned comparisons showed that although ethanol did not change supported rearing in session 1 when compared to the vehicle group, it increased the number of supported rears when administered in session 5 compared to the vehicle group in the same session $(p<0.01)$, and also compared to its administration in session $1(p<0.05)$. The ANOVA for the dependent variable unsupported rear showed a significant effect of ethanol dose $\left[F_{1,64}=127.4, p<0.01\right]$, a significant effect of session $\left[F_{1,64}=21.62, p<0.01\right]$, but did not show a significant interaction $\left[F_{1,64}=2.60, N S\right]$ (Fig 4C). 
A

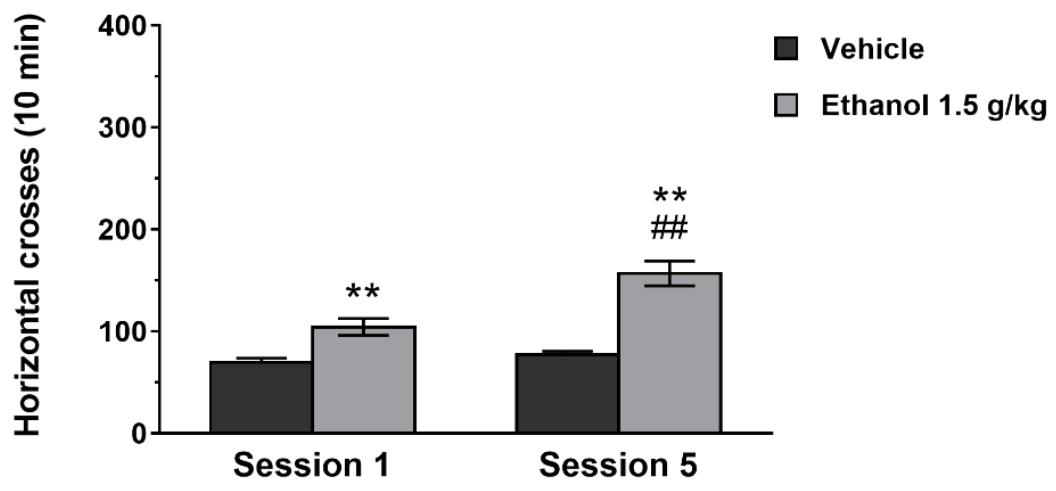

B

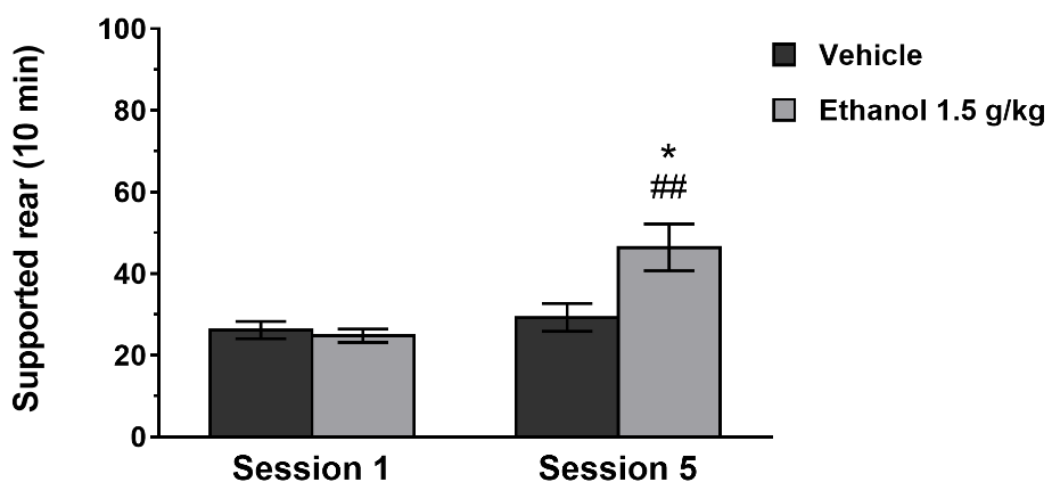

C

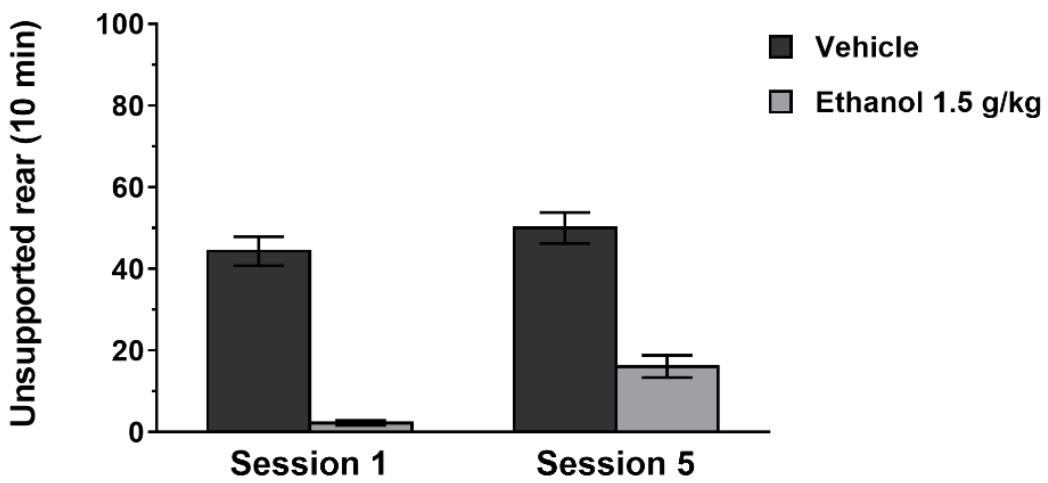

Figure 4. Effects of repeated administration of ethanol (0.0 or $1.5 \mathrm{~g} / \mathrm{kg}$ ) on horizontal locomotion (A), supported rear (B), and unsupported rear (C) in the OF. Data are expressed as mean ( \pm SEM) number of counts during 10 minutes. ${ }^{* *} p<0.01,{ }^{*} p<0.05$ significantly different between vehicle (ethanol $0 \mathrm{~g} / \mathrm{kg}$ ) and ethanol $(1.5 \mathrm{~g} / \mathrm{kg})$ in the same session. \#\#p<0.01 significantly different between sessions in the same ethanol $(1.5 \mathrm{~g} / \mathrm{kg})$ group. 
Effects of acute administration of caffeine on ethanol-induced locomotor sensitization

Figure 5 shows the effects of an acute administration of caffeine on ethanol $(1.5 \mathrm{~g} / \mathrm{kg})$ sensitized mice. Two days after the last drug administration, animals received an acute administration of caffeine $(0,15$ or $30 \mathrm{mg} / \mathrm{kg})$ in order to observe if there was a crosssensitization effect. The factorial ANOVA; previous ethanol treatment ( 0 or $1.5 \mathrm{~g} / \mathrm{kg}$ ) $\mathrm{x}$ caffeine dose $(0,15$ or $30 \mathrm{mg} / \mathrm{kg}$ ) showed an overall effect of previous ethanol dose $\left[F_{1,65}=11.48, p<0.01\right]$, caffeine dose $\left[F_{2,65}=25.45, p<0.01\right]$ and also a significant effect of their interaction $\left[F_{1,65}=3.82, p<0.05\right]$ on horizontal locomotion (Fig 5A). The same pattern of results was observed on supported rear (Fig 5B) $\left[F_{1,65}=9.66, p<0.01 ; F_{2,65}=29.28\right.$, $p<0.01 ; F_{1,65}=3.25, p<0.05$, respectively $]$ and unsupported rear (Fig $\left.5 C\right)\left[F_{1,65}=4.87, p<0.05\right.$; $F_{2,65}=10.90, p<0.01 ; F_{1,65}=5.36, p<0.01$, respectively]. Planned comparison showed a stimulant effect of caffeine at both doses $(15$ and $30 \mathrm{mg} / \mathrm{kg}$ ) in the ethanol $(0 \mathrm{~g} / \mathrm{kg}$ ) pretreated group $(p<0.01)$. Only the dose of $15 \mathrm{mg} / \mathrm{kg}$ of caffeine induced locomotion in the ethanol $(1.5 \mathrm{~g} / \mathrm{kg})$ pretreated group $(\mathrm{p}<0.01)$. Interestingly, caffeine at the highest dose $(30 \mathrm{mg} / \mathrm{kg}$ ) significantly decreased locomotion in animals pretreated with ethanol $(1.5 \mathrm{~g} / \mathrm{kg})$ when compared to the effect of this dose of caffeine in the ethanol $(0 \mathrm{~g} / \mathrm{kg})$ pretreated group $(p<0.01)$ (Fig $5 A$ ). The effect of caffeine on supported rear showed a similar pattern of effects. Caffeine increased supported rear at both doses (15 and 30 $\mathrm{mg} / \mathrm{kg}, \mathrm{p}<0.01$ and $\mathrm{p}<0.05$, respectively) in the ethanol $(0 \mathrm{~g} / \mathrm{kg})$ pretreated group. However, only caffeine $15 \mathrm{mg} / \mathrm{kg}$ significantly increased this variable in the ethanol pretreated group $(\mathrm{p}<0.01)$. Caffeine $30 \mathrm{mg} / \mathrm{kg}$ decreased supported rear in the ethanol $(1.5 \mathrm{~g} / \mathrm{kg})$ pretreated group compared to its effect in the ethanol $(0 \mathrm{~g} / \mathrm{kg})$ pretreated group ( $p<0.05$ ) (Fig 5B). Finally, caffeine $15 \mathrm{mg} / \mathrm{kg}$ increased unsupported rear in the ethanol $(1.5 \mathrm{~g} / \mathrm{kg})$ pretreated group, but at the highest dose $(30 \mathrm{mg} / \mathrm{kg})$ significantly decreased this variable $(p<0.05)$. Moreover, the effect of caffeine $30 \mathrm{mg} / \mathrm{kg}$ in the ethanol $(1.5 \mathrm{~g} / \mathrm{kg})$ pretreated group was significantly different to the effect observed in the ethanol $(0 \mathrm{~g} / \mathrm{kg})$ pretreated group $(\mathrm{p}<0.01)$. 
A

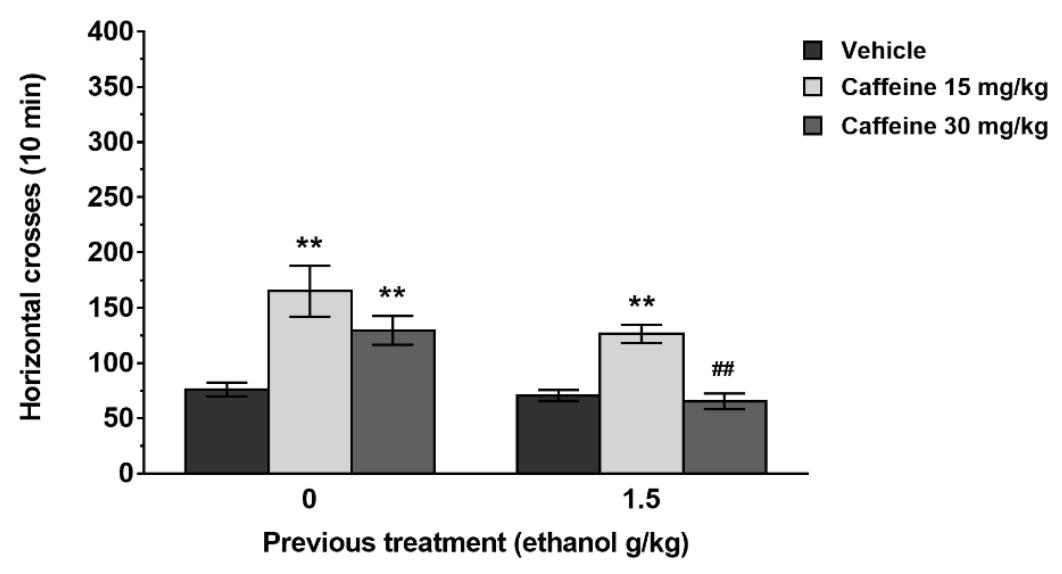

B

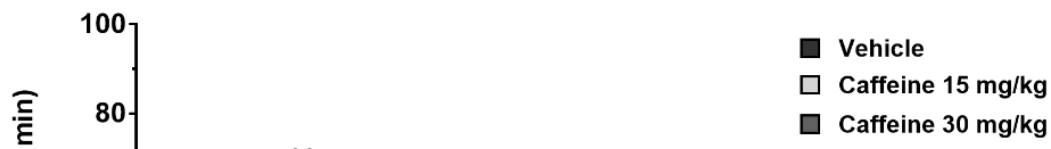

C

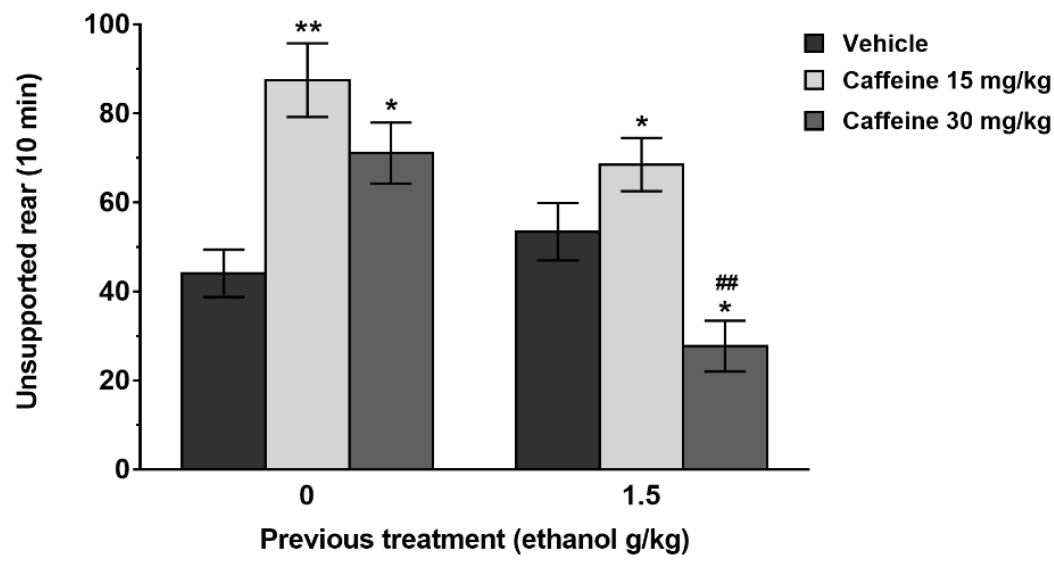

Figure 5. Effects of caffeine $(0,15$ or $30 \mathrm{mg} / \mathrm{kg})$ in mice treated with ethanol (0 or $1.5 \mathrm{~g} / \mathrm{kg})$ in previous days on horizontal locomotion (A), supported rear (B) and unsupported rear (C) in the OF. Data are expressed as mean ( \pm SEM) number of counts during 10 minutes. ${ }^{* *} p<0.01,{ }^{*} p<0.05$ significantly different from vehicle in the same pretreatment group. $\# \# p<0.01, \# p<0.05$ significantly different from the same dose of caffeine in animals that received vehicle in previous sessions. 
Effects of caffeine on the expression of ethanol-elicited pERK and pDARPP32(Thr75) in the nucleus accumbens

Figure 6 shows the effects of caffeine $(0,15$ or $30 \mathrm{mg} / \mathrm{kg})$ administered $20 \mathrm{~min}$ before of administration ethanol ( 0 or $1.5 \mathrm{~g} / \mathrm{kg}$ ) on the number of pERK- and pDARPP-32(Thr75)positive neurons in the $A c b C$ and AcbSh. Immunoreactivity levels were analyzed separately for Acb subregions. One-way ANOVA on the number of pERK-positive cells revealed an overall effect of treatment on $A c b C\left[F_{3,22}=10.18 ; p<0.01\right]$ and $A c b S h$ $\left[F_{3,22}=5.69 ; p<0.01\right]$ (Fig 6A). Planned comparison's analysis showed a significant increase on pERK expression after caffeine $(0 \mathrm{mg} / \mathrm{kg})+$ ethanol $(1.5 \mathrm{~g} / \mathrm{kg})$ treatment relative to caffeine $(0 \mathrm{mg} / \mathrm{kg})+$ ethanol $(0 \mathrm{~g} / \mathrm{kg})$ groups in the AcbC and AcbSh $(p<0.01)$. Furthermore, the administration of caffeine (15 and $30 \mathrm{mg} / \mathrm{kg})+$ ethanol $(1.5 \mathrm{~g} / \mathrm{kg})$ was significantly different from caffeine $(0 \mathrm{mg} / \mathrm{kg})$ + ethanol $(1.5 \mathrm{~g} / \mathrm{kg})$ in the AcbC and AcbSh ( $p<0.01$, both cases). Conversely, one-way ANOVA did not revealed a significant effect of caffeine $(0 \mathrm{mg} / \mathrm{kg})+$ ethanol $(1.5 \mathrm{~g} / \mathrm{kg})$ nor a significant effect of co-administration of caffeine $(15$ and $30 \mathrm{mg} / \mathrm{kg})$ + ethanol $(1.5 \mathrm{~g} / \mathrm{kg})$ on the number of pDARPP-32(Thr75)positive cells in the $A c b C\left[F_{3,24}=0.29 ; N S\right]$ and $A c b S h\left[F_{3,24}=0.27 ; N S\right]$ (Fig 6B).

A

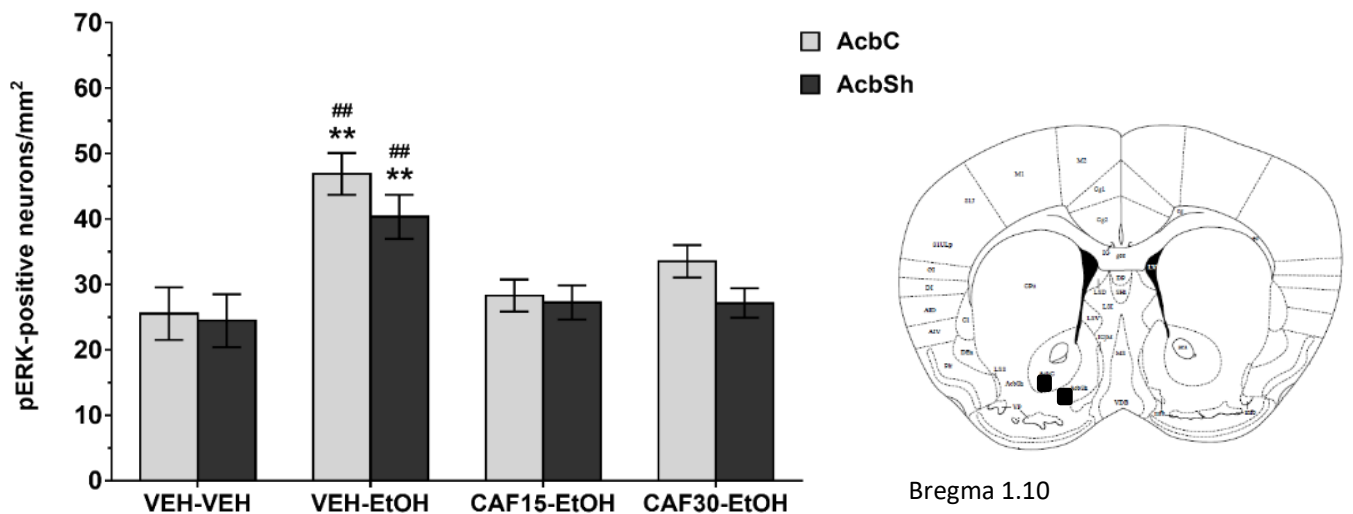

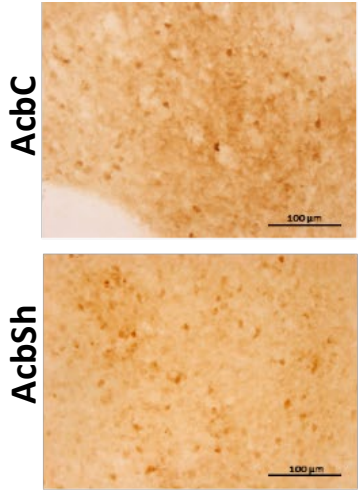

VEH-VEH

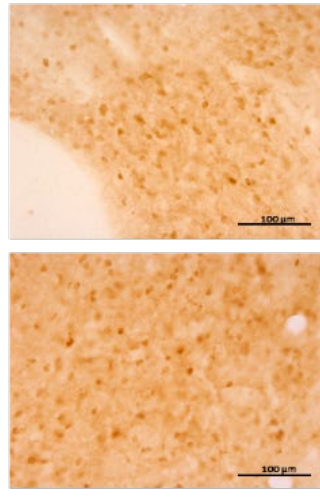

VEH-EtOH

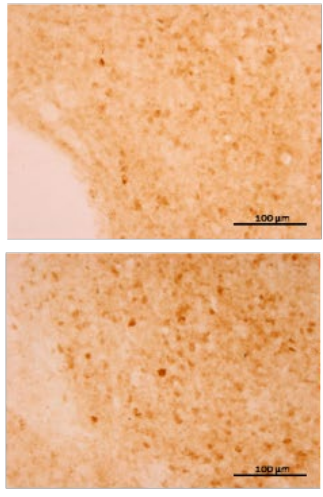

CAF15-EtOH

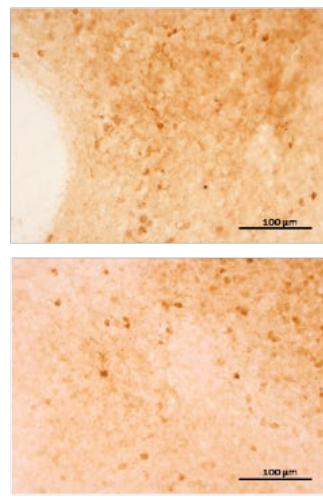

CAF30-EtOH 
B
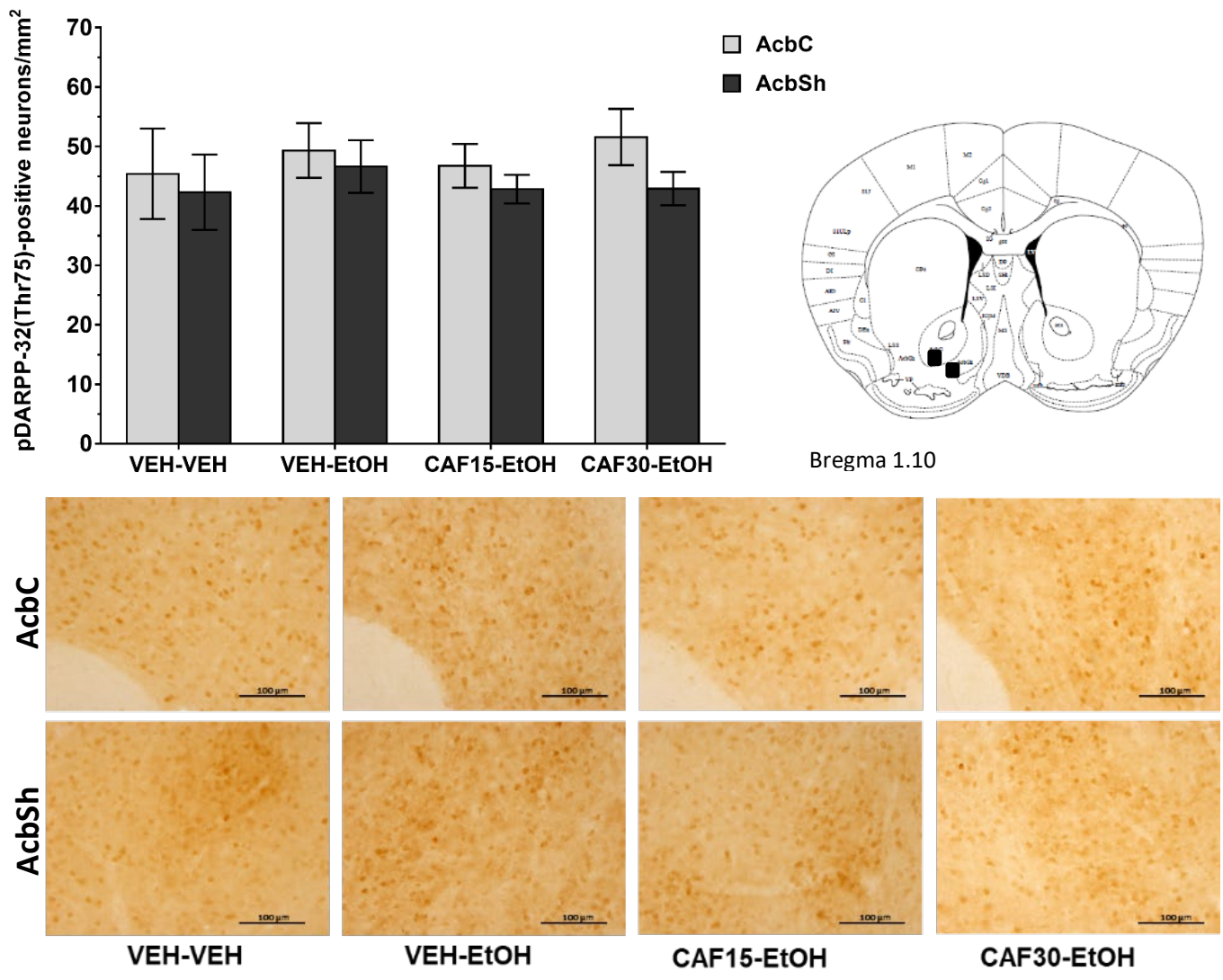

Figure 6. Effects of acute administration of caffeine on the expression of ethanol-elicited pERK and PDARPP-32(Thr75)-positive neurons in the Acb. Data are expressed as mean ( $\pm S E M)$ of the number of positive neurons $/ \mathrm{mm}^{2}$. Right upper parts: effect of caffeine acute treatment $(0,15$ and $30 \mathrm{mg} / \mathrm{kg})$ on the expression of $p E R K(A)$ and $p D A R P P-32(T h r 75)$ (B) positive neurons in mice treated with ethanol $(0,1.5 \mathrm{~g} / \mathrm{kg})$. Left upper part: diagram of a coronal section with bregma coordinates from Franklin and Paxinos (2001) showing location of the brain areas for $p E R K$ and $P D A R P P 32(T h r 75)$ immunoreactivity counting. Lower part: photomicrographs of pERK and pDARPP-32(Thr75) staining in AcbC and AcbSh from representative mice in each treatment group. Low power images (20X). ${ }^{* *} p<0.01$ significantly different from vehicle (caffeine 0 $\mathrm{mg} / \mathrm{kg}+$ ethanol $0 \mathrm{~g} / \mathrm{kg}$ ) groups in the $A c b C$ and AcbSh. \#\#p<0.01 significantly different from caffeine (15 and $30 \mathrm{mg} / \mathrm{kg})+$ ethanol $(1.5 \mathrm{~g} / \mathrm{kg})$ groups in the AcbC and AcbSh.

\section{DISCUSSION}

In the present studies, using male CD-1 mice, we investigated the acute interaction of caffeine and ethanol, two of the most widely used psychoactive drugs, on different measures of locomotor exploration in an open field; horizontal and vertical locomotion. Moreover, vertical locomotion was separated in two measures; one more dependent on postural coordination (non-supported rearing), and another less so (wall-supported rearing). The biphasic effects of ethanol on locomotion have been widely known, both in mice (Phillips \& Shen 1996; Correa et al. 2001a; Karlsson \& Roman 2016), but also in rats 
after central administration (Correa et al. 2003a b). Thus, at low doses, ethanol has stimulatory effects, whereas at high doses prevails the suppressant effect on locomotion (Correa et al. 2001b; Chuck et al. 2006), and then ataxia, incoordination and sedation predominate (Correa et al. 2001b; Chuck et al. 2006). Furthermore, the biphasic nature of caffeine on general locomotion has previously been described in mice (El Yacoubi et al. 2003; Zhang et al. 2011; López-Cruz et al. 2014) although only very high doses of caffeine $(100 \mathrm{mg} / \mathrm{kg})$, much higher than the ones used in the present study, suppress locomotion (Zhang et al. 2011). Accordingly, in the present studies, the acute intraperitoneal administration of caffeine or ethanol showed a dose dependent effect on locomotion, with low and moderate doses (caffeine 7.5 and $15 \mathrm{mg} / \mathrm{kg}$, and ethanol $2.5 \mathrm{~g} / \mathrm{kg}$ ) stimulating, and high doses (caffeine $30 \mathrm{mg} / \mathrm{kg}$ and ethanol $3.5 \mathrm{~g} / \mathrm{kg}$ ) reducing horizontal locomotion compared to the vehicle group. Furthermore, caffeine showed a bell-shaped dose response curve inducing stimulant effects on supported rear at low and moderate doses $(7.5$ and $15 \mathrm{mg} / \mathrm{kg}$ ), but not at the highest $(30 \mathrm{mg} / \mathrm{kg}$ ) dose used, whereas ethanol dose dependently decreased both types of rearing. Interestingly, the acute administration of both drugs revealed that stimulant $(15 \mathrm{mg} / \mathrm{kg})$ and non-stimulant $(30 \mathrm{mg} / \mathrm{kg})$ doses of caffeine enhanced locomotion in mice treated with low and moderate $(1.5$ and $2.5 \mathrm{~g} / \mathrm{kg}$, respectively) doses of ethanol. Remarkably, caffeine $(30 \mathrm{mg} / \mathrm{kg})$ increased horizontal locomotion and supported rearing in interaction with a dose of ethanol $(1.5 \mathrm{~g} / \mathrm{kg})$ that administered alone was not stimulatory. However, at the highest dose of ethanol (3.5 $\mathrm{g} / \mathrm{kg}$ ) caffeine was not able to reverse ethanol's effects in any of the three locomotion parameters. Our results are similar to previous results, in terms of the drug combination; caffeine in interaction with low doses of ethanol $(1.75 \mathrm{~g} / \mathrm{kg})$ potentiates stimulation and at higher doses $(2.5$ and $3.25 \mathrm{~g} / \mathrm{kg}$ ) potentiates reduction in locomotion (Hilbert et al. 2013). Thus, the synergistic activity of the two substances is revealed at low doses, while if one of the two is particularly high the antagonistic effect prevails and even at higher doses there is a potentiation in suppression of locomotion (Waldeck 1974; Hilbert et al. 2013). For example, $100 \mathrm{mg} / \mathrm{kg}$ of caffeine totally suppresses the locomotor activity induced by a low dose of ethanol ( $1 \mathrm{~g} / \mathrm{kg}$ ) (Waldeck 1974). In our study, a high dose of ethanol $(3.5 \mathrm{~g} / \mathrm{kg}$ ) co-administered with moderate doses of caffeine (15 or $30 \mathrm{mg} / \mathrm{kg}$ ) produced even a deeper suppression of locomotion. In addition, in terms of coordination, the oral administration of low dose of caffeine $(10 \mathrm{mg} / \mathrm{kg})$ reduced ethanol induced-ataxia 
(Kuribara et al. 1992) and local intracerebroventricularly administration of caffeine at low doses (less than 25 micrograms) dose-dependently reduced ethanol-elicited incoordination in mice, while a high dose (75 micrograms) potentiated it (Dar 1988).

In addition, we evaluated the impact of acute administration of caffeine on ethanolinduced sensitization of those exploration parameters after repeated administration. This phenomenon is defined as a progressive increase of motor response measured as a behavioral consequence of a repeated ethanol exposure (Camarini \& Pautassi 2016). There are very few evidences of cross-sensitization between ethanol and caffeine after repeated intragastric administration of both drugs which induced significantly greater locomotor sensitization than the substances alone (May et al. 2015). However, in our experiment, the repeated administration of a low dose of ethanol $(1.5 \mathrm{~g} / \mathrm{kg})$ induced locomotor and supported rearing sensitization, and the acute administration of caffeine on ethanol (1.5 g/ $/ \mathrm{kg})$-induced sensitization increase locomotion only at $15 \mathrm{mg} / \mathrm{kg}$ dose, whereas the highest dose $(30 \mathrm{mg} / \mathrm{kg}$ ) significantly decreased locomotion in animals that had been repeatedly exposed to ethanol in previous days, when compared with the effect of this dose of caffeine in the vehicle pretreated group. The impact of caffeine on supported rear showed a similar pattern of effects. Furthermore, although both doses of caffeine increased unsupported rear in naïve animals, in the ethanol pretreated group caffeine at the highest dose $(30 \mathrm{mg} / \mathrm{kg})$ significantly decreased this variable compared to vehicle. Thus, a non-stimulant dose of caffeine $(30 \mathrm{mg} / \mathrm{kg})$ totally blocked or produced suppression in all behavioral parameters in ethanol sensitized animals.

These behavioral effects induced by the interaction of caffeine and ethanol can be due to neurobiological mechanisms involving neurotransmission systems common to the two substances. Thus, the dopaminergic and adenosinergic systems are the ones more evidently affected by ethanol and caffeine. The stimulatory effect of ethanol can be related to an increase in dopaminergic stimulation in the nucleus accumbens (Di Chiara \& Imperato 1988; Ibba et al. 2009), whereas caffeine seems to act as a non-selective $A_{1} / A_{2 A}$ receptor antagonist and, as such, mediates its stimulant (Ferré 2008; Pardo et al., 2013), anxiogenic (Correa \& Font 2008) and motivational effects (López-Cruz et al. 2018). The colocalization of adenosinergic and dopaminergic receptors in brain striatal areas, such as nucleus accumbens (Acb), reflects a possible functional interaction and 
can converge on common mechanisms, such as intracellular signaling cascades with opposite effects (Fuxe et al. 2003; Ferré 2008).

Finally, as we have previously observed (Ibba et al. 2009), ethanol significantly increased postsynaptic intracellular markers related to DA signaling; the phosphorylated ERK and this ethanol-induced increase in markers of DA-related signal transduction were significantly reversed by caffeine at stimulant and non-stimulant doses. In contrast, pDARPP-32(Thr75) was not affected by any of the pharmacological manipulations, indicating that ethanol, at least under the present conditions, does not seem to change DA function in Acb. Caffeine at stimulant dose $(15 \mathrm{mg} / \mathrm{kg})$ in mice has previously demonstrated to suppress the increase in pDARPP-32(Thr34) produced by a DA depleting agent (tetrabenazine, TBZ) using western blotting (López-Cruz et a., 2018). Also in rats, using immunohistochemistry, DA suppression potentiate phosphorylation of DARPP-32 (-Thr75 and -Thr34) in Acb shell and core, but in different populations of neurons (Nunes et al, 2013).

The effects of caffeine on DA release in Acb are not very conclusive. In microdialysis experiments it has been shown that caffeine can elicit DA release in the shell of Acb (Solinas et al. 2002), and in the medial prefrontal cortex (Acquas et al. 2002), although not in the core of Acb (Acquas et al. 2002). Caffeine, as nonselective adenosine antagonist, can interact with both of adenosine receptors, that are co-localized with DA receptors in striatal medium spiny neurons. Both sets of receptors interact in an antagonistic way; agonism of dopamine $D_{1}$ and $D_{2}$ receptors leads to actions on the metabotropic cascade that are opposite to those produced by stimulation of adenosine $A_{1}$ and $A_{2 A}$ receptors respectively (Svenningsson et al. 1999). Thus, in a direct or in an indirect way, caffeine can have similar effects on the mesolimbic circuit to drugs that act on the dopaminergic systems. Caffeine seems to act predominantly in $A_{1}$ receptors (Ferré 2008), leading to increase phosphorylation of DARPP-32 at Thr34. These receptors are widely distributed in the brain, but in Acb they are colocalized with $D_{1}$ receptors typically located in Substance P containing medium spiny neurons (Svenningsson et al. 1999; Segovia et al. 2012; Nunes et al. 2013). Conversely, blockade of adenosine $A_{2 A}$ receptors results in increased phosphorylation of DARPP-32 at Thr75 (Lindskog et al. 2002), in enkephalin containing neurons (Nunes et al. 2013). In the present results, an increase in 
pDARPP32(Thr75) expression was not observed after the administration of ethanol, or after co-administration of caffeine plus ethanol. Is also possible that, ethanol at high doses or when enough time has elapsed can increase adenosine levels (Carmichael et al. 1991; Diamond \& Gordon 1994) and this purine is the endogenous agonist for adenosine receptors. If ethanol at $1.5 \mathrm{~g} / \mathrm{kg}$ had induced potentiation of adenosine synthesis it would lead to a stimulation of $A_{1}$ receptor activity by adenosine, which in turn would have increased pDARPP32(Thr75). In previous studies, ethanol at this dose but in rats which are much more sensitive to ethanol sedative and ataxic effects, was shown to increase phosphorylation of DARPP-32 at Thr34 in striatum (Nuutinen et al. 2011) pointing to an increase in adenosine formation and action on $A_{1}$ receptors. Those receptors are widely distributed in the brain; thus, it is possible that the stimulating effects of this drug are not mediated by Acb actions.

In summary, despite the popular assumptions about the ability of caffeine in energy drinks to counteract the impact of alcohol, the potential dangers of combining highcaffeine "energy" drinks with ethanol have been demonstrated using the animal models employed in the present experiments. Our results have confirmed how caffeine can exacerbate the already disruptive effects of ethanol, and have identified at least one potential brain area, the nucleus accumbens, in which caffeine and ethanol interact to modulate behavior. This brain region also appears to be very important for the regulation of behavioral processes involved in ethanol seeking behavior and consumption, which can lead to phenomena such as ethanol dependence, abuse and addiction. 


\section{REFERENCES}

Acquas E, Tanda G \& Di Chiara G (2002) Differential Effects of Caffeine on Dopamine and Acetylcholine Transmission in Brain Areas of Drug-naive and Caffeinepretreated Rats. Neuropsychopharmacology 27:182-193.

Acquas E, Vinci S, Ibba F, Spiga S, De Luca MA \& Di Chiara G (2010) Role of dopamine D1 receptors in caffeine-mediated ERK phosphorylation in the rat brain. Synapse 64:341-349.

Agnati LF, Ferré S, Lluis C, Franco R \& Fuxe K (2003) Molecular mechanisms and therapeutical implications of intramembrane receptor/receptor interactions among heptahelical receptors with examples from the striatopallidal GABA neurons. Pharmacol Rev 55:509-550.

Astorino TA \& Roberson DW (2010) Efficacy of acute caffeine ingestion for short-term high-intensity exercise performance: A systematic review. J Strength Cond Res 24:257-265.

Attwood AS, Rogers PJ, Ataya AF, Adams S \& Munafò MR (2012) Effects of caffeine on alcohol-related changes in behavioural control and perceived intoxication in light caffeine consumers. Psychopharmacology (Berl) 221:551-560.

Camarini R \& Pautassi RM (2016) Behavioral sensitization to ethanol: Neural basis and factors that influence its acquisition and expression. Brain Res Bull 125:53-78.

Carboni E, Silvagni A, Rolando MTP \& Di Chiara G (2000) Stimulation of In Vivo Dopamine Transmission in the Bed Nucleus of Stria Terminalis by Reinforcing Drugs . J Neurosci 20:RC102-RC102.

Carmichael FJ, Israel Y, Crawford M, Minhas K, Saldivia V, Sandrin S, Campisi P \& Orrego H (1991) Central nervous system effects of acetate: Contribution to the central effects of ethanol. J Pharmacol Exp Ther 259:403-408.

Celik E, Uzbay IT \& Karakas S (2006) Caffeine and amphetamine produce crosssensitization to nicotine-induced locomotor activity in mice. Prog NeuroPsychopharmacology Biol Psychiatry 30:50-55.

Di Chiara G \& Imperato A (1988) Drugs abused by humans preferentially increase synaptic dopamine concentrations in the mesolimbic system of freely moving rats (amphetamine/cocaine/ethanol/nicotine/opiates). Proc Natl Acad Sci USA 85:5274-5278.

Chuck TL, McLaughlin PJ, Arizzi-LaFrance MN, Salamone JD \& Correa M (2006) Comparison between multiple behavioral effects of peripheral ethanol administration in rats: Sedation, ataxia, and bradykinesia. Life Sci 79:154-161.

Correa M, Arizzi MN, Betz A, Mingote S \& Salamone JD (2003a) Locomotor stimulant effects of intraventricular injections of low doses of ethanol in rats: acute and repeated administration. Psychopharmacology (Berl) 170:368-75. 
Correa M, Arizzi MN, Betz A, Mingote S \& Salamone JD (2003b) Open field locomotor effects in rats after intraventricular injections of ethanol and the ethanol metabolites acetaldehyde and acetate. Brain Res Bull 62:197-202.

Correa $M$ \& Font $L$ (2008) Is there a major role for adenosine A2A receptors in anxiety? Front Biosci 13:4058-70.

Correa M, Sanchis-Segura C \& Aragon CM (2001a) Brain catalase activity is highly correlated with ethanol-induced locomotor activity in mice. Physiol Behav 73:641-7.

Correa M, Sanchis-Segura C \& Aragon CM (2001b) Influence of brain catalase on ethanol-induced loss of righting reflex in mice. Drug Alcohol Depend 65:9-15.

Correa M, Sanchis-Segura C, Pastor R \& Aragon CMG (2004) Ethanol intake and motor sensitization: The role of brain catalase activity in mice with different genotypes. Physiol Behav 82:231-240.

Dar MS (1988) The Biphasic Effects of Centrally and Peripherally Administered Caffeine on Ethanol-induced Motor Incoordination in Mice. J Pharm Pharmacol 40:482487.

Diamond I \& Gordon AS (1994) The role of adenosine in mediating cellular and molecular responses to ethanol. EXS 71:175-83.

Drake CL, Roehrs T, Turner L, Scofield HM \& Roth T (2003) Caffeine reversal of ethanol effects on the multiple sleep latency test, memory, and psychomotor performance. Neuropsychopharmacology 28:371-378.

Duncan MJ, Smith M, Cook K \& James RS (2012) The acute effect of a caffeinecontaining energy drink on mood state, readiness to invest effort, and resistance exercise to failure. J Strength Cond Res 26:2858-2865.

Duncan MJ, Stanley M, Parkhouse N, Cook K \& Smith M (2013) Acute caffeine ingestion enhances strength performance and reduces perceived exertion and muscle pain perception during resistance exercise. Eur J Sport Sci 13:392-399.

Ferré S (2008) An update on the mechanisms of the psychostimulant effects of caffeine. J Neurochem 105:1067-1079.

Ferré S, Ciruela F, Borycz J, Solinas M, Quarta D, Antoniou K, Quiroz C, Justinova Z, Lluis C, Franco R \& Goldberg SR (2008) Adenosine A1-A2A receptor heteromers: new targets for caffeine in the brain. Front Biosci 13:2391-9.

Ferreira SE, Abrahao KP \& Souza-Formigoni MLO (2013) Expression of behavioral sensitization to ethanol is increased by energy drink administration. Pharmacol Biochem Behav 110:245-248.

Fuxe K, Agnati LF, Jacobsen K, Hillion J, Canals M, Torvinen M, Tinner-Staines B, Staines W, Rosin D, Terasmaa A, Popoli P, Leo G, Vergoni V, Lluis C, Ciruela F, Franco R \& Ferre $S$ (2003) Receptor heteromerization in adenosine A2A receptor signaling: 
Relevance for striatal function and Parkinson's disease. Neurology 61:S19-S23.

Gessa GL, Muntoni F, Collu M, Vargiu L \& Mereu G (1985) Low doses of ethanol activate dopaminergic neurons in the ventral tegmental area. Brain Res 348:201203.

Hasenfratz M, Bunge A, Dal Prá G \& Bättig K (1993) Antagonistic effects of caffeine and alcohol on mental performance parameters. Pharmacol Biochem Behav 46:463465.

Hilbert MLT, May CE \& Griffin WC (2013) Conditioned Reinforcement and Locomotor Activating Effects of Caffeine and Ethanol Combinations in Mice. Pharmacol Biochem Behav 110:168-173.

Ibba F, Vinci S, Spiga S, Peana AT, Assaretti AR, Spina L, Longoni R \& Acquas E (2009) Ethanol-induced extracellular signal regulated kinase: Role of dopamine $D 1$ receptors. Alcohol Clin Exp Res 33:858-867.

Karlsson O \& Roman E (2016) Dose-dependent effects of alcohol administration on behavioral profiles in the MCSF test. Alcohol 50:51-56.

Keppel G (1991) Design and Analysis: A Researcher's Handbook, Englewood. PrenticeHall.

Kuribara H, Asahi T \& Tadokoro S (1992) Ethanol enhances, but diazepam and pentobarbital reduce the ambulation-increasing effect of caffeine in mice. Arukoru Kenkyuto Yakubutsu Ison 27:528-39.

López-Cruz L, Pardo M, Salamone JD \& Correa M (2014) Differences between the nonselective adenosine receptor antagonists caffeine and theophylline in motor and mood effects: Studies using medium to high doses in animal models. Behav Brain Res 270:213-222.

López-Cruz L, Salamone JD \& Correa M (2018) Caffeine and selective adenosine receptor antagonists as new therapeutic tools for the motivational symptoms of depression. Front Pharmacol 9.

López-Cruz L, Salamone JD \& Correa M (2013) The Impact of Caffeine on the Behavioral Effects of Ethanol Related to Abuse and Addiction: A Review of Animal Studies. $J$ Caffeine Res 3:9-21.

López-Cruz L, San-Miguel N, Bayarri P, Baqi Y, Müller CE, Salamone JD \& Correa M (2016) Ethanol and caffeine effects on social interaction and recognition in mice: Involvement of adenosine A2A and A1 receptors. Front Behav Neurosci 10.

May CE, Haun HL \& lii WCG (2015) Sensitization and Tolerance Following Repeated Exposure to Caffeine and Alcohol in Mice. Alcohol Clin Exp Res 39:1443-1452.

Melis M, Enrico P, Peana AT \& Diana M (2007) Acetaldehyde mediates alcohol activation of the mesolimbic dopamine system. Eur J Neurosci 26:2824-2833.

Nunes EJ, Randall PA, Hart EE, Freeland C, Yohn SE, Baqi Y, Muller CE, Lopez-Cruz L, 
Correa M \& Salamone JD (2013) Effort-Related Motivational Effects of the VMAT2 Inhibitor Tetrabenazine: Implications for Animal Models of the Motivational Symptoms of Depression. J Neurosci 33:19120-19130.

Nuutinen S, Kiianmaa K \& Panula P (2011) DARPP-32 and Akt regulation in ethanolpreferring AA and ethanol-avoiding ANA rats. Neurosci Lett 503:31-36.

Paxinos G \& Franklin K (2001) The mouse brain in stereotaxic coordinates, 2nd editio. Academic (ed). Sydney.

Phillips TJ \& Shen EH (1996) Neurochemical bases of locomotion and ethanol stimulant effects. Int Rev Neurobiol 39:243-82.

Robinson TE \& Berridge KC (2000) The psychology and neurobiology of addiction: an incentive-sensitization view. Addiction 95 Suppl 2:S91-117.

Salamone JD, Pardo M, Yohn SE, López-Cruz L, Sanmiguel N \& Correa M (2016) Mesolimbic dopamine and the regulation of motivated behavior. Curr Top Behav Neurosci 27:231-257.

Segovia KN, Correa M, Lennington JB, Conover JC \& Salamone JD (2012) Changes in nucleus accumbens and neostriatal c-Fos and DARPP-32 immunoreactivity during different stages of food-reinforced instrumental training. Eur J Neurosci 35:13541367.

Smirmaul BPC, de Moraes AC, Angius L \& Marcora SM (2017) Effects of caffeine on neuromuscular fatigue and performance during high-intensity cycling exercise in moderate hypoxia. Eur J Appl Physiol 117:27-38.

Solinas M, Ferré S, You ZB, Karcz-Kubicha M, Popoli P \& Goldberg SR (2002) Caffeine induces dopamine and glutamate release in the shell of the nucleus accumbens. $J$ Neurosci 22:6321-6324.

Steketee JD \& Kalivas PW (2011) Drug wanting: behavioral sensitization and relapse to drug-seeking behavior. Pharmacol Rev 63:348-65.

Svenningsson P, Le Moine C, Fisone G \& Fredholm BB (1999) Distribution, biochemistry and function of striatal adenosine A(2A) receptors. Prog Neurobiol 59:355-396.

Temple JL, Bernard C, Lipshultz SE, Czachor JD, Westphal JA \& Mestre MA (2017) The Safety of Ingested Caffeine: A Comprehensive Review. Front Psychiatry 8:1-19.

Valjent E, Pascoli V, Corvol J, Svenningsson P, Paul S, Stipanovich A, Caboche J, Lombroso PJ, Nairn AC, Greengard P, Herve D \& Girault J (2005) Regulation of a protein phosphatase cascade allows convergent dopamine and glutamate signals to activate ERK in the striatum. PNAS 102:491-496.

Waldeck B (1974) Ethanol and caffeine: a complex interaction with respect to locomotor activity and central catecholamines. Psychopharmacologia 36:209-20.

Xu S \& Kang UG (2017) Characteristics of ethanol-induced behavioral sensitization in rats: Molecular mediators and cross-sensitization between ethanol and cocaine. 
Pharmacol Biochem Behav 160:47-54.

El Yacoubi M, Ledent C, Parmentier M, Costentin J \& Vaugeois JM (2003) Caffeine reduces hypnotic effects of alcohol through adenosine $A 2 A$ receptor blockade. Neuropharmacology 45:977-985.

Zhang Q, Yu YP, Ye YL, Zhang JT, Zhang WP \& Wei EQ (2011) Spatiotemporal properties of locomotor activity after administration of central nervous stimulants and sedatives in mice. Pharmacol Biochem Behav 97:577-585. 
General Discussion 



\section{GENERAL DISCUSSION}

The present doctoral thesis was aimed at investigating the significance of the role of Extracellular signal-regulated kinase (ERK) expression and in broader perspective of the involvement of the ERK/MAPK signaling cascade in the behavioral and biochemical effects of ethanol. This aim was pursued through different behavioral and biochemical approaches: the behavioral one utilized the place conditioning paradigm (chapters 1 and 2) and the assessment of locomotor activation (chapter 3); the biochemical approach was based on the immunohistochemical quantification of the phosphorylation of ERK-positive neurons in several areas of the addiction circuitry (chapters 1-3).

Addiction can be considered as a result of molecular and cellular adaptations that take place in neurons of specific brain areas following repeated exposure to drugs of abuse (Nestler 2001). The involvement of phosphorylated ERK (pERK) in the action of addictive drugs has been widely demonstrated (Valjent et al. 2000, 2004; Cahill et al. 2014; Sun et al. 2016). Accordingly, although still to be fully understood, ERK/MAPK pathway may be considered as a strategic tool through which these substances exert their addictive potential, generating neuronal changes that may underlie the onset of a series of pathological process which can evolve in addiction (Valjent et al. 2000, 2004). This signaling pathway is characterized by a phosphorylation cascade, among which key protagonists are the protein kinases ERK and MEK responsible of ERK's activation. ERK, in turn, by activating transcription factors and early genes such as c-fos (BramiCherrier et al. 2005), appear to be essential components to exert protein synthesis, changes in gene expression, stabilization of dendritic spines implicated in synaptic plasticity and memory formation (Sweatt 2004). Thus, ERK result important regulators of neuronal function and activity. Accordingly, several studies have correlated these biochemical markers with learning paradigms, such as conditioned taste aversion (Marotta et al. 2014), fear conditioning (Atkins et al. 1998; Villarreal \& Barea-Rodriguez 2006), spatial learning (Blum et al. 1999; Selcher et al. 1999), recognition memory (Kelly et al. 2003), appetitive-reward seeking behavior (Kirschmann et al. 2014) and 
drug-elicited place conditioning (Valjent et al. 2000; Gerdjikov et al. 2004; Girault et al. 2007; Spina et al. 2010; Longoni et al. 2011; Rosas et al. 2018).

ERK phosphorylation has also been reported to be activated, in a dose-dependent manner, in the core and shell of nucleus accumbens (Acb) and in the nuclei of extended amygdala (bed nucleus of stria terminalis and central nucleus of the amygdala), by ethanol through a mechanism mediated by dopaminergic $D_{1}$ receptors (Ibba et al. 2009). However still occurs, to date, a number of unanswered questions regarding, in particular, whether and in which brain regions ERK are involved in the effects conditioned to ethanol as well as whether the association of ethanol with other psychotropic substances also extends involving ERK at the basis of their behavioral effects. In this regard, recent evidence, both on the experimental (López-Cruz et al. 2013) and on the clinical and epidemiological sides (Marczinski \& Fillmore 2014; Kristjansson et al. 2015), reveals increasing interest on the combination of ethanol with the most consumed legal psychostimulant in the world, caffeine, often considered in the composition of "energy drinks", as a consequence of the increasingly popular belief that this substance could decrease the adverse effects of ethanol in terms of motor impairment and narcosis (Hasenfratz et al. 1993; Drake et al. 2003; Attwood et al. 2012). Therefore, in the perspective of the general aim of this work as defined above, we considered also critical to investigate the pharmacological consequences of the interaction between caffeine and ethanol in terms of motivational, locomotor and motor coordination effects and, also, in the perspective of the impact of such interaction on ERK expression in different brain regions.

In chapter 1 we described our investigation on the role of MEK/ERK cascade by studying to what extent these intracellular kinases are involved in the process of acquisition and expression of ethanol-elicited place conditioning. In particular, to investigate a possible differential involvement of this pathway in the acquisition and expression of the positive (conditioned place preference, CPP) and negative (conditioned place aversion, CPA) memories associated with ethanol (the unconditioned stimulus, US), we have chosen to adopt two distinct and appropriate behavioral schedules (Spina et al. 2015; Rosas et al. 2017) by which ethanol could result able, as a single US, to prompt two opposite effects, CPP or CPA. The results 
disclosed, as a consequence of the systemic administration the blood brain barrierpenetrant compound, SL327, unable to affect other kinases such as protein kinase A (PKA) or $\mathrm{Ca}^{2+} /$ calmodulin-dependent protein kinase II (CAMKII) (Atkins et al. 1998; Selcher et al. 1999), a differential involvement of the MEK/ERK pathway in the effects of ethanol. In particular, SL327 (50 mg/ $/ \mathrm{kg}$ ) significantly prevents the acquisition of ethanol-elicited CPP, whereas its administration (50 and $100 \mathrm{mg} / \mathrm{kg}$ ) fails to prevent, although significantly reducing, the acquisition of ethanol-elicited CPA. The result of CPP acquisition experiment is in agreement with previous data that showed the ability of different MEK inhibitors to impair the ability of this kinase of transferring ethanol's affective value to conditioned stimuli (Valjent et al. 2000, 2001; Salzmann et al. 2003; Gerdjikov et al. 2004; Spina et al. 2010). Furthermore, the results of the expression experiments reveal that SL327 (50 and $100 \mathrm{mg} / \mathrm{kg}$ ) is able to significantly reduce the expression of ethanol-elicited CPP, but not that of CPA. Moreover, the observation that SL327 (50 and $100 \mathrm{mg} / \mathrm{kg}$ ) significantly reduces the expression of ethanol-CPP is in agreement with previous studies showing that MEK inhibitors could prevent retrieval of cocaine-(Miller \& Marshall 2005) and morphine (Lin et al. 2010)-elicited CPP and with the observation that presentation of conditioned stimuli, either in CPP (Nygard et al. 2015) and in operant self-administration (Radwanska et al. 2008; Peana et al. 2013; Faccidomo et al. 2015) is related to the enhancement of phosphorylated ERK expression. Conversely, we found, in agreement with previous studies (Longoni et al. 2011), that SL327 administration (50 and $100 \mathrm{mg} / \mathrm{kg}$ ) fails to prevent the expression of ethanol-elicited CPA. The interpretation of the role of ERK in these conditioning effects is supported by the immunohistochemistry experiments demonstrating that pretreatment with SL327 prevents the increases of pERK-positive neurons elicited by ethanol in the prefrontal cortex, Acb core and shell and in other nuclei of extended amygdala. Interestingly, as mentioned above, the MEK/ERK pathway is involved also in ethanol self-administration experiments (Faccidomo et al. 2009) as pERK expression has been demonstrated in the Acb, medial prefrontal cortex and nuclei of amygdala (Faccidomo et al. 2015) upon ethanol oral self-administration supporting the hypothesis of the present dissertation that this kinases' cascade is preferentially implicated in the positive reinforcement of ethanol. Overall, the first experimental study of this thesis work reveals that the acquisition phase of a behavior conditioned 
to a US, i.e. the initial phase in which learning is established, seems to be more sensitive to the interruption of the MEK/ERK pathway than the expression phase (presentation of the CS after learning the US-CS association). Similarly, appetitive motivation (place preference) discloses a preferential sensitivity of a modulation of this pathway with respect to aversive motivation (place aversion), an observation that further highlights the complexity of the involvement of this pathway in ethanolsustained associative learning.

In chapter 2 we studied the effects of pretreatment with caffeine on ethanol-elicited place conditioning with the aim of exploring the consequences of their interaction in terms of motivational properties, a subject of great translational valence, that is still inadequately investigated. In fact, very little is known about the pharmacological outcome of this interaction when using doses of ethanol that result in frank motivational effects devoid of serious intoxicative consequences and of caffeine, at doses with uncertain motivational effect (Liu et al. 2008) and considered in the low to moderate range to elicit behavioral activation (Zhang et al. 2011). Furthermore, in this chapter we also assessed the results of their combination in terms of pERK expression in different areas of the addiction circuity as well as in terms of the ability of stimuli conditioned to ethanol or to caffeine and ethanol (i.e. upon the expression of ethanolelicited CPP and CPA) to elicit ERK phosphorylation in those brain regions. Notably, ethanol and caffeine act in opposite manner on the adenosinergic system: the neuromodulator adenosine controls several mechanisms such as neuronal excitability and neurotransmitter release, and the combination of these substances is reflected in the modulation of multiple behavioral effects (López-Cruz et al. 2013). However, the literature does not provide sufficient information about the results of pre-treatment with caffeine on ethanol place conditioning and especially with reference to the aversive (negative motivational) effects of ethanol (CPA) there is a total lack of data.

The results of these place conditioning experiments showed that caffeine ( 3 and 15 $\mathrm{mg} / \mathrm{kg}$ ) was devoid of conditioning effects while, in agreement with previous reports (Cunningham et al. 2003; Spina et al. 2015; Rosas et al. 2017), ethanol (2 g/ $/ \mathrm{kg}$ ) elicited significant CPP and CPA. Moreover, caffeine $(15 \mathrm{mg} / \mathrm{kg})$ significantly prevented ethanol-elicited CPP and, at both doses ( 3 and $15 \mathrm{mg} / \mathrm{kg}$ ), significantly impaired 
ethanol-elicited CPA. These findings suggest that low and intermediate doses of caffeine are able to interfere with the acute effects of ethanol, expressed in the place conditioning paradigm, by preventing the establishment of the conditioned association and therefore by blocking such ethanol-induced acquisition of CPP and CPA. We postulate that these results can be referred to the antagonistic actions exerted by caffeine on $A_{1}$ and $A_{2 A}$ receptors. This hypothesis is supported by the results of the acute administrations in the immunohistochemical experiments in which caffeine at both doses also prevented ethanol-elicited increased pERK expression in all brain areas examined. Specifically, also on the basis of the observation made by Ibba et al. (2009) that ethanol-elicited ERK expression is mediated by dopaminergic $D_{1}$ receptors, it is likely to assume that caffeine exerts the described antagonistic effect on ethanolelicited acquisition of conditioned responses by acting onto $A_{1}$ adenosine receptors are colocalized with dopamine $D_{1}$ receptors (Svenningsson et al. 1999; Nunes et al. 2013). Future experiments devoted to test this hypothesis will allow to confirm or reject this possibility.

Furthermore, the set of results referred to the expression of ethanol-elicited CPP and CPA indicated that ethanol-conditioned stimuli, either positive (CPP) or negative (CPA), have a different impact on the expression of ERK phosphorylation. In particular, the "identical" US, but with opposite motivational properties, is able to increase the expression of ERK in the core and shell of Acb as well as in other brain regions of the extended amygdala in opposite manner, in agreement with previous studies of our laboratory in which the expression of lithium-induced CPA is not associated to increased pERK expression in the Acb (Longoni et al. 2011). In this study, unfortunately, the expression of pERK was determined only in the Acb and dorsal striatum and therefore we cannot extend the agreement of the interpretation of the present data also to other brain regions. However, pERK increases were detected in others nuclei of extended amygdala suggesting an involvement of these structures in stimulus-stimulus learning and in negative reinforcement (McDonald et al. 2010; Pati et al. 2019; Wscieklica et al. 2019). In summary, the findings of the second chapter demonstrated that caffeine is unable of eliciting PERK expression but interferes with both positive (CPP) and negative (CPA) properties of ethanol. This finding is also 
supported by the dissociation between the behavioral expression of CPP and CPA and the differential anatomical localization of pERK expression (Acb in case of CPP expression and bed nucleus of stria terminals, central and basolateral nuclei of the amygdala in case of (PA). We postulate that these effects could be due to the functional antagonistic actions exerted by caffeine and ethanol on adenosinergic system as well as to the antagonistic effect of caffeine onto $A_{1}$ adenosine receptors. These interpretations need to be corroborated by future experiments.

Finally, in chapter $\mathbf{3}$ we examined the consequences of caffeine and ethanol interaction by exploring the results in terms of locomotor activation and motor coordination. The rationale at the basis of these experiments was the clinical observation of frequently consumed caffeine with ethanol in order to reduce its psychomotor slowing, sedation and motor incoordinating effects. We used an open field to test novelty-induced exploration expressed as horizontal and vertical locomotion. This last parameter was further distinguished into two measures: one more dependent on postural coordination (i.e.: non-supported rearing) and another less so (i.e.: wall-supported rearing). Furthermore, we also evaluated the expression of another biochemical marker of dopamine signaling, upstream of activation of pERK, the Dopamine- and cAMP-regulated phosphoprotein, Mr 32 kDa (DARPP-32) phosphorylated at Threonine75 site (pDARPP-Thr75).

The biphasic effects of caffeine and ethanol have been widely described in literature (Phillips \& Shen 1996; Correa et al. 2001a b, 2003a b; El Yacoubi et al. 2003; Zhang et al. 2011; López-Cruz et al. 2014; Karlsson \& Roman 2016). However, there is a lack of data on further parameters concerning locomotion such as postural stability while the effects of caffeine on ethanol-induced sensitization require further investigation. The results of the present experiments revealed that, acutely, low and moderate doses of caffeine (7.5 and $15 \mathrm{mg} / \mathrm{kg})$ and a moderate dose of ethanol $(2.5 \mathrm{~g} / \mathrm{kg})$ stimulate the horizontal locomotion whereas high doses of caffeine $(30 \mathrm{mg} / \mathrm{kg})$ and ethanol $(3.5 \mathrm{~g} / \mathrm{kg})$ reduce it. Moreover, ethanol decreased both types of rearing whereas caffeine $(7.5$ and $15 \mathrm{mg} / \mathrm{kg}$ ) increased only wall-supported rearing. Interestingly, the acute drugs combination showed that stimulant $(15 \mathrm{mg} / \mathrm{kg})$ and non-stimulant $(30 \mathrm{mg} / \mathrm{kg})$ doses of caffeine enhanced locomotion in mice treated with the stimulant $(2.5 \mathrm{~g} / \mathrm{kg})$ dose of ethanol but did not 
affect the supported rearing. In addition, a non-stimulant dose of caffeine $(30 \mathrm{mg} / \mathrm{kg}$ ) increased horizontal locomotion and supported rearing with the lowest and nonstimulant dose of ethanol $(1.5 \mathrm{~g} / \mathrm{kg})$. On the contrary at the highest dose of ethanol (3.5 $\mathrm{g} / \mathrm{kg}$ ) caffeine $(30 \mathrm{mg} / \mathrm{kg}$ ) was not able to reverse the ethanol's ataxic effect in any of the locomotion parameters. These results suggest that caffeine potentiates locomotion at stimulant doses of ethanol but at higher doses or after suppression of locomotion, caffeine at medium to high doses potentiates the incoordinating effects of ethanol. Hence, although this synergistic or antagonist dose-dependent effect of these substances was reported in the literature (Waldeck 1974; Dar 1988; Kuribara et al. 1992; Phillips \& Shen 1996; Marin et al. 2011; Hilbert et al. 2013; López-Cruz et al. 2013) showing that only very high doses of caffeine (100 mg/kg) suppress locomotion (Zhang et al. 2011), this study for the first time evaluates the impact of the combined treatment of stimulant and non-stimulant doses of the two drugs on horizonal and vertical locomotion. Furthermore, we examined also the effects of caffeine pre-treatment (15 and $30 \mathrm{mg} / \mathrm{kg}$ ) on mice previously sensitized to ethanol $(1.5 \mathrm{~g} / \mathrm{kg})$, to investigate possible cross-sensitization effects. The results, compared to those from ethanol naive mice, disclosed that the stimulant dose of caffeine $(15 \mathrm{mg} / \mathrm{kg}$ ) blunted the stimulating effects of ethanol whereas the non-stimulant $(30 \mathrm{mg} / \mathrm{kg}$ ) dose of caffeine produced suppression of locomotion in ethanol sensitized mice. Notably, and in contrast, this high dose of caffeine $(30 \mathrm{mg} / \mathrm{kg}$ ) when administered in combination with ethanol (at the dose of $1.5 \mathrm{~g} / \mathrm{kg}$ ) to nonsensitized animals was able to increase horizontal locomotion and supported rearing. Thus, when caffeine is administered at high doses not only fails to reverse the impairing effects of ethanol, but in ethanol-experienced mice has a blunting or even impairing effect on horizontal and vertical exploration. Finally, the results of immunohistochemical experiments revealed that, in line with previous studies (Ibba et al. 2009), ethanol is able to significantly induce pERK-expression in the Acb core and shell and that combination with caffeine at both doses (15 or $30 \mathrm{mg} / \mathrm{kg}$ ) significantly reversed this increase. Accordingly, caffeine resulted in a reduction of ethanol-induced ERK expression that, similarly to our previous speculation on data of chapter 2 , we hypothesize to be mediated by $D_{1}$ receptors. This possibility would also be in agreement with the suggestion of the preponderant role of $A_{1}$ receptors in these effects of caffeine, which may be a key element in the regulation of the caffeine-mediated modulation of ethanol-induced 
behavioral activation. On the contrary, there was no significant effect on pDARPP32(Thr75).

In conclusion, with the experiments of this doctoral thesis we aimed at investigating the differential involvement of ERK in a number of experimental conditions related to direct and conditioned effects of ethanol, as well as in relation to the effects of ethanol after a previous administration of caffeine. Using ethanol-elicited place conditioning we assessed not only the ability of MEK blockade to interfere with learning the association between US and CS (acquisition) but also the possibility that MEK blockade may also affect the behavioral performance evoked by the presentation of either the CS+ associated to positive, reinforcing effects of ethanol and the CS+ associated to negative, aversive effects of ethanol (that is, associated to the expression of CPP and CPA, respectively). Strikingly, these effects of ERK/MAPK kinase pathway result in a differential involvement of the expression of this phosphorylated kinase in different brain regions (nucleus accumbens core and shell vs bed nucleus of stria terminalis, central and basolateral amygdala). Overall, these studies suggest a different and complex involvement of the MEK/ERK pathway in associative learning and in the expression of conditioned responses. Furthermore, we also examined the effects of ethanol and caffeine interaction to explore the consequences on the motivational properties of ethanol assessed in the place conditioning model. The results of these experiments also indicate that the administration of caffeine at appropriate doses prevents the manifestation of the motivational properties of ethanol and suggest that its ability to induce pERK expression could be prevented by caffeine through the blockade of adenosinergic $A_{1}$ receptors. Finally, the results of the experiments that evaluated locomotion demonstrate that caffeine does interact in a complex way with the effects of stimulant and non-stimulant doses of ethanol, sometimes increasing the impairing and sometimes blunting the stimulatory effect of ethanol on behavior.

Overall, the impact of the translational value of these findings resides in the significant contribution toward the clarification of the complex interaction between caffeine and ethanol that is mostly highlighted by the dangerousness toward public safety of their prejudice-based use. 
References 



\section{REFERENCES}

Acquas E, Pisanu A, Spiga S, Plumitallo A, Zernig G \& Chiara G Di (2007) Differential effects of intravenous $\mathrm{R}, \mathrm{S}-( \pm)-3,4-$ methylenedioxymethamphetamine (MDMA, Ecstasy) and its $\mathrm{S}(+)$ - and $\mathrm{R}(-)$-enantiomers on dopamine transmission and extracellular signal regulated kinase phosphorylation (pERK) in the rat nucleus accumbens shell and core. J Neurochem 102:121-132.

Acquas E, Tanda G \& Di Chiara G (2002) Differential Effects of Caffeine on Dopamine and Acetylcholine Transmission in Brain Areas of Drug-naive and Caffeinepretreated Rats. Neuropsychopharmacology 27:182-193.

Acquas E, Vinci S, Ibba F, Spiga S, De Luca MA \& Di Chiara G (2010) Role of dopamine D1 receptors in caffeine-mediated ERK phosphorylation in the rat brain. Synapse 64:341-349.

Ahsan HM, de la Peña JBI, Botanas CJ, Kim HJ, Yu GY \& Cheong JH (2014) Conditioned place preference and self-administration induced by nicotine in adolescent and adult rats. Biomol Ther 22:460-466.

Altar CA \& Marien MR (1987) Picomolar affinity of 125I-SCH 23982 for D1 receptors in brain demonstrated with digital subtraction autoradiography. J Neurosci 7:21322.

Atkins CM, Selcher JC, Petraitis JJ, Trzaskos JM \& Sweatt JD (1998) The MAPK cascade is required for mammalian associative learning. Nat Neurosci 1:602-609.

Attwood AS, Rogers PJ, Ataya AF, Adams S \& Munafò MR (2012) Effects of caffeine on alcohol-related changes in behavioural control and perceived intoxication in light caffeine consumers. Psychopharmacology (Berl) 221:551-560.

Bahi A \& Dreyer JL (2012) Involvement of nucleus accumbens dopamine D1 receptors in ethanol drinking, ethanol-induced conditioned place preference, and ethanolinduced psychomotor sensitization in mice. Psychopharmacology (Berl) 222:141153.

Baik JH (2013) Dopamine signaling in reward-related behaviors. Front Neural Circuits 7:1-16.

Barbano PE, Spivak M, Flajolet M, Nairn AC, Greengard P \& Greengard L (2007) A mathematical tool for exploring the dynamics of biological networks. Proc Natl Acad Sci 104:19169-19174.

Bardo MT \& Bevins RA (2000) Conditioned place preference: What does it add to our preclinical understanding of drug reward? Psychopharmacology (Berl) 153:31-43.

Bateup HS, Santini E, Shen W, Birnbaum S, Valjent E, Surmeier DJ, Fisone G, Nestler EJ \& Greengard P (2010) Distinct subclasses of medium spiny neurons differentially regulate striatal motor behaviors. Proc Natl Acad Sci 107:14845-14850. 
Bateup HS, Svenningsson $P$, Kuroiwa $M$, Gong S, Nishi A, Heintz N \& Greengard P (2008) Cell type-specific regulation of DARPP-32 phosphorylation by psychostimulant and antipsychotic drugs. Nat Neurosci 11:932-939.

Berhow MT, Hiroi N \& Nestler EJ (1996) Regulation of ERK ( Extracellular Signal Regulated Kinase), Part of the Neurotrophin Signal Transduction Cascade, in the Rat Mesolimbic Dopamine System by Chronic Exposure to Morphine or Cocaine. $J$ Neurosci 16:4707-4715.

Berridge KC \& Robinson TE (1998) What is the role of dopamine in reward: Hedonic impact, reward learning, or incentive salience? Brain Res Rev 28:309-369.

Bhutada $\mathrm{P}$, Mundhada $\mathrm{Y}$, Bansod K, Rathod S, Hiware R, Dixit P, Umathe S \& Mundhada $D$ (2010) Inhibitory effect of berberine on the motivational effects of ethanol in mice. Prog Neuro-Psychopharmacology Biol Psychiatry 34:1472-1479.

Bibb JA, Snyder GL, Nishi A, Yan Z, Meijer L, Flenberg AA, Tsai LH, Kwon YT, Girault JA, Czernik AJ, Huganir RL, Hemmings HC, Nairn AC \& Greengard P (1999) Phosphorylation of DARPP-32 by Cdk5 modulates dopamine signalling in neurons. Nature 402:669-671.

Blum S, Moore AN, Adams F \& Dash PK (1999) A mitogen-activated protein kinase cascade in the CA1/CA2 subfield of the dorsal hippocampus is essential for longterm spatial memory. J Neurosci 19:3535-3544.

Borgkvist A \& Fisone G (2007) Psychoactive drugs and regulation of the CAMP/PKA/DARPP-32 cascade in striatal medium spiny neurons. Neurosci Biobehav Rev 31:79-88.

Bradley CA \& Palmatier MI (2019) Intravenous and oral caffeine self-administration in rats. Drug Alcohol Depend 203:72-82.

Brami-Cherrier K, Valjent E, Hervé D, Darragh J, Corvol JC, Pages C, Simon AJ, Girault JA \& Caboche J (2005) Parsing molecular and behavioral effects of cocaine in mitogen- and stress-activated protein kinase-1-deficient mice. J Neurosci 25:11444-11454.

Brent Bedingfield J, King DA \& Holloway FA (1998) Cocaine and caffeine: Conditioned place preference, locomotor activity, and additivity. Pharmacol Biochem Behav 61:291-296.

Briscoe RJ, Vanecek SA, Vallett M, Baird TJ, Holloway FA \& Gauvin D V. (1998) Reinforcing effects of caffeine, ephedrine, and their binary combination in rats. Pharmacol Biochem Behav 60:685-693.

Brockwell NT, Eikelboom R \& Beninger RJ (1991) Caffeine-induced place and taste conditioning: Production of dose-dependent preference and aversion. Pharmacol Biochem Behav 38:513-517.

Brodie MS \& Appel SB (1998) The effects of ethanol on dopaminergic neurons of the ventral tegmental area studied with intracellular recording in brain slices. Alcohol 
Clin Exp Res 22:236-44.

Cahill E, Salery M, Vanhoutte P \& Coboche J (2014) Convergence of dopamine and glutamate signaling onto striatal ERK activation in response to drugs of abuse TRANSMISSION. Front Pharmacol 4:1-13.

Caine SB, Thomsen M, Gabriel KI, Berkowitz JS, Gold LH, Koob GF, Tonegawa S, Zhang J \& Xu M (2007) Lack of Self-Administration of Cocaine in Dopamine D 1 Receptor Knock-Out Mice. J Neurosci 27:13140-13150.

Carboni E, Silvagni A, Rolando MTP \& Di Chiara G (2000) Stimulation of In Vivo Dopamine Transmission in the Bed Nucleus of Stria Terminalis by Reinforcing Drugs . J Neurosci 20:RC102-RC102.

Catani M, Dell'Acqua F \& Thiebaut de Schotten M (2013) A revised limbic system model for memory, emotion and behaviour. Neurosci Biobehav Rev 37:17241737.

Charara A \& Grace AA (2003) Dopamine receptor subtypes selectively modulate excitatory afferents from the hippocampus and amygdala to rat nucleus accumbens neurons. Neuropsychopharmacology 28:1412-1421.

Di Chiara G (2002) Nucleus accumbens shell and core dopamine: Differential role in behavior and addiction. Behav Brain Res 137:75-114.

Di Chiara G Di \& Bassareo V (2007) Reward system and addiction : what dopamine does and doesn' t do. Curr Opin Pharmacol:69-76.

Di Chiara G \& Imperato A (1988) Drugs abused by humans preferentially increase synaptic dopamine concentrations in the mesolimbic system of freely moving rats (amphetamine/cocaine/ethanol/nicotine/opiates). Proc Natl Acad Sci USA 85:5274-5278.

Cole JC, Sumnall HR, O'Shea E \& Marsden CA (2003) Effects of MDMA exposure on the conditioned place preference produced by other drugs of abuse. Psychopharmacology (Berl) 166:383-90.

Correa M, Arizzi MN, Betz A, Mingote S \& Salamone JD (2003a) Locomotor stimulant effects of intraventricular injections of low doses of ethanol in rats: acute and repeated administration. Psychopharmacology (Berl) 170:368-75.

Correa M, Arizzi MN, Betz A, Mingote S \& Salamone JD (2003b) Open field locomotor effects in rats after intraventricular injections of ethanol and the ethanol metabolites acetaldehyde and acetate. Brain Res Bull 62:197-202.

Correa M \& Font $L$ (2008) Is there a major role for adenosine A2A receptors in anxiety? Front Biosci 13:4058-70.

Correa M, Sanchis-Segura C \& Aragon CM (2001a) Brain catalase activity is highly correlated with ethanol-induced locomotor activity in mice. Physiol Behav 73:641-7. 
Correa M, Sanchis-Segura C \& Aragon CM (2001b) Influence of brain catalase on ethanol-induced loss of righting reflex in mice. Drug Alcohol Depend 65:9-15.

Cunningham CL (2019) Genetic Relationships Between Ethanol-Induced Conditioned Place Aversion and Other Ethanol Phenotypes in 15 Inbred Mouse Strains. Brain Sci 9.

Cunningham CL, Clemans JM \& Fidler TL (2002) Injection timing determines whether intragastric ethanol produces conditioned place preference or aversion in mice. Pharmacol Biochem Behav 72:659-668.

Cunningham CL, Ferree NK \& Howard MA (2003) Apparatus bias and place conditioning with ethanol in mice. Psychopharmacology (Berl) 170:409-422.

Cunningham CL, Gremel CM \& Groblewski PA (2006) Drug-induced conditioned place preference and aversion in mice. Nat Protoc 1:1662-1670.

Cunningham CL \& Henderson CM (2000) Ethanol-induced conditioned place aversion in mice. Behav Pharmacol 11:591-602.

Cunningham CL, Okorn DM \& Howard CE (1997) Interstimulus interval determines whether ethanol produces conditioned place preference or aversion in mice. Anim Learn Behav 25:31-42.

Daly JW \& Fredholm BB (1998) Caffeine--an atypical drug of dependence. Drug Alcohol Depend 51:199-206.

Dar MS (1988) The Biphasic Effects of Centrally and Peripherally Administered Caffeine on Ethanol-induced Motor Incoordination in Mice. J Pharm Pharmacol 40:482487.

Davis S \& Laroche S (2006) Mitogen-activated protein kinase / extracellular regulated kinase signalling and memory stabilization : a review. Genes, Brain Behav 5:61-72.

Drake CL, Roehrs T, Turner L, Scofield HM \& Roth T (2003) Caffeine reversal of ethanol effects on the multiple sleep latency test, memory, and psychomotor performance. Neuropsychopharmacology 28:371-378.

Evans J \& Battisti AS (2019) Caffeine.

Faccidomo S, Besheer J, Stanford PC \& Hodge CW (2009) Increased operant responding for ethanol in male C57BL/6J mice : specific regulation by the ERK $1 / 2$, but not JNK , MAP kinase pathway. Psychopharmacology (Berl):135-147.

Faccidomo S, Salling MC, Galunas C \& Hodge CW (2015) Operant ethanol selfadministration increases extracellular-signal regulated protein kinase (ERK) phosphorylation in reward-related brain regions: Selective regulation of positive reinforcement in the prefrontal cortex of $\mathrm{C} 57 \mathrm{BL} / 6 \mathrm{~J}$ mice. Psychopharmacology (Berl) 232:3417-3430.

Fanselow MS \& Wassum KM (2016) The origins and organization of vertebrate Pavlovian Conditioning. Cold Spring Harb Perspect Biol:1-27. 
Ferré S (2008) An update on the mechanisms of the psychostimulant effects of caffeine. J Neurochem 105:1067-1079.

Ferré S (2016) Mechanisms of the psychostimulant effects of caffeine: implications for substance use disorders. Psychopharmacology (Berl) 233:1963-1979.

Ferré S \& O'Brien MC (2011) Alcohol and Caffeine: The Perfect Storm. J Caffeine Res 1:153-162.

Fidler TL, Bakner L \& Cunningham CL (2004) Conditioned place aversion induced by intragastric administration of ethanol in rats. Pharmacol Biochem Behav 77:731743.

Font L, Aragon CMG \& Miquel M (2006) Ethanol-induced conditioned place preference, but not aversion, is blocked by treatment with D-penicillamine, an inactivation agent for acetaldehyde. Psychopharmacology (Berl) 184:56-64.

Fontana D, Weiss SRB \& Pert A (1993) The role of D1-and D2-dopamine receptors in the acquisition and expression of cocaine-induced conditioned increases in locomotor behavior. BehavPharmacol 4:375-387.

Fredholm BB \& Wallman-Johansson A (1996) Effects of ethanol and acetate on adenosine production in rat hippocampal slices. Pharmacol Toxicol 79:120-3.

Fuxe K, Agnati LF, Jacobsen K, Hillion J, Canals M, Torvinen M, Tinner-Staines B, Staines W, Rosin D, Terasmaa A, Popoli P, Leo G, Vergoni V, Lluis C, Ciruela F, Franco R \& Ferre $S$ (2003) Receptor heteromerization in adenosine A2A receptor signaling: Relevance for striatal function and Parkinson's disease. Neurology 61:S19-S23.

Gasior M, Jaszyna M, Peters J \& Goldberg SR (2000) Changes in the ambulatory activity and discriminative stimulus effects of psychostimulant drugs in rats chronically exposed to caffeine: effect of caffeine dose. J Pharmacol Exp Ther 295:1101-11.

Gatto GJ, McBride WJ, Murphy JM, Lumeng L \& Li TK (1994) Ethanol self-infusion into the ventral tegmental area by alcohol-preferring rats. Alcohol 11:557-564.

Gerdjikov T V., Ross GM \& Beninger RJ (2004) Place preference induced by nucleus accumbens amphetamine is impaired by antagonists of ERK or p38 MAP kinases in rats. Behav Neurosci 118:740-750.

Gessa GL, Muntoni F, Collu M, Vargiu L \& Mereu G (1985) Low doses of ethanol activate dopaminergic neurons in the ventral tegmental area. Brain Res 348:201203.

Girault J, Valjent E, Caboche J \& Herve D (2007) ERK2 : a logical AND gate critical for drug-induced plasticity ? Curr Opin Pharmacol:77-85.

Gonzales RA, Job MO \& Doyon WM (2004) The role of mesolimbic dopamine in the development and maintenance of ethanol reinforcement. Pharmacol Ther 103:121-146.

Hasenfratz M, Bunge A, Dal Prá G \& Bättig K (1993) Antagonistic effects of caffeine and 
alcohol on mental performance parameters. Pharmacol Biochem Behav 46:463465.

Hilbert MLT, May CE \& Griffin WC (2013) Conditioned Reinforcement and Locomotor Activating Effects of Caffeine and Ethanol Combinations in Mice. Pharmacol Biochem Behav 110:168-173.

Hodge CW, Samson HH \& Chappelle AM (1997) Alcohol Self-Administration: Further Examination of the Role of Dopamine Receptors in the Nucleus Accumbens. Alcohol Clin Exp Res 21:1083-1091.

Horger BA, Wellman PJ, Morien A, Davies BT \& Schenk S (1991) Caffeine exposure sensitizes rats to the reinforcing effects of cocaine. Neuroreport 2:53-56.

Ibba F, Vinci S, Spiga S, Peana AT, Assaretti AR, Spina L, Longoni R \& Acquas E (2009) Ethanol-induced extracellular signal regulated kinase: Role of dopamine $D 1$ receptors. Alcohol Clin Exp Res 33:858-867.

Itzhak Y, Roger-Sánchez C \& Anderson KL (2009) Role of the nNOS gene in ethanolinduced conditioned place preference in mice. Alcohol 43:285-291.

Johnson LC, Spinweber CL \& Gomez SA (1990) Benzodiazepines and caffeine: effect on daytime sleepiness, performance, and mood. Psychopharmacology (Berl) 101:160-167.

Kalivas PW \& Volkow ND (2005) Reviews and Overviews The Neural Basis of Addiction : A Pathology of Motivation and Choice. Am J Psychiatry:1403-1413.

Karlsson O \& Roman E (2016) Dose-dependent effects of alcohol administration on behavioral profiles in the MCSF test. Alcohol 50:51-56.

Kelley AE (2004) Memory and Addiction. Neuron 44:161-179.

Kelly A, Laroche S \& Davis S (2003) Activation of mitogen-activated protein kinase/extracellular signal-regulated kinase in hippocampal circuitry is required for consolidation and reconsolidation of recognition memory. J Neurosci 23:535460.

Khokhlatchev A V, Canagarajah B, Wilsbacher J, Robinson M, Atkinson M, Goldsmith E \& Cobb MH (1998) Phosphorylation of the MAP Kinase ERK2 Promotes Its Homodimerization and Nuclear Translocation. Cell 93:605-615.

Kirschmann EKZ, Mauna JC, Willis CM, Foster RL, Chipman AM \& Thiels E (2014) Appetitive cue-evoked ERK signaling in the nucleus accumbens requires NMDA and D1 dopamine receptor activation and regulates CREB phosphorylation. Learn Mem 21:606-615.

Koob GF \& Volkow ND (2009) Neurocircuitry of Addiction. Neuropsychopharmacology 35:217-238.

Kristjansson AL, Mann MJ, Sigfusdottir ID \& James JE (2015) Mode of daily caffeine consumption among adolescents and the practice of mixing alcohol with energy 
drinks: Relationships to drunkenness. J Stud Alcohol Drugs 76:397-405.

Kuribara H, Asahi T \& Tadokoro S (1992) Ethanol enhances, but diazepam and pentobarbital reduce the ambulation-increasing effect of caffeine in mice. Arukoru Kenkyuto Yakubutsu Ison 27:528-39.

Lazarus M, Shen HY, Cherasse Y, Qu WM, Huang ZL, Bass CE, Winsky-Sommerer R, Semba K, Fredholm BB, Boison D, Hayaishi O, Urade Y \& Chen JF (2011) Arousal effect of caffeine depends on adenosine A2A receptors in the shell of the nucleus accumbens. J Neurosci 31:10067-10075.

Lin X, Wang Q, Ji J \& Yu L (2010) Role of MEK-ERK Pathway in Morphine-Induced Conditioned Place Preference in Ventral Tegmental Area of Rats. J Neurosci Res 1604:1595-1604.

Liu Y, Le Foll B, Liu Y, Wang X \& Lu L (2008) Conditioned Place Preference Induced by Licit Drugs: Establishment, Extinction, and Reinstatement. Sci World J 8:12281245.

Longoni R, Spina L \& Vinci S (2011) The MEK inhibitor SL327 blocks acquisition but not expression of lithium-induced conditioned place aversion: a behavioral and immunohistochemical study. Psychopharmacology (Berl):63-73.

López-Cruz L, Pardo M, Salamone JD \& Correa M (2014) Differences between the nonselective adenosine receptor antagonists caffeine and theophylline in motor and mood effects: Studies using medium to high doses in animal models. Behav Brain Res 270:213-222.

López-Cruz L, Salamone JD \& Correa M (2018) Caffeine and selective adenosine receptor antagonists as new therapeutic tools for the motivational symptoms of depression. Front Pharmacol 9.

López-Cruz L, Salamone JD \& Correa M (2013) The Impact of Caffeine on the Behavioral Effects of Ethanol Related to Abuse and Addiction: A Review of Animal Studies. $J$ Caffeine Res 3:9-21.

Lorrai I, Contini A, Gessa GL, Mugnaini C, Corelli F, Colombo G \& Maccioni P (2019) Operant, oral alcohol self-administration: Sex differences in Sardinian alcoholpreferring rats. Alcohol 79:147-162.

Lu L, Koya E, Zhai H, Hope BT \& Shaham Y (2006) Role of ERK in cocaine addiction. Trends Neurosci 29:695-703.

Lu XY, Ghasemzadeh MB \& Kalivas PW (1997) Expression of D1 receptor, D2 receptor, substance $P$ and enkephalin messenger RNAs in the neurons projecting from the nucleus accumbens. Neuroscience 82:767-780.

Maldve RE, Zhang TA, Ferrani-Kile K, Schreiber SS, Lippmann MJ, Snyder GL, Fienberg AA, Leslie SW, Gonales RA \& Morrisett RA (2002) DARPP-32 and regulation of the ethanol sensitivity of NMDA receptors in the nucleus accumbens. Nat Neurosci 5:641-648. 
Marczinski CA \& Fillmore MT (2014) Energy drinks mixed with alcohol: what are the risks? Nutr Rev 72 Suppl 1:98-107.

Marin MT, Zancheta R, Paro AH, Possi APM, Cruz FC \& Planeta CS (2011) Comparison of caffeine-induced locomotor activity between adolescent and adult rats. Eur J Pharmacol 660:363-367.

Marotta R, Fenu S, Scheggi S, Vinci S, Rosas M, Falqui A, Gambarana C, De Montis MG \& Acquas E (2014) Acquisition and expression of conditioned taste aversion differentially affects extracellular signal regulated kinase and glutamate receptor phosphorylation in rat prefrontal cortex and nucleus accumbens. Front Behav Neurosci 8:153.

McDonald RJ, Yim TT, Lehmann H, Sparks FT, Zelinski EL, Sutherland RJ \& Hong NS (2010) Expression of a conditioned place preference or spatial navigation task following muscimol-induced inactivations of the amygdala or dorsal hippocampus: A double dissociation in the retrograde direction. Brain Res Bull 83:29-37.

De Mei C, Ramos M, litaka C \& Borrelli E (2009) Getting specialized: presynaptic and postsynaptic dopamine D2 receptors. Curr Opin Pharmacol 9:53-58.

Meredith SE, Juliano LM, Hughes JR \& Griffiths RR (2013) Caffeine Use Disorder: A Comprehensive Review and Research Agenda. J Caffeine Res 3:114-130.

Miller CA \& Marshall JF (2005) Molecular substrates for retrieval and reconsolidation of cocaine-associated contextual memory. Neuron 47:873-884.

Muller DL \& Unterwald EM (2004) In vivo regulation of extracellular signal-regulated protein kinase (ERK) and protein kinase $B$ (Akt) phosphorylation by acute and chronic morphine. J Pharmacol Exp Ther 310:774-782.

Nagy LE (1992) Ethanol metabolism and inhibition of nucleoside uptake lead to increased extracellular adenosine in hepatocytes. Am J Physiol Physiol 262:C1175c1180.

Nagy LE, Diamond I, Casso DJ, Franklin C \& Gordon AS (1990) Ethanol increases extracellular adenosine by inhibiting adenosine uptake via the nucleoside transporter. J Biol Chem 265:1946-51.

Nestler EJ (2001) Molecular Neurobiology of Addiction. Am J Addict 10:201-217.

Nishi A \& Shuto T (2017) Potential for targeting dopamine/DARPP-32 signaling in neuropsychiatric and neurodegenerative disorders. Expert Opin Ther Targets 21:259-272.

Nunes EJ, Randall PA, Hart EE, Freeland C, Yohn SE, Baqi Y, Muller CE, Lopez-Cruz L, Correa M \& Salamone JD (2013) Effort-Related Motivational Effects of the VMAT2 Inhibitor Tetrabenazine: Implications for Animal Models of the Motivational Symptoms of Depression. J Neurosci 33:19120-19130. 
Nygard SK, Klambatsen A, Balouch B \& Jenab S (2015) Region and context-specific intracellular responses associated with cocaine-induced conditioned place preference expression. Neuroscience 287:1-8.

Olds J \& Milner P (1954) Positive reinforcement produced by electrical stimulation of septal area and other regions of rat brain. J Comp Physiol Psychol 47:419.

Ouimet CC, Langley-Gullion KC \& Greengard P (1998) Quantitative immunocytochemistry of DARPP-32-expressing neurons in the rat caudatoputamen. Brain Res 808:8-12.

Pascoli V, Besnard A, Herv D, Pags C, Heck N, Girault JA, Caboche J \& Vanhoutte P (2011) Cyclic adenosine monophosphateindependent tyrosine phosphorylation of NR2B mediates cocaine-induced extracellular signal-regulated kinase activation. Biol Psychiatry 69:218-227.

Pati D, Pina MM \& Kash TL (2019) Ethanol-induced conditioned place preference and aversion differentially alter plasticity in the bed nucleus of stria terminalis. Neuropsychopharmacology 0:1-12.

Patkina NA \& Zvartau EE (1998) Caffeine place conditioning in rats: Comparison with cocaine and ethanol. Eur Neuropsychopharmacol 8:287-291.

Peana AT, Enrico P, Assaretti AR, Pulighe E, Muggironi G, Nieddu M, Piga A, Lintas A \& Diana M (2008) Key role of ethanol-derived acetaldehyde in the motivational properties induced by intragastric ethanol: A conditioned place preference study in the rat. Alcohol Clin Exp Res 32:249-258.

Peana AT, Giugliano V, Rosas M, Sabariego M \& Acquas E (2013) Effects of I-Cysteine on Reinstatement of Ethanol-Seeking Behavior and on Reinstatement-Elicited Extracellular Signal-Regulated Kinase Phosphorylation in the Rat Nucleus Accumbens Shell. Alcohol Clin Exp Res 37.

Peana AT, Muggironi G, Spina L, Rosas M, Kasture SB, Cotti E \& Acquas E (2014) Effects of Withania somnifera on oral ethanol self-administration in rats. Behav Pharmacol 25:618-628.

Phillips TJ \& Shen EH (1996) Neurochemical bases of locomotion and ethanol stimulant effects. Int Rev Neurobiol 39:243-82.

Pontieri FE, Tanda G \& Di Chiara G (1995) Intravenous cocaine, morphine, and amphetamine preferentially increase extracellular dopamine in the 'shell' as compared with the 'core' of the rat nucleus accumbens. Proc Natl Acad Sci U S A 92:12304-8.

Radwanska K, Wrobel E, Korkosz A, Rogowski A, Kostowski W, Bienkowski P \& Kaczmarek L (2008) Alcohol relapse induced by discrete cues activates components of AP-1 transcription factor and ERK pathway in the rat basolateral and central amygdala. Neuropsychopharmacology 33:1835-1846.

Ramsey AJ, Laakso A, Cyr M, Sotnikova TD, Salahpour A, Medvedev IO, Dykstra LA, 
Gainetdinov RR \& Caron MG (2008) Genetic NMDA receptor deficiency disrupts acute and chronic effects of cocaine but not amphetamine. Neuropsychopharmacology 33:2701-2714.

Risinger FO, Brown MM, Oakes RA \& Love JA (1999) Effects of haloperidol or SCH23390 on ethanol-induced conditioned taste aversion. Alcohol 18:139-45.

Risinger FO, Freeman PA, Greengard P \& Fienberg AA (2018) Motivational Effects of Ethanol in DARPP-32 Knock-Out Mice. J Neurosci 21:340-348.

Risinger FO \& Oakes RA (1995) Nicotine-induced conditioned place preference and conditioned place aversion in mice. Pharmacol Biochem Behav 51:457-461.

Robledo P, Balerio G, Berrendero F \& Maldonado R (2004) Study of the behavioural responses related to the potential addictive properties of MDMA in mice. Naunyn Schmiedebergs Arch Pharmacol 369:338-349.

Rodd ZA, Melendez R, Bell R, Kuc K, Zhang Y, Murphy J \& McBride W (2004) Intracranial Self-Administration of Ethanol within the Ventral Tegmental Area of Male Wistar Rats: Evidence for Involvement of Dopamine Neurons. J Neurosci 24:1050-1057.

Ron D \& Wang J (2009) Frontiers in Neuroscience $r$ The NMDA Receptor and Alcohol Addiction. In: Biology of the NMDA Receptor. A.M. Van Dongen (ed). CRC Press/Taylor \& Francis\rTaylor \& Francis Group, LLC.: Boca Raton (FL).

Rosas M, Porru S, Longoni R, Spina L, Peana AT, Collu M \& Acquas E (2017) Differential effects of the MEK inhibitor SL327 on the acquisition and expression of ethanolelicited conditioned place preference and aversion in mice. J Psychopharmacol 31:105-114.

Rosas M, Porru S, Sabariego M, Piludu MA, Giorgi O, Corda MG \& Acquas E (2018) Effects of morphine on place conditioning and ERK1/2 phosphorylation in the nucleus accumbens of psychogenetically selected Roman low- and high-avoidance rats. Psychopharmacology (Berl) 235:59-69.

Ruiu S, Longoni R, Spina L, Orrù A, Cottiglia F, Collu M, Kasture S \& Acquas E (2013) Withania somnifera prevents acquisition and expression of morphine-elicited conditioned place preference. Behav Pharmacol 24:133-143.

Salamone JD (2010) Motor Function and Motivation. Encycl Behav Neurosci:267-272.

Salamone JD \& Correa M (2012) The mysterious motivational functions of mesolimbic dopamine. Neuron 76:470-485.

Salamone JD, Correa M, Ferrigno S, Yang JH, Rotolo RA \& Presby RE (2018) The psychopharmacology of effort-related decision making: Dopamine, adenosine, and insights into the neurochemistry of motivation. Pharmacol Rev 70:747-762.

Salzmann J, Marie-Claire C, Le Guen S, Roques BP \& Noble F (2003) Importance of ERK activation in behavioral and biochemical effects induced by MDMA in mice. $\mathrm{Br} J$ Pharmacol 140:831-838. 
Satel S (2006) Is caffeine addictive? - A review of the literature. Am J Drug Alcohol Abuse 32:493-502.

Schenk S \& Partridge B (1999) Cocaine-seeking produced by experimenteradministered drug injections: Dose-effect relationships in rats. Psychopharmacology (Berl) 147:285-290.

Schenk S, Valadez A, Horger BA, Snow S \& Wellman PJ (1994) Interactions between caffeine and cocaine in tests of self-administration. Behav Pharmacol 5:153-158.

Schroeder JP, Spanos M, Stevenson JR, Besheer J, Salling M \& Hodge CW (2008) Cueinduced reinstatement of alcohol-seeking behavior is associated with increased ERK1/2 phosphorylation in specific limbic brain regions: Blockade by the mGluR5 antagonist MPEP. Neuropharmacology 55:546-554.

Selcher JC, Atkins CM, Trzaskos JM, Paylor R \& Sweatt JD (1999) A necessity for MAP kinase activation in mammalian spatial learning. Learn Mem 6:478-90.

Sellings LHL (2006) Evidence for Multiple Sites within Rat Ventral Striatum Mediating Cocaine-Conditioned Place Preference and Locomotor Activation. J Pharmacol Exp Ther 317:1178-1187.

Simpson EH \& Balsam PD (2016) HHS Public Access. Curr Top Behav Neurosci 27:1-12.

Spanagel R \& Weiss F (1999) 1-s2.0-S0166223699014472-main. Trends Neurosci 22:521-527.

Spina L, Longoni R, Rosas M, Collu M, Peana AT, Espa E, Kasture S, Cotti E \& Acquas E (2015) Withania somnifera Dunal (Indian ginseng) impairs acquisition and expression of ethanol-elicited conditioned place preference and conditioned place aversion. J Psychopharmacol 29:1191-1199.

Spina L, Longoni R, Vinci S, Ibba F, Peana AT, Muggironi G, Spiga S \& Acquas E (2010) Role of dopamine $D 1$ receptors and extracellular signal regulated kinase in the motivational properties of acetaldehyde as assessed by place preference conditioning. Alcohol Clin Exp Res 34:607-616.

Steigerwald ES, Rusiniak KW, Eckel DL \& O’Regan MH (1988) Aversive conditioning properties of caffeine in rats. Pharmacol Biochem Behav 31:579-584.

Stinus L, Cador M, Zorrilla EP \& Koob GF (2005) Buprenorphine and a CRF1 antagonist block the acquisition of opiate withdrawal-induced conditioned place aversion in rats. Neuropsychopharmacology 30:90-98.

Stipanovich A, Valjent E, Matamales M, Ahn J, Maroteaux M, Bertran-gonzalez- J, Enslen H, Corbillé A, Filhol O, Angus C, Greengard P, Hervé D \& Girault J (2009) Stipanovich-08(Ser97).pdf. Nature 453:879-884.

Sun W, Quizon PM \& Zhu J (2016) Molecular Mechanism : ERK Signaling , Drug Addiction, and Behavioral Effects Molecular Mechanism: ERK Signaling, Drug Addiction, and Behavioral Effects. Prog Mol Biol Sci 137. 
Svenningsson P, Le Moine C, Fisone G \& Fredholm BB (1999) Distribution, biochemistry and function of striatal adenosine A(2A) receptors. Prog Neurobiol 59:355-396.

Svenningsson P, Nairn AC \& Greengard P (2005) DARPP-32 mediates the actions of multiple drugs of abuse. Drug Addict From Basic Res to Ther 7:3-16.

Sweatt JD (2004) Mitogen-activated protein kinases in synaptic plasticity and memory. Curr Opin Neurobiol:311-317.

Tabakoff B \& Hoffman PL (2013) The neurobiology of alcohol consumption and alcoholism: An integrative history. Pharmacol Biochem Behav 113:20-37.

Trudell JR, Messing RO, Mayfield J \& Harris RA (2014) Alcohol dependence: Molecular and behavioral evidence. Trends Pharmacol Sci 35:317-323.

Tzschentke TM (2007) Measuring reward with the conditioned place preference (CPP) paradigm: Update of the last decade. Addict Biol 12:227-462.

Valjent E, Bertran-Gonzalez J, Aubier B, Greengard P, Hervé D \& Girault JA (2010) Mechanisms of locomotor sensitization to drugs of abuse in a two-injection protocol. Neuropsychopharmacology 35:401-415.

Valjent E, Caboche J \& Vanhoutte P (2001) Mitogen-Activated Protein Kinase / Extracellular Signal-Regulated Kinase Induced Gene Regulation in Brain. Mol Neurobiol 23:83-99.

Valjent E, Corvol J, Page C, Besson M, Maldonado R, Curie M, Neurofarmacologia L De \& De F (2000) Involvement of the Extracellular Signal-Regulated Kinase Cascade for Cocaine-Rewarding Properties. J Neurosci 20:8701-8709.

Valjent E, Pagès C, Hervé D, Girault JA \& Caboche J (2004) Addictive and non-addictive drugs induce distinct and specific patterns of ERK activation in mouse brain. Eur $J$ Neurosci 19:1826-1836.

Valjent E, Pascoli V, Corvol J, Svenningsson P, Paul S, Stipanovich A, Caboche J, Lombroso PJ, Nairn AC, Greengard P, Herve D \& Girault J (2005) Regulation of a protein phosphatase cascade allows convergent dopamine and glutamate signals to activate ERK in the striatum. PNAS 102:491-496.

Vann RE, Gamage TF, Warner JA, Marshall EM, Taylor NL, Martin BR \& Wiley JL (2008) Divergent effects of cannabidiol on the discriminative stimulus and place conditioning effects of $\Delta 9$-tetrahydrocannabinol. Drug Alcohol Depend 94:191198.

Villarreal JS \& Barea-Rodriguez EJ (2006) ERK phosphorylation is required for retention of trace fear memory. Neurobiol Learn Mem 85:44-57.

Volkow ND, Wise RA \& Baler R (2017) The dopamine motive system : implications for drug and food addiction. Nat Rev Neurosci 18.

Waldeck B (1974) Ethanol and caffeine: a complex interaction with respect to locomotor activity and central catecholamines. Psychopharmacologia 36:209-20. 
Wscieklica T, Le Sueur-Maluf L, Prearo L, Conte R, Viana M de B \& Céspedes IC (2019) Chronic intermittent ethanol administration differentially alters DeltaFosB immunoreactivity in cortical-limbic structures of rats with high and low alcohol preference. Am J Drug Alcohol Abuse 45:264-275.

Xu M, Guo Y, Vorhees C \& Zhang J (2000) Behavioral responses to cocaine and amphetamine administration in mice lacking the dopamine D1 receptor. Brain Res 852:198-207.

El Yacoubi M, Ledent C, Parmentier M, Costentin J \& Vaugeois JM (2003) Caffeine reduces hypnotic effects of alcohol through adenosine A $2 \mathrm{~A}$ receptor blockade. Neuropharmacology 45:977-985.

Yger M \& Girault J (2011) DARPP-32, Jack of All Trades? Master of Which? Front Behav Neurosci 5:1-14.

Young EA, Dreumont SE \& Cunningham CL (2014) Role of nucleus accumbens dopamine receptor subtypes in the learning and expression of alcohol-seeking behavior. Neurobiol Learn Mem 108:28-37.

Zachariou V, Sgambato-Faure V, Sasaki T, Svenningsson P, Berton O, Fienberg AA, Nairn AC, Greengard P \& Nestler EJ (2006) Phosphorylation of DARPP-32 at threonine-34 is required for cocaine action. Neuropsychopharmacology 31:555562.

Zhang L, Lou D, Jiao H, Zhang D, Wang X, Xia Y, Zhang J \& Xu M (2004) Cocaine-Induced Intracellular Signaling and Gene Expression Are Oppositely Regulated by the Dopamine D1 and D3 Receptors. J Neurosci 24:3344-3354.

Zhang Q, Yu YP, Ye YL, Zhang JT, Zhang WP \& Wei EQ (2011) Spatiotemporal properties of locomotor activity after administration of central nervous stimulants and sedatives in mice. Pharmacol Biochem Behav 97:577-585.

Zhu X, Sun W, Li X, Tan S \& Zhang X (2015) Effects of spatial memory on morphine CPP and locomotor sensitization in mice. Physiol Behav 149:187-191. 
Acknowledgments 



\section{ACKNOWLEDGMENTS}

Questa tesi di dottorato è il risultato di anni di esperienze indimenticabili che hanno, sotto diversi aspetti, cambiato la mia vita. Ringrazio chi mi ha insegnato qualcosa, chi mi ha aiutato, chi ci è sempre stato e chi è arrivato dopo diventando parte fondamentale delle mie giornate.

Grazie alla mia famiglia per avermi supportato e, molto spesso, sopportato incondizionatamente durante gli alti e bassi di questo lungo percorso, anche per tutte le volte che mi avete visto partire e fare avanti e indietro tra due Paesi. Grazie ai miei nonni che, anche se non più fisicamente, continuano ad essere per me un infinito esempio di onestà e perseveranza.

Grazie Michela per essere una amica preziosa, per tutte le chiaccherate, i consigli, gli abbracci e le parole di conforto nei momenti opportuni. Grazie per avermi insegnato tanto e per aver reso indimenticabili questi anni, per i nostri pranzi gourmet e le pause in serenità.

Grazie Claudia per essere la parte spensierata del mio cuore, per tutte le risate e le passeggiate anche quando dicevi che ti facevo camminare troppo, per la tua curiosità nell'interessarti alle mie "cose di laboratorio" e per essere comunque presente nonostante la distanza.

Grazie Chiara per gli aperitivi e le seadas durante il periodo di scrittura della tesi che sono stati un ottimo anti-stress.

Grazie Lilli per le risate durante i pranzi, per tutte le volte che facevamo a gara per vedere chi per prima offriva il caffè e per le domeniche al mare.

Grazie Elio Acquas per la fiducia nell'avermi scelto come dottoranda dandomi la possibilità di conoscere il mondo della ricerca, per avermi coinvolto in ogni progetto e per avermi sempre spinto a crescere e fare nuove esperienze. Grazie anche per l'incoraggiamento nei momenti di sconforto e per aver saputo comprendere le mie scelte.

Grazie Riccardo ed Enrica per aver sopportato il mio stress durante l'ultimo anno di dottorato.

Grazie Valentina Bassareo e Roberto Frau per essere un'isola felice dove ho sempre trovato un sorriso, per la disponibilità e gentilezza che vi contraddistingue.

Grazie Anna Liscia per l'affetto e l'energia che mi ha positivamente travolto.

Inoltre, durante il secondo anno ho avuto l'opportunità di trascorrere due periodi in Spagna presso I'Universitat Jaume I di Castellón de la Plana. È stata, senza alcun 
dubbio, l'esperienza più bella della mia vita che mi ha permesso di crescere e aprire la mente, facendomi conoscere tante persone e luoghi speciali.

Gracias Isis por haber mirado a mi lado. Grazie per il tuo cuore grande, per camminare insieme a me nei momenti di gioia e anche in quelli più difficili dandomi sempre una nuova prospettiva sulla quale riflettere. Grazie per avermi aiutato a rendere più colorata questa tesi e per aver risolto tutti i miei disastri con la tecnologia. Grazie per essere il regalo più bello di questo dottorato e per starmi vicino migliorando la mia vita giorno dopo giorno.

Grazie Aitor per le tue adorabili stranezze, per essere un amico sincero, per tutto l'aiuto che mi hai offerto dentro e fuori dal laboratorio, e per tutte le risate che ci siamo fatti cercando di stabilire chi dei due sapesse più parole in Valenciano.

Grazie Patri per i bei momenti passati insieme, per il supporto che mi hai offerto e per essermi stata vicino specialmente nelle difficoltà dell'ultimo periodo dimostrandomi di essere una grande amica.

Grazie Andrea per avermi contagiato con la tua voglia di vivere che ha reso divertenti anche le reazioni di immunoistochimica, per avere la capacità di rendere tutto più leggero perché la vita è fatta per sorridere.

Grazie Regu per essere stato di fondamentale aiuto durante il primo periodo e per aver condiviso con me tante ricette di cucina.

Grazie Lizbeth per il tuo sorriso e la tua infinita dolcezza, per continuare ad essere presente anche se dall'altra parte del mondo.

Grazie Mercè per avermi accolto in Spagna facendomi sentire come a casa, per avermi guidato nei primi passi in una nuova casa e città, anche quando il mio ippocampo non sapeva da che parte dirigermi. Grazie per avermi fatto sentire da subito parte integrante del gruppo. Grazie per avermi ascoltato e dato fiducia nel realizzare parte degli esperimenti necessari per questa tesi, per tutto l'aiuto e l'affetto.

Un sincero ringraziamento va anche a tutti gli altri componenti della UJI per la disponibilità nell'aiutarmi in qualsiasi momento. Grazie Carla, Edgar, Laura Lopez, Paula, Olga, Nacho, Julian, Marta, Laura Font e Raul per le parole gentili e le risate a pieni polmoni.

Sono colma di ricordi e sorrisi che mai dimenticherò: un grazie di cuore a tutti per essere stati parte del viaggio. 
